\title{
ADVANCED HYDRAULIC FRACTURING TECHNOLOGY FOR UNCONVENTIONAL TIGHT GAS RESERVOIRS
}

\section{Final Report}

Project Period: April 1, 2006 - April 1, 2007

PI: Stephen A. Holditch, A. Daniel Hill, and D. Zhu,

\author{
Research Team: \\ F. Chen, Post-Doc \\ P. Pongthunya \\ P. Limthongchai \\ O. Ogueri \\ Y. Wang \\ F. Marpaung
}

Texas A\&M University

April 2007 
TABLE OF CONTENTS

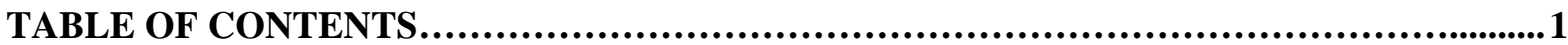

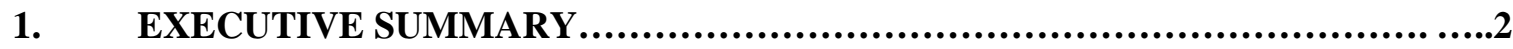

2. COMPARISON WITH THE ORIGINAL GOALS $\ldots \ldots \ldots \ldots \ldots \ldots \ldots \ldots \ldots \ldots \ldots \ldots . . . . . \ldots$

3. SUMMARY OF PROJECT ACTIVITY AND RESULTS.....................

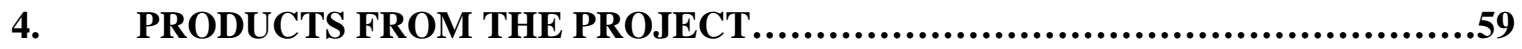

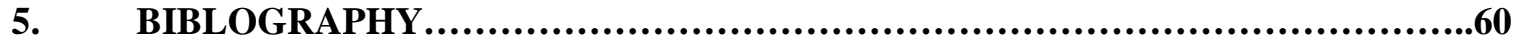

6. APPENDIX

"This report was prepared as an account of work sponsored by an agency of the United States Government. Neither the United States Government nor any agency thereof, nor any of their employees, makes any warranty, express or implies, or assumes any legal liability or responsibility for the accuracy, completeness, or usefulness of any information, apparatus, product, or process disclosed, or represents that its use would not infringe privately owned rights. Reference herein to any specific commercial product, process, or service by trade name, trademark, manufacture, or otherwise does not necessarily constitute or imply its endorsement, recommendation, or favoring by the United States Government or any agency thereof. The views and opinions of authors expressed herein do not necessarily state or reflect those of the United States Government or any agency thereof." 


\section{Executive Summary}

The objectives of this project are to develop and test new techniques for creating extensive, conductive hydraulic fractures in unconventional tight gas reservoirs by statistically assessing the productivity achieved in hundreds of field treatments with a variety of current fracturing practices ranging from "water fracs" to conventional gel fracture treatments; by laboratory measurements of the conductivity created with high rate proppant fracturing using an entirely new conductivity test - the "dynamic fracture conductivity test"; and by developing design models to implement the optimal fracture treatments determined from the field assessment and the laboratory measurements.

One of the tasks of this project is to create an "advisor" or expert system for completion, production and stimulation of tight gas reservoirs. A central part of this study is an extensive survey of the productivity of hundreds of tight gas wells that have been hydraulically fractured. We have been doing an extensive literature search of the SPE eLibrary, DOE, Gas Technology Institute (GTI), Bureau of Economic Geology and IHS Energy, for publicly available technical reports about procedures of drilling, completion and production of the tight gas wells. We have downloaded numerous papers and read and summarized the information to build a database that will contain field treatment data, organized by geographic location, and hydraulic fracture treatment design data, organized by the treatment type.

We have conducted experimental study on "dynamic fracture conductivity" created when proppant slurries are pumped into hydraulic fractures in tight gas sands. Unlike conventional fracture conductivity tests in which proppant is loaded into the fracture artificially; we pump proppant/frac fluid slurries into a fracture cell, dynamically placing the proppant just as it occurs in the field. From such tests, we expect to gain new insights into some of the critical issues in tight gas fracturing, in particular the roles of gel damage, polymer loading (water-frac versus gel frac), and proppant concentration on the created fracture conductivity. To achieve this objective, we have designed the experimental apparatus to conduct the dynamic fracture conductivity tests. The experimental apparatus has been built and some preliminary tests have been conducted to test the apparatus.

\section{Comparison with the Original Goals}

The original project was proposed for four years with three phases, but the project was terminated after one year due to the funding cut. The tasks proposed in Phase I during the first year of the project have been accomplished and summarized as following.

\section{Phase I - Feasibility and Concept Approval}

Task 1 Assessment of Field Treatment Results

We have conducted a thorough literature study to collect the field treatment data and the publications for different basins, and this effort turned to building an advisory system for tight gas sand stimulation. The database served the purpose of further building the advisory system, which is of more practical use for the industry.

\section{Task 2 Dynamic Fracture Conductivity Tests}

\section{Subtask 2.1 Experimental Apparatus Setup}

The experimental apparatus for dynamic conductivity test has been setup and tested for the mixing fracturing fluid, pumping through the conductivity cell at defined back pressure, and measuring conductivity at different closure stress. The task is completed successfully. The experimental condition was designed according to the field operation condition, and actual fracturing fluids will be used in the experiments. There is no other successful dynamic conductivity test apparatus in the recent published literature. 


\section{$\underline{\text { Subtask 2.2 Preliminary Tests }}$}

Preliminary tests have been conducted on the apparatus built in Task 2.1, and results have been analyzed. The proposed tests have been completed successfully.

\section{Task 3 Gel Damage Investigation}

Gel damage has been investigated in this task by a detailed literature study. The causes of gel damages have been summarized in this report, and recommendations for further experimental test have been made based on the study. A theoretical work has been initiated for modeling of gel damage.

In summary, all of the tasks proposed in Phase I of the project have been accomplished successfully, and several of them have been extended further than the original proposal.

\section{Summary of Project Activity and Results}

The following summarizes the project activities during project period and current status of the work for each task of Phase I- Feasibility and Concept Approval.

\section{Task 1 - Research Management Plan}

Completed.

\section{$\underline{\text { Task } 2 \text { - Technology Status Assessment }}$}

\section{Completed.}

\section{$\underline{\text { Task } 3 \text { Assessment of Field Treatment Results }}$}

This task will build an expert system to determine the optimum drilling, completion, stimulation and production methods for typical tight gas sand reservoirs. An expert system is composed of several basic components: a user interface, a database, a knowledge base, and an inference mechanism. The structure of an expert system is as Figure 1.

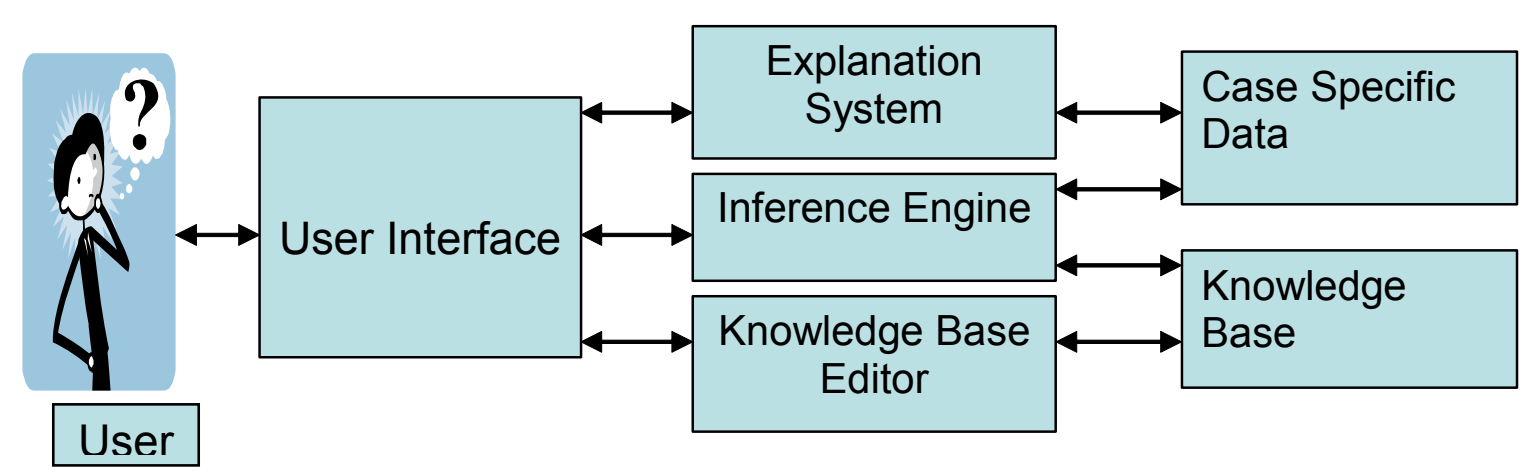

Figure 1 Expert System Architecture

The user interacts with the system through a user interface which may use menus, natural language or any other style of interaction. An inference engine is used to reason with both the expert knowledge and the data specific to the particular problem being solved. The 
expert knowledge can typically be in the form of a set of IF-THEN rules. The case specific data include both data provided by the user and partial conclusions based on the data. An expert system can also have an explanation subsystem, which allows the program to explain its reasoning to the user. Some systems also have a knowledge base editor that helps the expert or knowledge engineer to easily update and check the knowledge base.

The development of an expert system usually proceeds through several phases:

1. Problem selection. The problem has been determined for our expert system. The objective is to build an expert system for the development of unconventional gas reservoirs. We will first define the basin or formation analog in North America for a specific or a target basin. The expert system should provide the best practices on drilling, completion, production and stimulation for the target unconventional gas reservoir.

2. Knowledge acquisition. By using all available data from the petroleum literature, we will identify and evaluate historic levels of technology used to drill, complete stimulate and produce. We will study the petroleum literature to document best practices for the well drilling, completion and stimulation. Then according to the study results and the documented best practices, a multi-user and server-based database for the expert system will be built. Microsoft SQL server (MSSQL) is used as the language for the database. Tables from already existing MS Access database model were transferred into MSSQL. The database design was evaluated and improved: unecceasry tables were eliminated, while needed tables added. Relations between the tables are being improved and simplified. A Webpage was proposed as an interface for the MSSQL-written database (Figure 2). Web-based interface for each table was build in collaboration with the departmetn web-developer. The interface allows to enter, search and edit data on-line.

We have been doing an extensive literature search of the SPE eLibrary, DOE, Gas Research Institute (GTI), Bureau of Economic Geology, IHS Energy, USGS, AAPG, and CIM. We have downloaded over 350 papers written on tight gas reservoirs from SPE eLibrary. These papers were categorized into the bibliography, by technology/operation, mainly described in the paper. We have been reading and summarizing the information to build the database. Appendix A shows a bibliography of the papers sorting by technology/operation. EndNote X software is used to document the papers as shown in Figure 3.

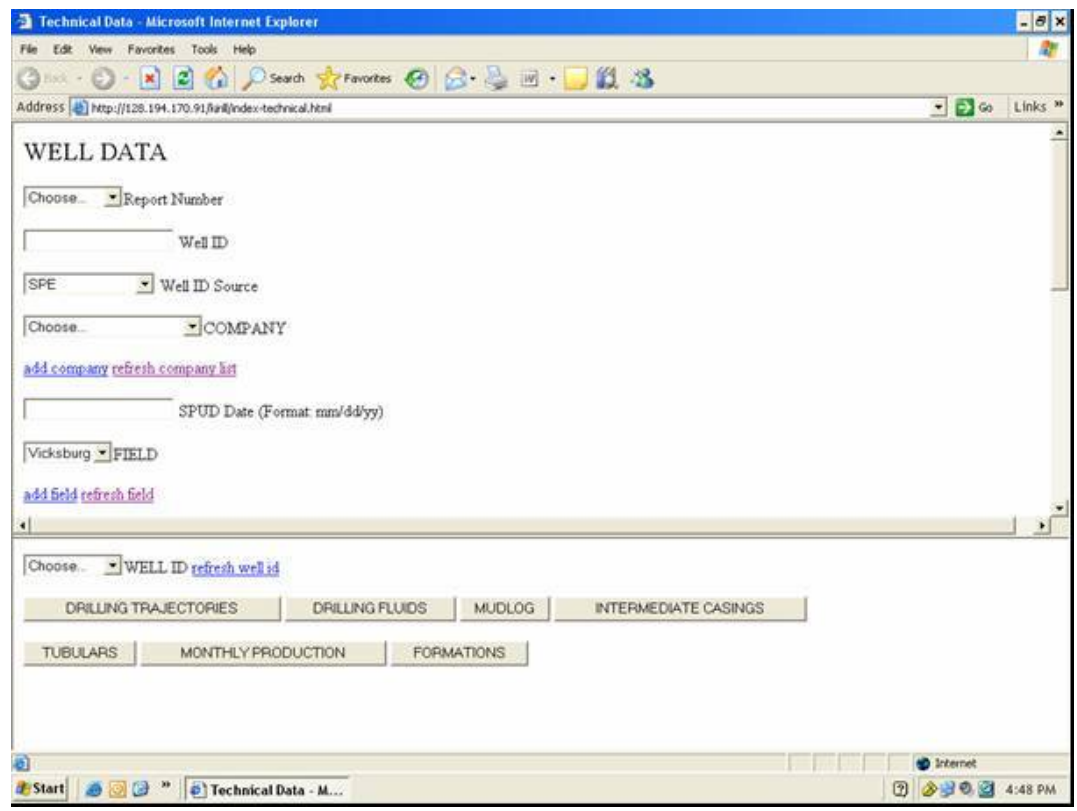

Figure 2 An example of web-based interface for MSSQL. 


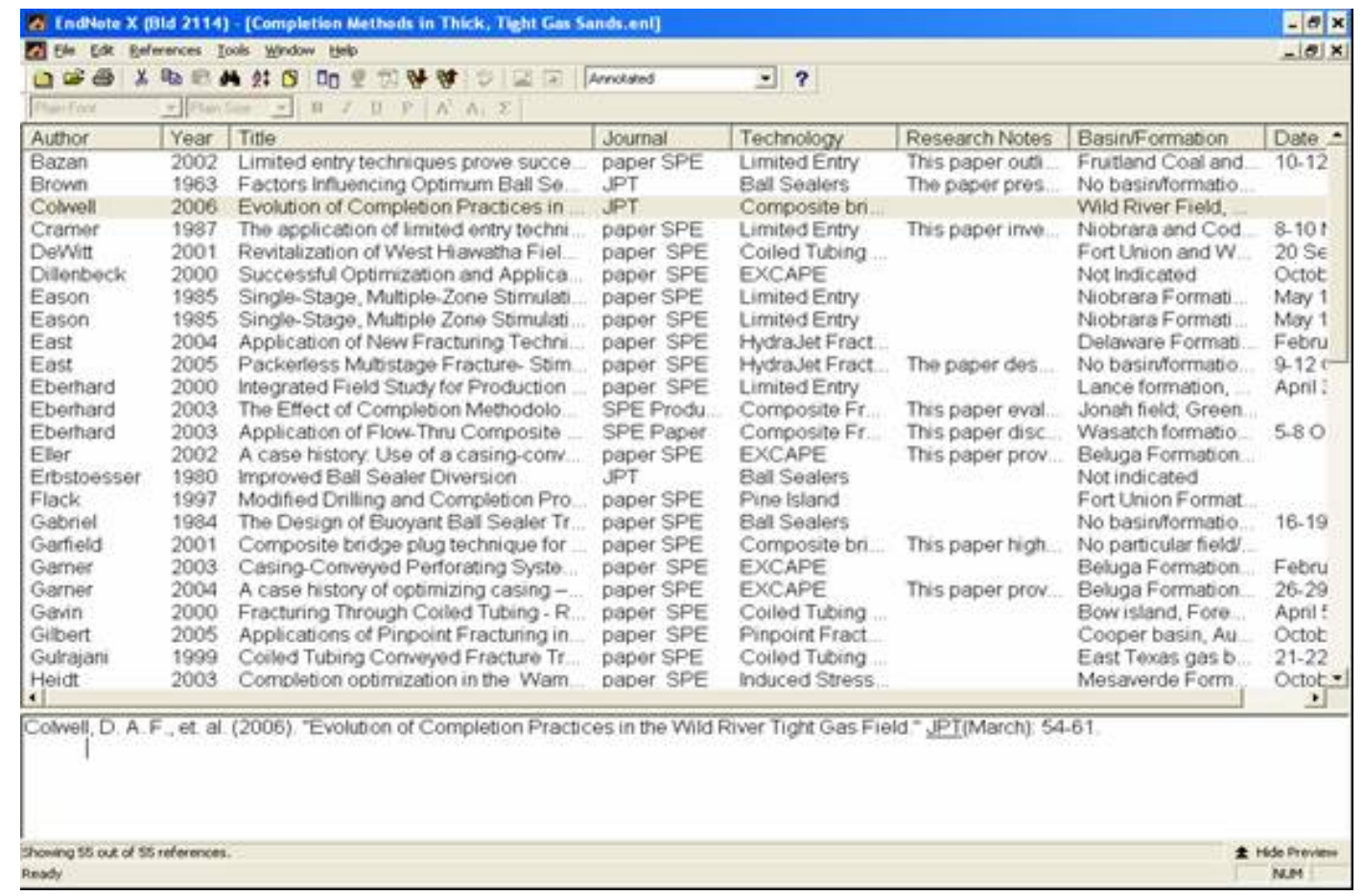

Figure 3: Papers documented using EndNote X

3. Knowledge representation. Knowledge representation of the expert system is the most time consuming and difficult task. It is the core of the expert system and all the decision or recommendation are referred from the knowledge base which is represented with a formal logic language. Currently, we plan to apply the widely used rule-based systems. A rule consists of an IF part and a THEN part. The IF part lists a set of conditions in some logical combinations. The piece of knowledge represented by the production rule is relevant to the line of reasoning being developed if the IF part of the rule is satisfied; consequently, the THEN part can be concluded. We will evaluate several ways to represent knowledge, to include fuzzy logic system and neural network.

From the information got from our study of the petroleum literature, we developed various flow charts. These flow charts group the diversion techniques, based on certain reservoir parameters. A detailed a high-hierarchy flow chart for the TG "Advisor" has been developed (Figure 4). We determined that TG "Advisor" will have a modular architecture and every module might be run as a stand alone application. For the stimulation module in our expert system, it is separated into several working areas for stimulation design, such as base fluid selection, proppant selection, candidate well selection, treatment size determination, etc. Each area is defined as a sub-module. Programming on some sub-modules in the stimulation module is developed.

A technology overview for proppants and perforation has been completed. We have identified technologies, which are potentially applicable for TGRs, and created decisionmaking trees (flow charts): proppant selection (Figure 5), perforating phasing selection (Figure 6) and perforation intervals selection (Figure 7). We have completed an overview of possible technologies and techniques and created decision trees for Flowback after Hydraulic Fracturing (Figure 8) and for Completion (Figure 9). 
For completion methods of thick, multi-layered tight gas payzones, flow charts (Figure $10 \mathrm{a}, \mathrm{b}, \mathrm{c}$ ) were drawn by looking at the depth ranges, bottom-hole pressures and net pay under which these diversion techniques can be effectively operated.
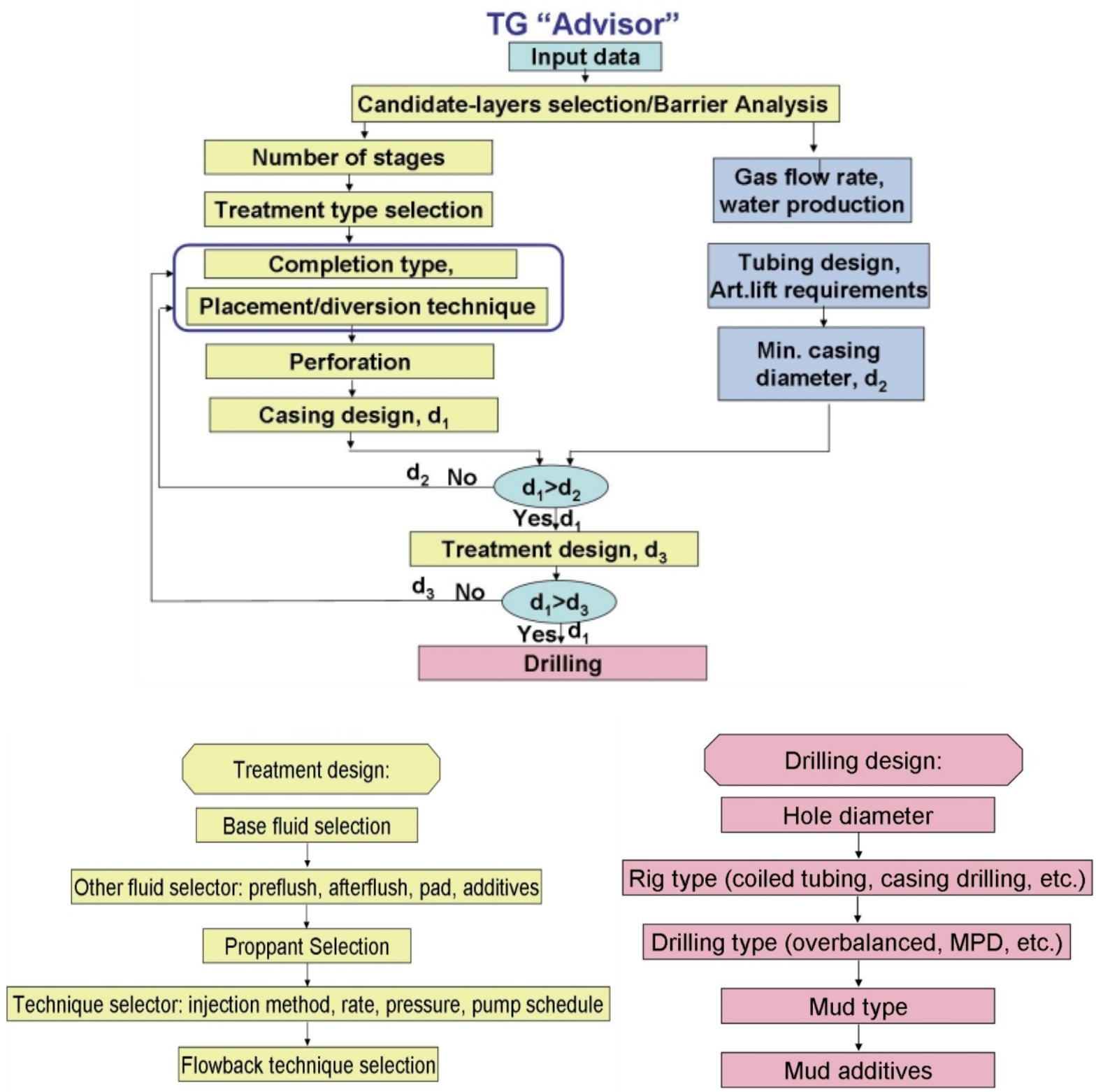

Figure 4 High-hierarchy flow chart for the TG "Advisor" 


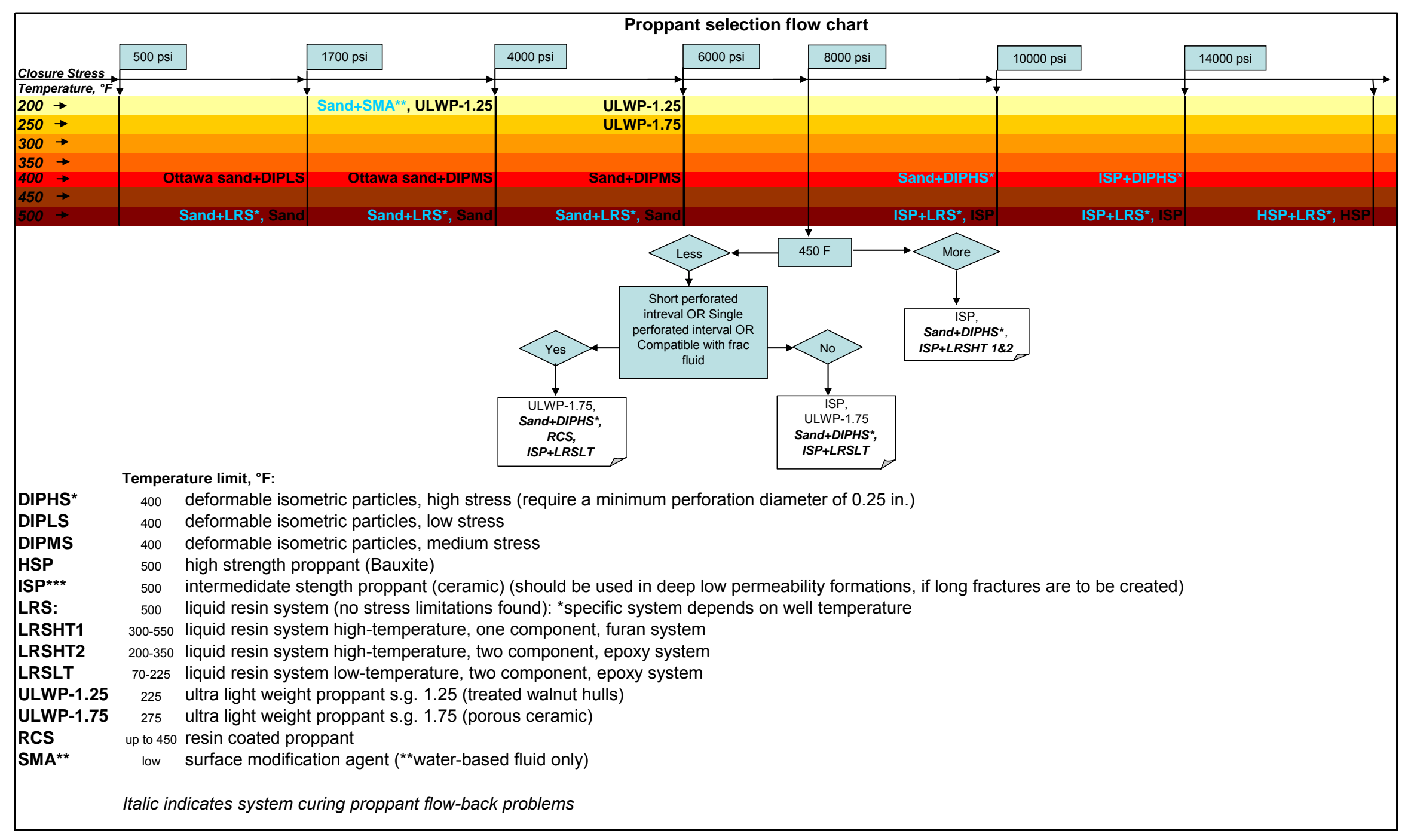

Figure 5 Proppant selection flow chart 


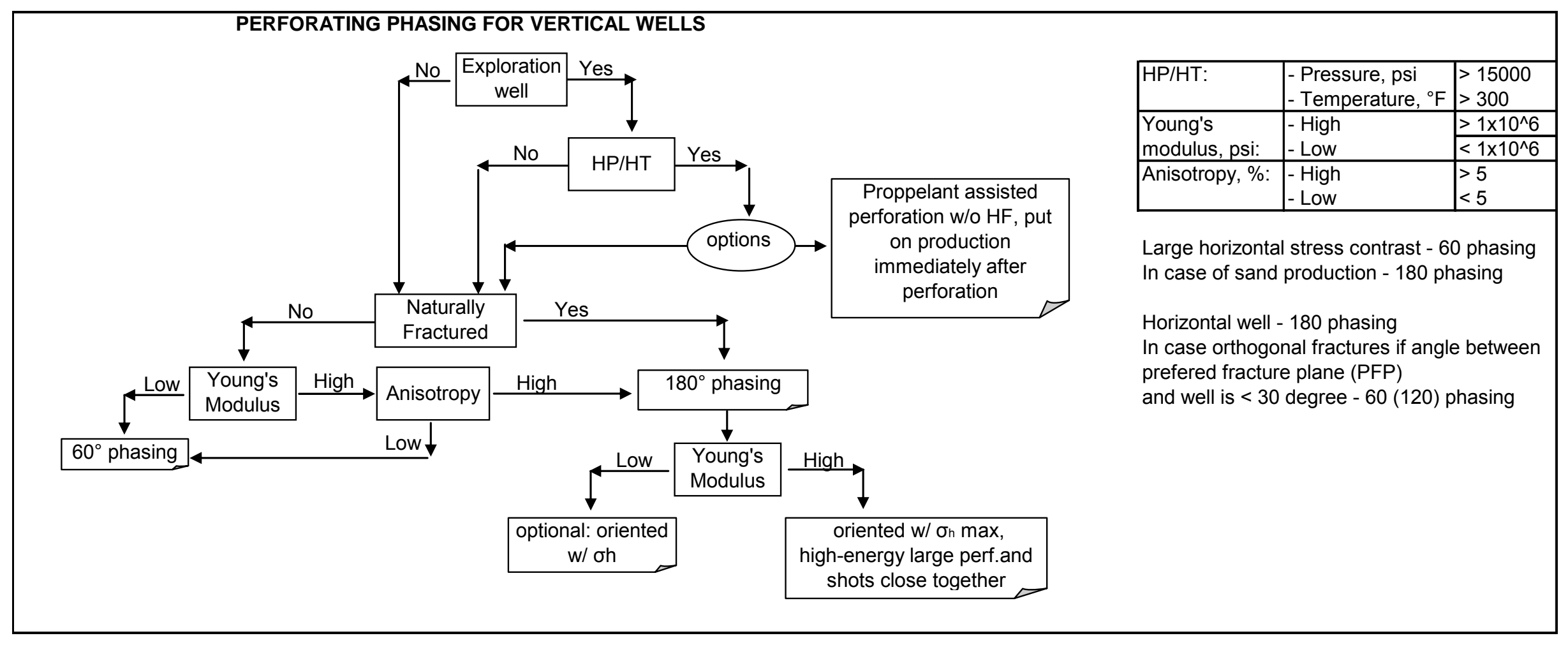

Figure 6 Perforation phasing selection flow chart 
PERFORATION INTERVALS for PRODUCING VERTICAL WELL for ONE STIMULATION STAGE

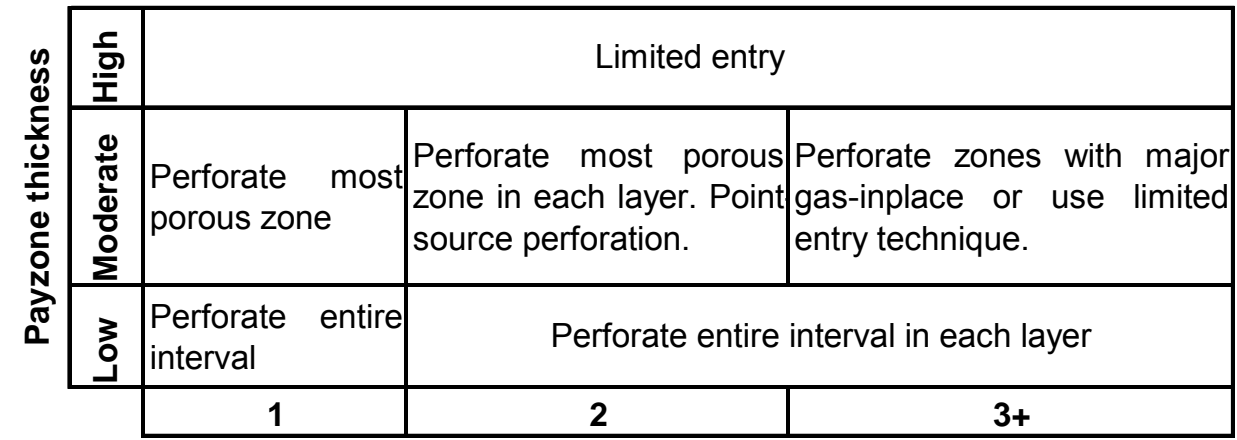

Number of separate fractures

In case foramtion sand production (weak foramtion) intreval should not be $>20 \mathrm{ft}$ In case low layer/barrier stress contrast - point-source perforation Horizontal well:

Longitudual fracture - $20-25 \mathrm{ft}$ interval

Orthogonal fractures: point-source perf, $2-4 \mathrm{ft}$

Figure 7 Perforation intervals selection flow chart

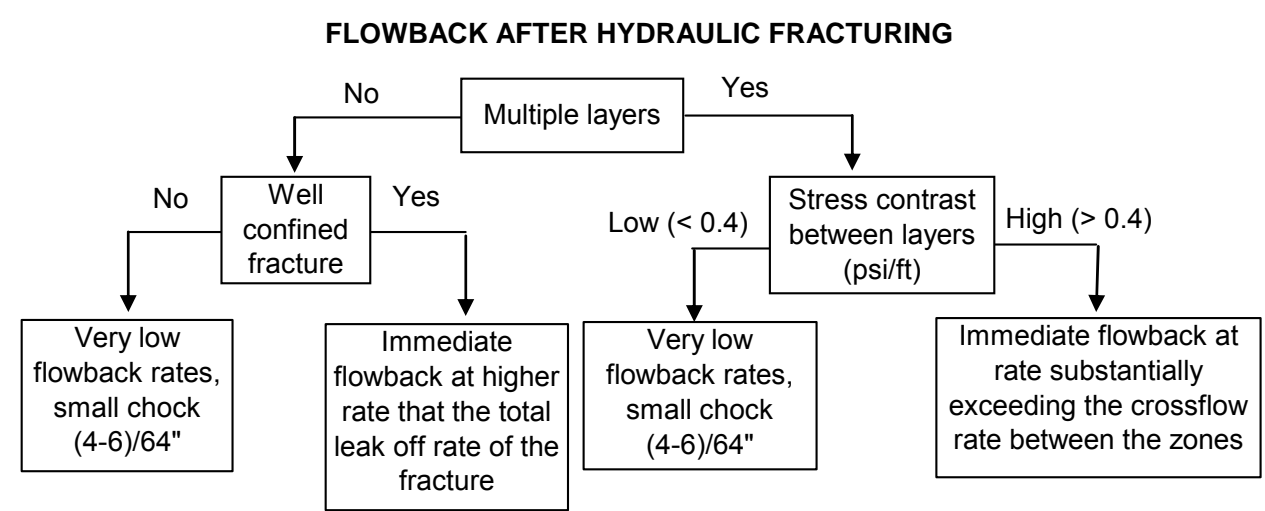

Figure 8 Decision tree for flowback after hydraulic fracturing

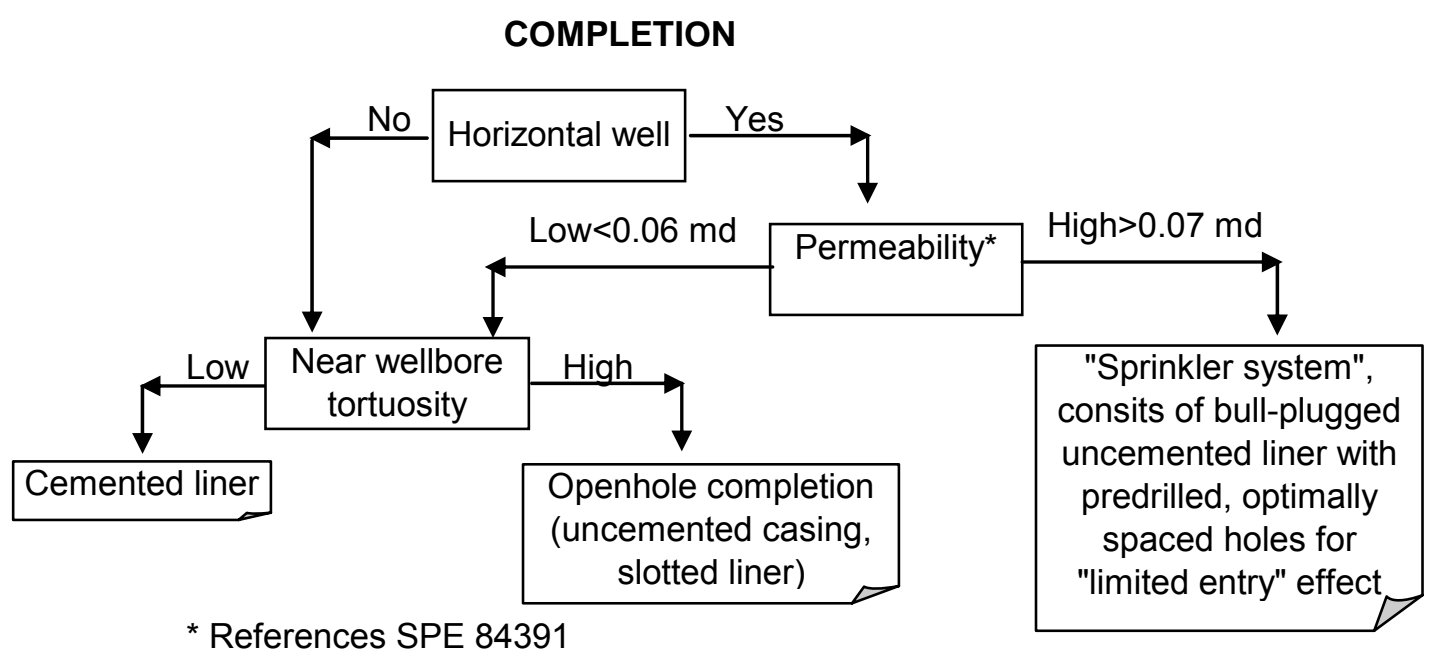

Figure 9 Decision tree for completion 


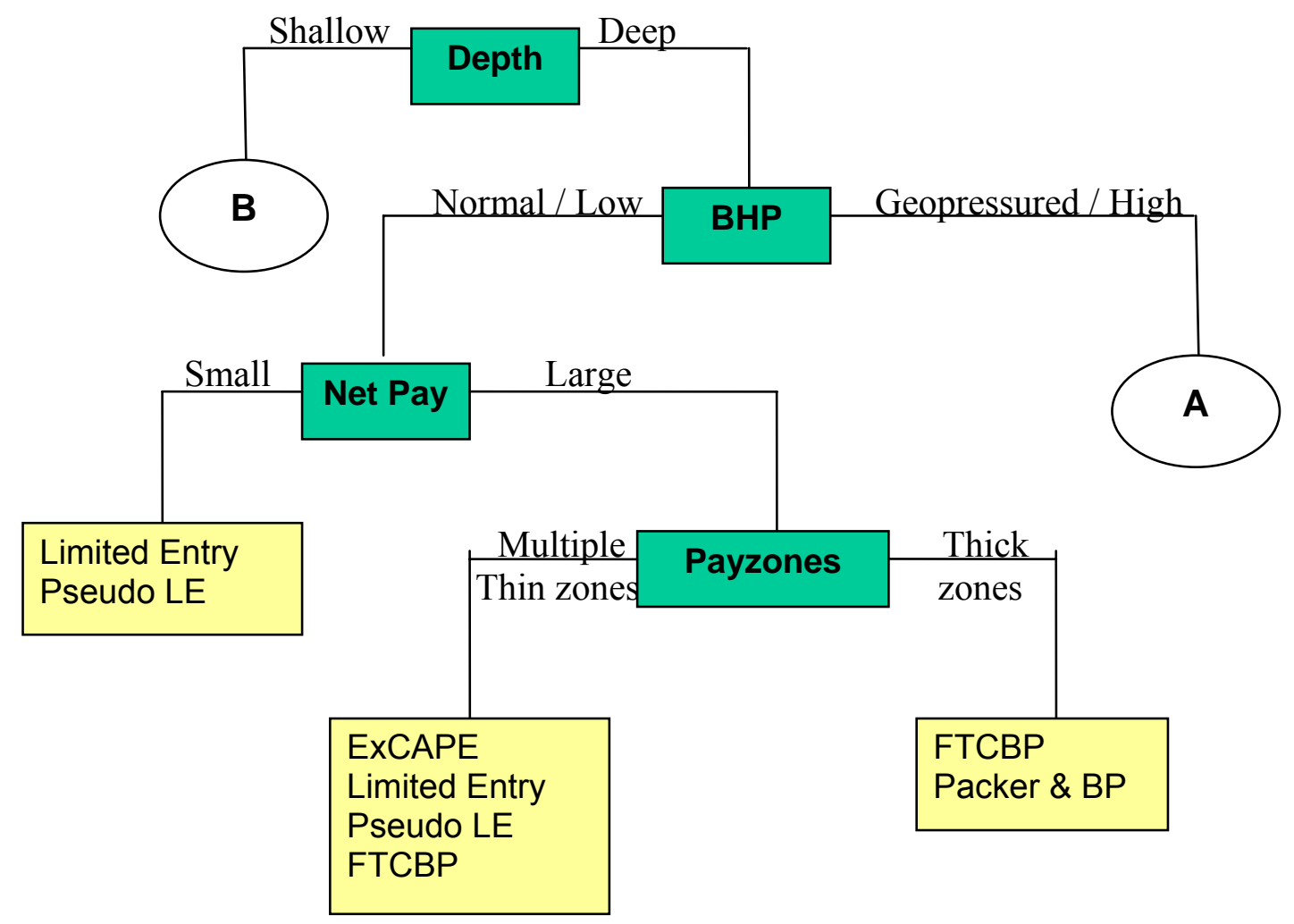

Figure 10a Flow charts showing decisions being made in choosing the various diversion techniques

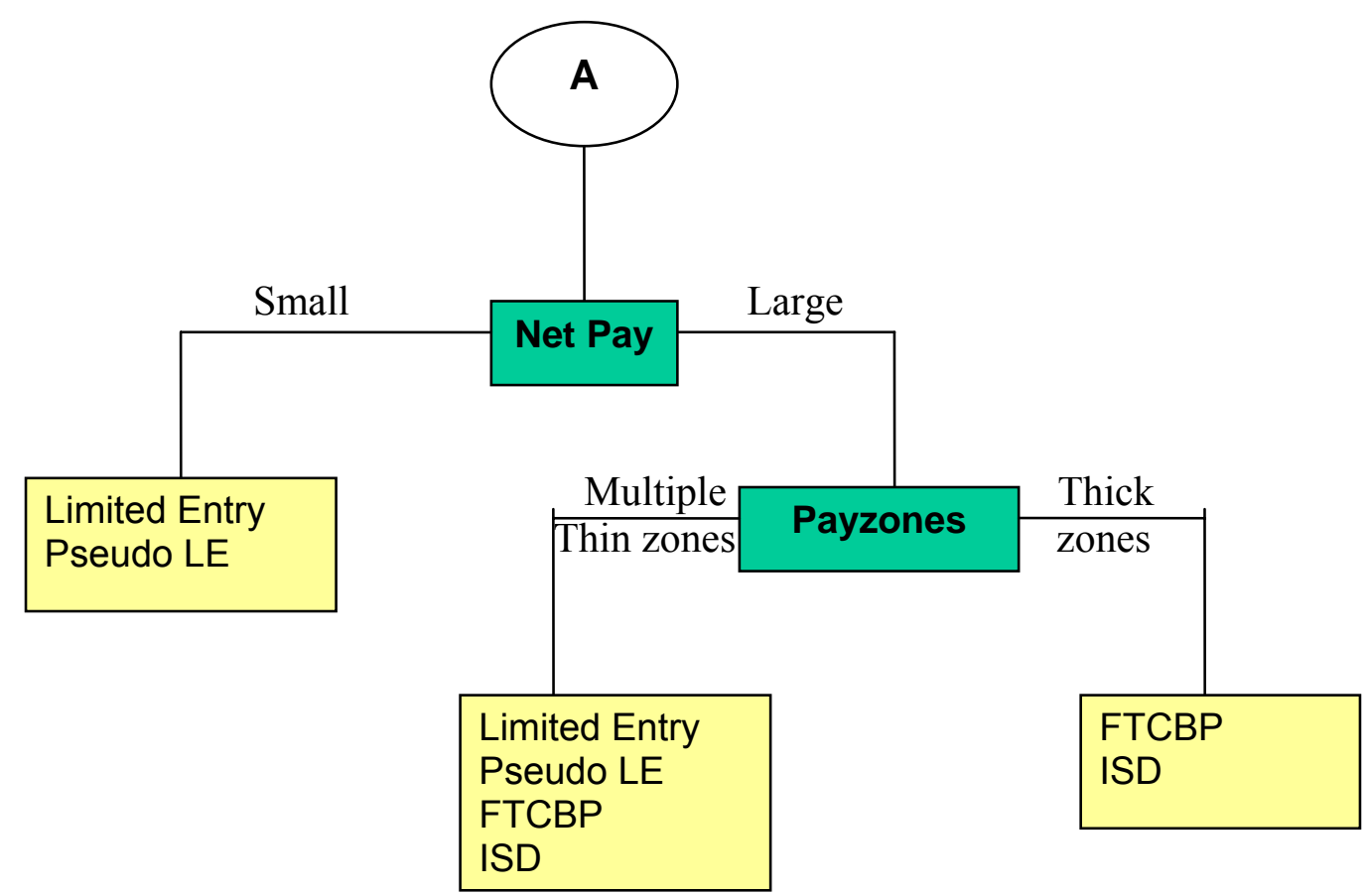

Figure 10b Flow charts showing decisions being made in choosing the various diversion techniques 


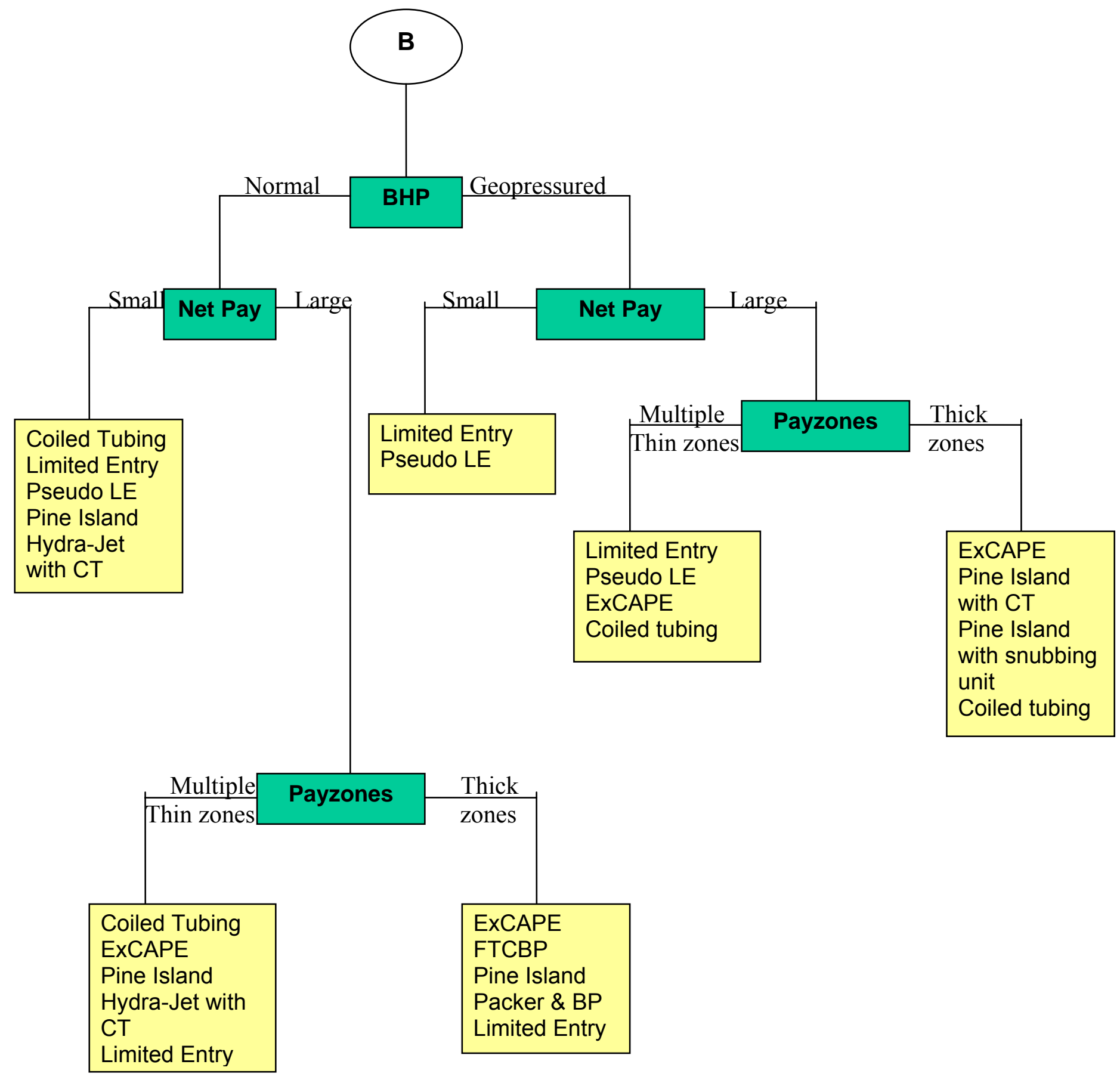

Figure 10c Flow charts showing the various diversion techniques

\section{NOMENCLATURE}

FTCBP: Flow through Composite

Bridge Plug

CT: Coiled Tubing

ExCAPE: External Casing Perforating

BP: Bridge Plug

Pseudo LE: Pseudo-Limited Entry

BHP: Bottomhole Pressure

ISD: Induced Stress Diversion

\section{KEY}

Deep: $>10000 \mathrm{ft}$

Shallow: < 10000ft

Normal BHP: $<=0.45 \mathrm{psi} / \mathrm{ft}$

Geopressured: $>=0.8 \mathrm{psi} / \mathrm{ft}$

Small Net Pay: $<30 \mathrm{ft}$

Large Net Pay: >30ft

Multiple Thin Payzones: $<15 \mathrm{ft}$

Thick Payzones: $>15 \mathrm{ft}$ 
4. Programming. The represented knowledge will be coded into the framework to build a working prototype. In implementation, we will use the program development tool to build a working prototype to document and organize information collected during the previous stage. An expert system tool, or shell, is a software development environment containing the basic components of expert systems. Associated with a shell is a prescribed method for building applications by configuring and instantiating these components. It is critical to choose a proper expert shell to build our expert system. Different kinds of expert systems and the feature of the expert system shells are studied. Finally, VB programming language is decided for building the expert system.

In this project, we will find the best practices on drilling, completion, stimulation and production on tight gas sand. It is necessary to design the layout of the four modules and pack them into one package. Currently, the layout of the four modules has been designed and the four modules can cooperate with each other very well. The user can transfer from one module to another module easily by just clicking one button.

We have developed a VBA program that covers the flow charts described above. This program will assist engineers in making decisions concerning the appropriate diversion technique(s) to be used in fracture treating a tight gas formation.

We created in VBA a Proppant selection module. The VBA subroutine concedes the input well/reservoir parameters, determines required fracture conductivity and suggests suitable proppants ranked by their price. Proppant data (conductivity, price, etc.) is stored in the separate MS Access database. Moreover, the module has an option of selection of proppant flowback control additives.

Another programmed module is perforation. It has three major sub-modules: perforation interval selection, perforation phasing selection and perforation shot density determination. Shot density and interval selection sub-modules were built using conventional methods based on information available in the literature and experts opinions. Meanwhile, perforation phasing selection was programmed using fuzzy logic approach. Five parameters are considered to have impact onto phasing selection: formation Young's modulus, formation anisotropy, existence of natural fractures, possibility of sand production, and horizontal stress contrast. A membership function and weighting factor was identified for every parameter (Appendix B).

5. User interface. Whether or not an expert system achieves success may be determined by the nature of its user interface. This is the part of the expert system that interacts with the user. For this reason, we will interactive with out User/Sponsor to make the expert system as easy for the user to operate as possible. Figure 11 shows an example of the interface for the expect system developed. 


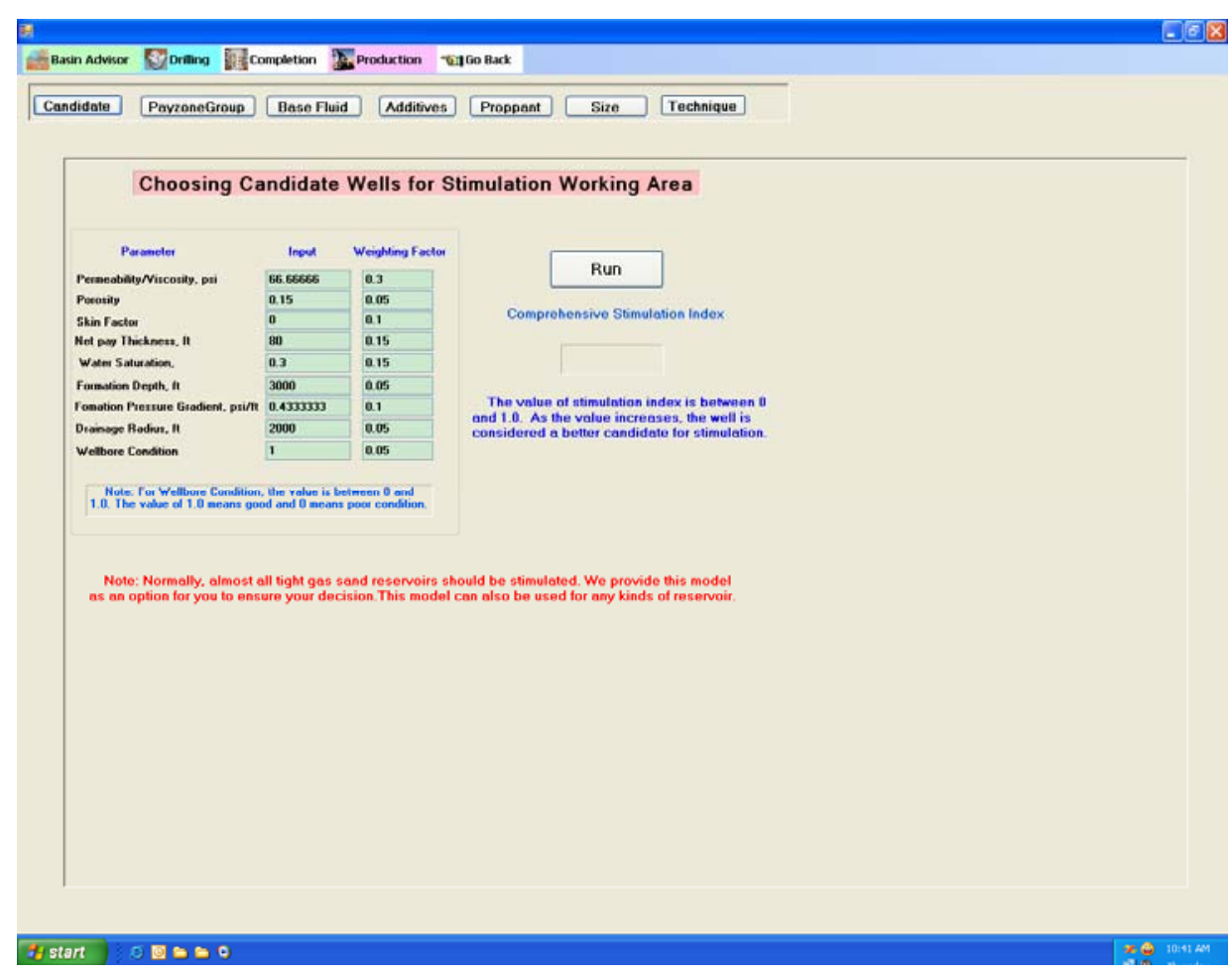

Figure 11 An example of the interface for the expert system developed.

6. Testing and Evaluation. The last stage, testing, involves considerably more than finding and fixing syntax errors. The program will be tested and validated using various case studies from the literature. This step will cover the verification of individual relationships, validation of program performance and evaluation of the utility of the software package. Testing guides reformulation of concepts, redesign of representations and other refinements. We will send the software to a group of experts and the feedback will be used to improve the software.

To build an expert system, the strong computer science background is needed. We have obtained the necessary knowledge of programming language, algorithm, database, artificial intelligent and fuzzy logic.

\section{Task 4 Dynamic Fracture Conductivity Tests}

\section{Subtask 4.1 Experimental Apparatus Setup}

The equipment used for the dynamic facture conductivity experiments has been studied carefully. The main objective is to set up an experimental apparatus that will simulate the field conditions of hydraulic fracturing as close as possible. This requires some unique equipment in this project. The pumping system should have high enough flow rate, be able to handle slurry, and also specified temperature and pressure in the system. The pumping design consists of a mixing tank to prepare base gel and slurry mixture, a base gel tank, multi-stage centrifugal pumps to pump fluid at high pressure condition, a modified API fracture conductivity cell, a load frame to apply closure stress, a flow system with leakoff capability, and auxiliary equipment as shown in Figure 12. The proppant pack conductivity is measured by flowing wet nitrogen gas through the conductivity cell at vary gas flow rates (Figure 13). 
We have successfully conducted the first phase of experiments including preliminary tests and several tests with this design.

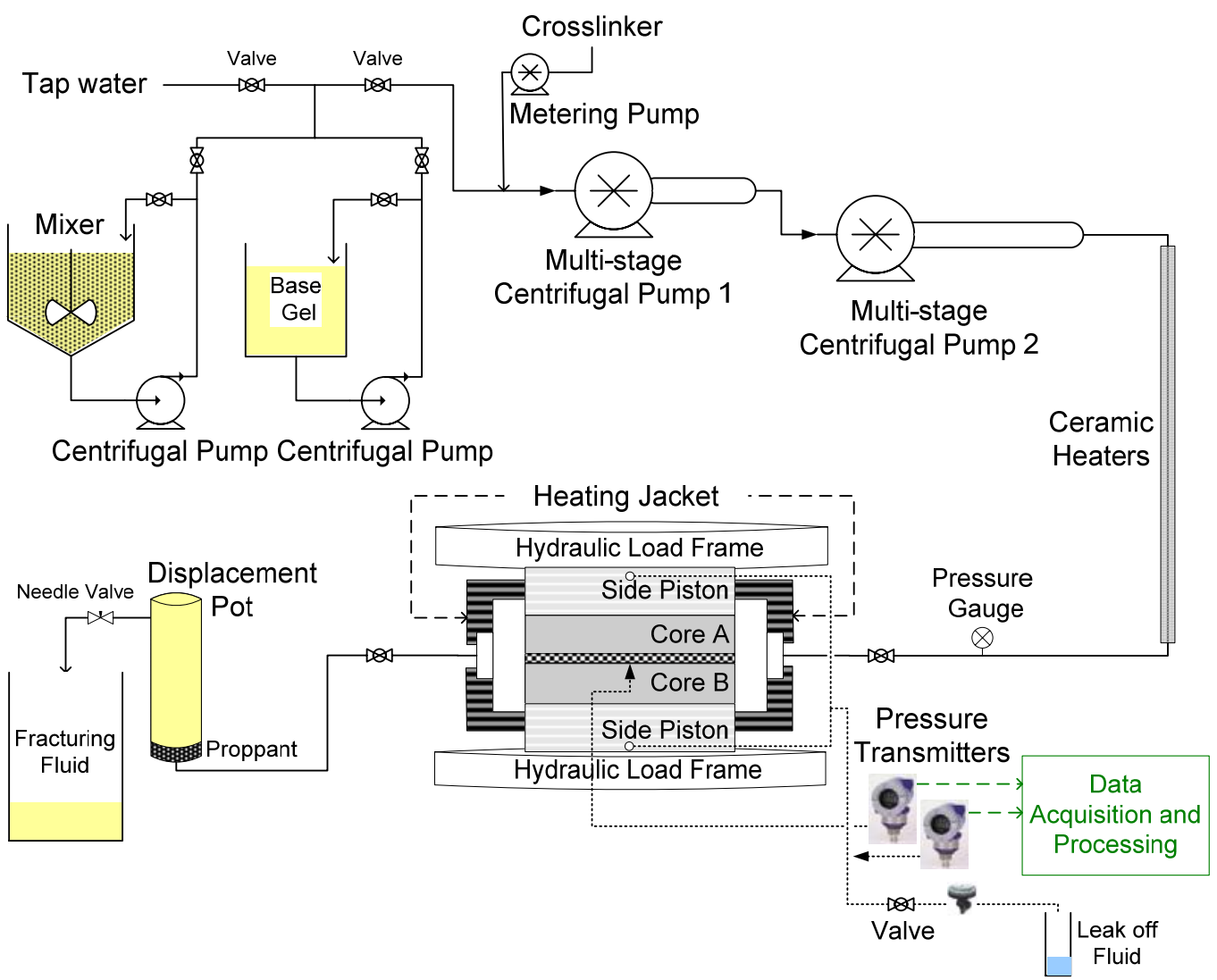

Figure 12 Schematic of Dynamic Fracture Conductivity Laboratory Setup - pumping

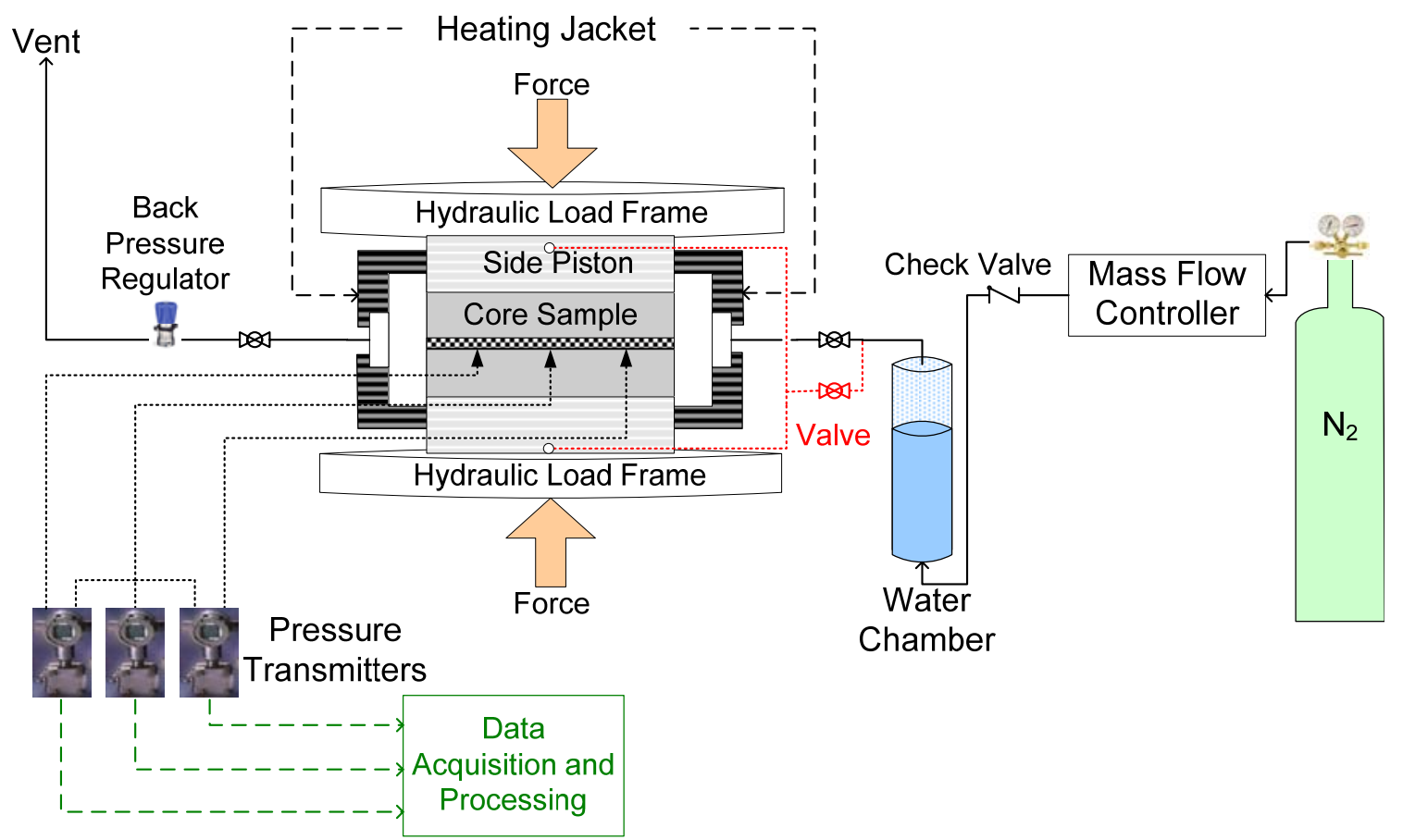

Figure 13 Schematic of Laboratory Setup - conductivity measurement 


\subsubsection{Mixing system}

The original design was to mix a base gel in the tank by using a centrifugal pump to circulate fluid. Then, proppant was fed on the fly from a container into the flow line by rotating a ship auger bit. However, this design was unsuccessful implemented because fluid flows into the proppant container.

The new design of mixing system consists of a 55-gallon alloy tank, a mixer, and a centrifugal pump (Figure 14). The mixer blends mixture in the tank, whereas the centrifugal pump circulates the mixture from the bottom to the top. This design is proved to provide uniformly mixed fluid as revealed in Figure 15. The mixing process starts with filling a desired volume of tap water for both base gel and slurry into the mixing tank via a flexible tube connected to the PVC tube. Polymer and $\mathrm{pH}$ buffer are added into the mixing tank to prepare the base gel while circulating with the mixer and the centrifugal pump. After mixing for 30 minutes, the base gel is then transferred to the 55-gallon Polyethylene drum that is connected to another centrifugal pump used to drive the base gel into the high pressure pump. Other additives and the desired amount of proppant are added into the mixing tank. Now, both pad and slurry are ready to be pumped into the high pressure pump through the line with a valve on the most right hand side.

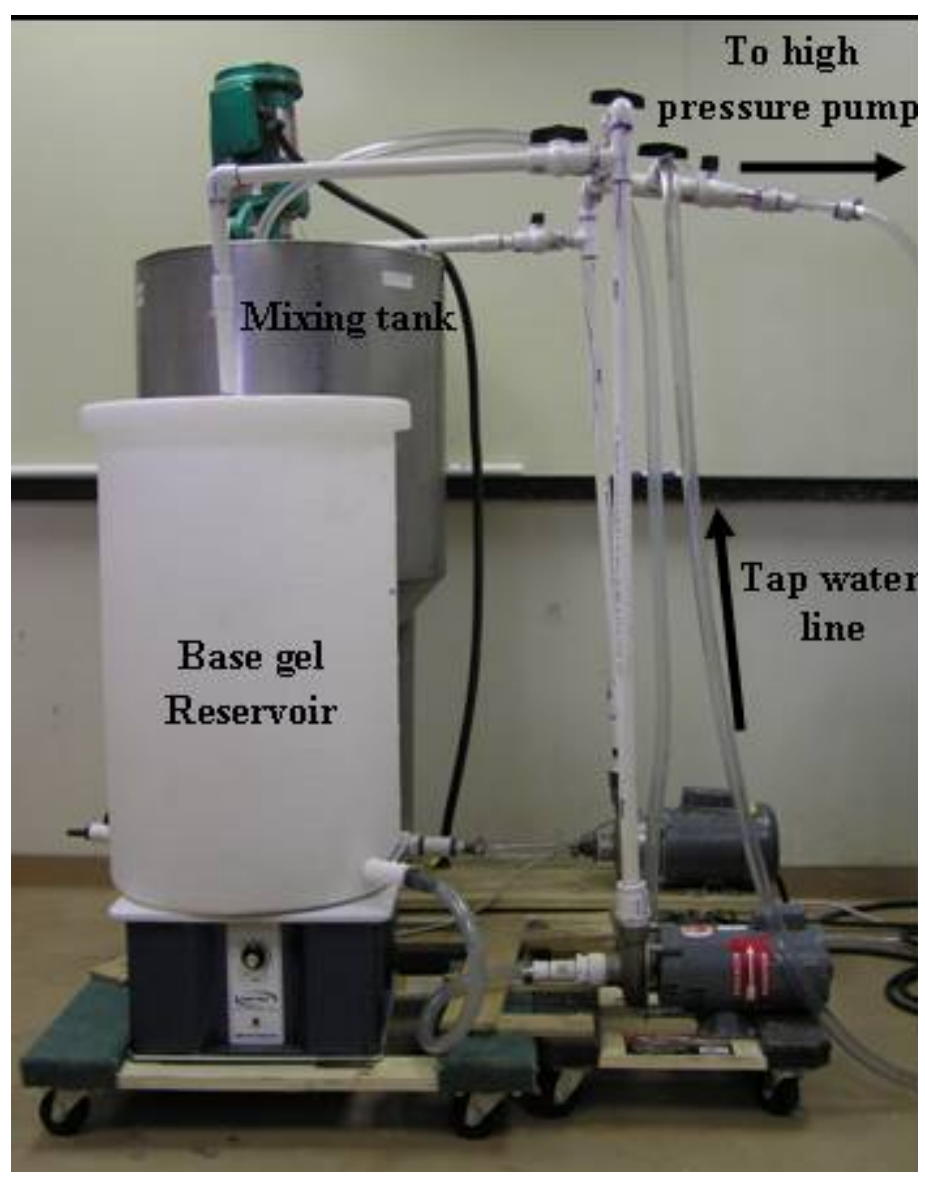

Figure 14 Mixing system 


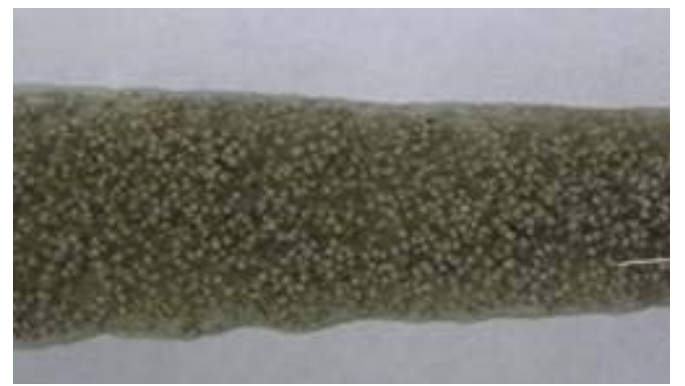

Figure 15 Uniformly distributed slurry created by the mixing system

\subsubsection{Crosslinker addition}

Crosslinker and crosslinker accelerator are mixed in a beaker and injected in the system while slurry flows into the high pressure pump by using a meter pump (SP Thermo Separation Product, P/N 92014903) (Figure 16). The crosslinker pumping rate is calculated based on the pumping rate of slurry and the mixture recipe provided by the service company.

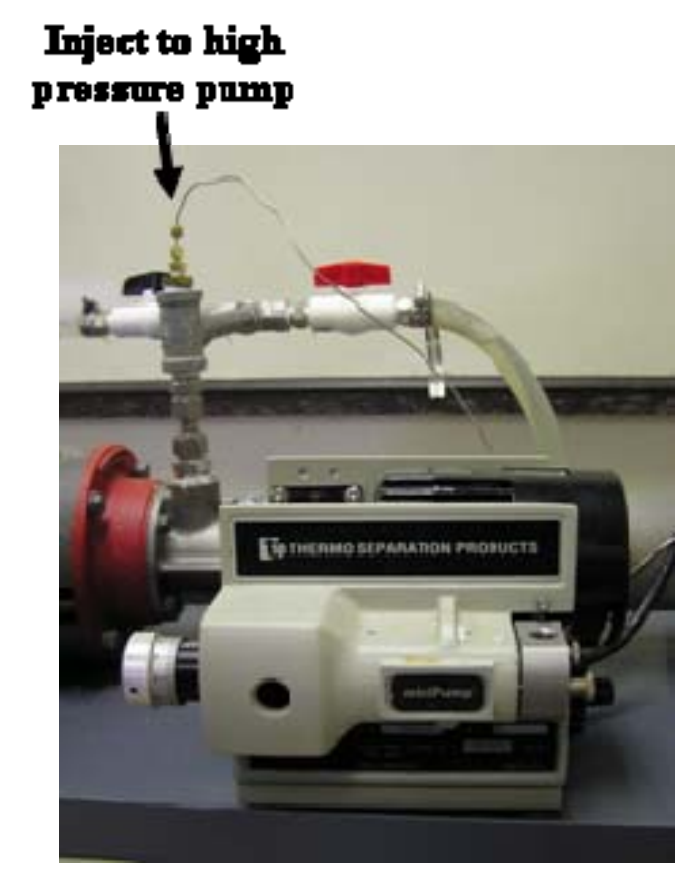

Figure 16 Metering pump

\subsubsection{High pressure pump}

To mimic field treatment conditions, the slurry is desired to pump at flow rates from 1 to $4 \mathrm{~L} / \mathrm{min}$ and pressure of $1000 \mathrm{psi}$. The flow rates are calculated to reproduce the Reynold's numbers that occur in actual fracture treatments.

Initially, we refurbished two Bran \& Lubbe simplex plunger pumps (Figure 17) which were available at the Petroleum Engineering Department at Texas A\&M University and fit to the application conditions. After two-month trials, we conclude that these pumps with spring loaded valves cannot pump slurry at high pressure condition because proppant particles prevent the valves from fully close (Figure 18). We tried to run Tonkaflo multi-stage centrifugal pumps which were also available at the Petroleum Engineering Department. The pumps have successfully pumped the slurry at the designed pressure of $350 \mathrm{psi}$ and $600 \mathrm{psi}$ for the pump models SS538X and SS558X, respectively. We therefore decided to use the Tonkaflo multi-stage centrifugal pumps for our experiments. 
To achieve the pressure of 950 psi, the pumps are put in series as shown in Figure 19. The model SS538 pump with 38 stages boosts fluid pressure up to 350 psi before entering to the 58 stages centrifugal pump- model SS558. In this way, the discharge pressure from second pump can reach up to 950 psi. The mechanical seal of the second pump had been changed to high pressure mechanical seal which can handle high inlet pressure up to 400 psi.

After several dry runs, the SS538 model was damaged due to stopping the pump in the middle of slurry injection. We realized that we should keep the pumps running by flushing with polymer and then water following slurry injection to prevent the proppant from settling down inside the pumps. The SS538 was shipped to repair and got back at the end of April 2007. We therefore used only the SS538 model in the first phase of experiments.

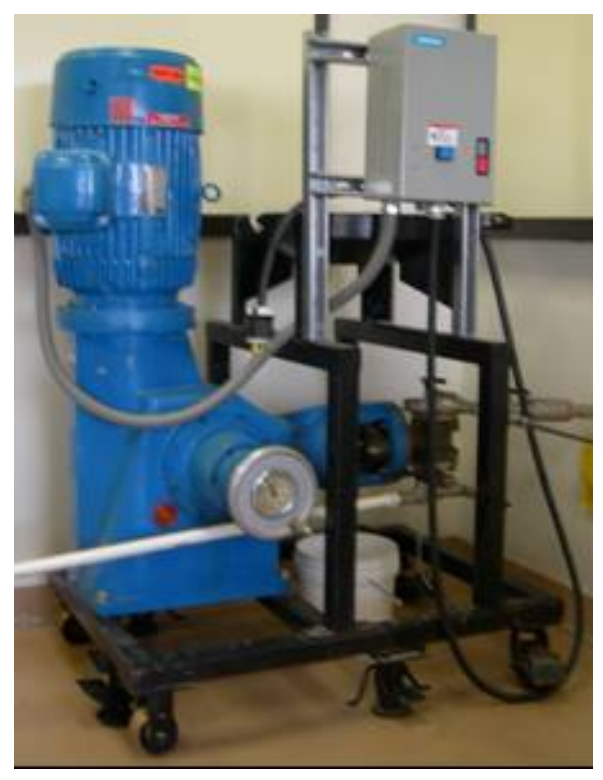

Figure 17 Bran \& Lubbe simplex plunger pump

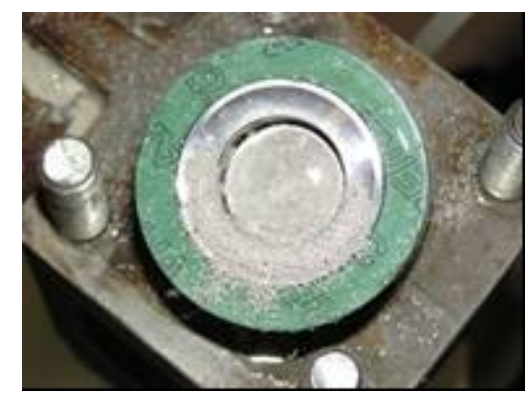

Figure 18 Proppant particles prevent the valves from fully close 


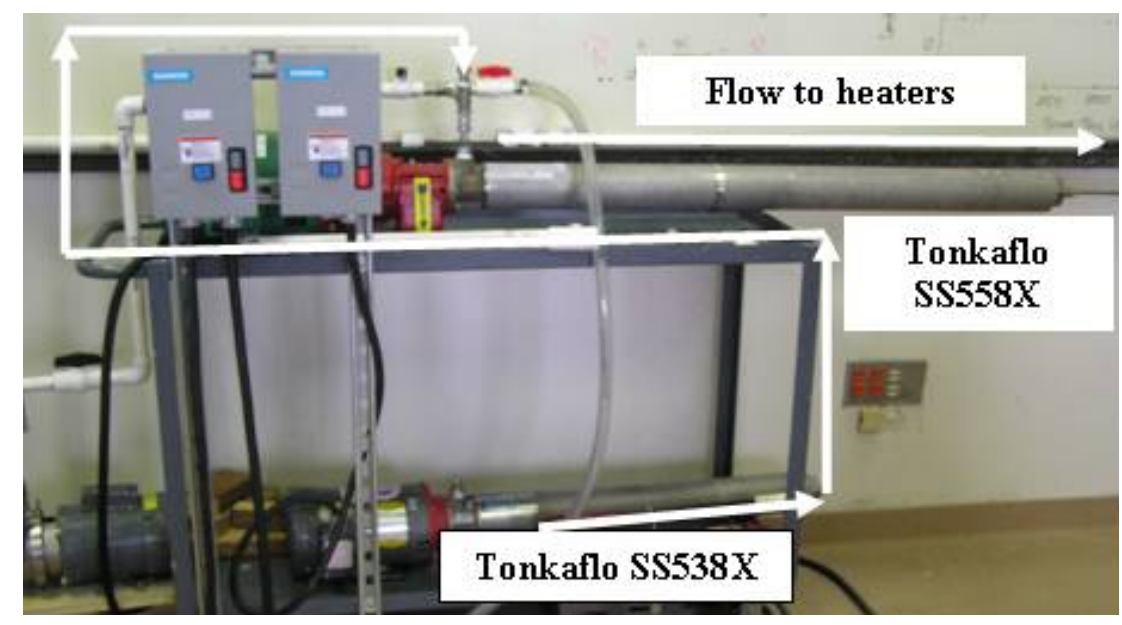

Figure 19 Series of Tonkaflo multi-stage centrifugal pumps

\subsubsection{Cylindrical heaters and heating jacket}

Temperature is a critical parameter in hydraulic fracturing treatments. It directly affects thermo dynamical properties of fracturing fluids which influence on the results of fracturing jobs. To represent the field conditions experimentally, the fracturing fluid is heated by cylindrical heaters before entering the conductivity cell which is wrapped with a heating jacket (Figure 20). To study residual gel damage resulting from unbroken polymer, experiments in a temperature range of $150-250{ }^{\circ} \mathrm{F}$ will be conducted. The fluid is heated to the desired temperature using six Omegalux CRWS series semi-cylindrical ceramic radiant heaters. Each semi-cylindrical radiant heater is 24-inch long and 1200 watts. Two semicylindrical heaters are combined as a pair with the flow tubing in the center. The total length of the cylindrical heaters is twelve feet. A thermal couple installed at the downstream of the heaters is connected to a temperature controller. The controller is set to the desired temperature with $5^{\circ} \mathrm{F}$ upper and lower ranges. The heaters are activated if the fluid temperature is $5^{\circ} \mathrm{F}$ below the desired temperature and deactivated if the temperature goes $5^{\circ} \mathrm{F}$ beyond the desired temperature. The conductivity cell is heated to simulate reservoir conditions by a Glas-Col heating jacket. The heating jacket is made from fiberglass fabric heating mantle with custom design to fit to the conductivity cell. The mantle is secured with straps. The jacket is half-inch thickness and 400 watts. A thermal sensor pad attached between the heating jacket and the conductivity cell is connected to another temperature controller with the same setting as the temperature controller of cylindrical heaters. The cylindrical heaters and its controller are turned off after finish pumping slurry, while the heating jacket is still on until the experiment is completed.
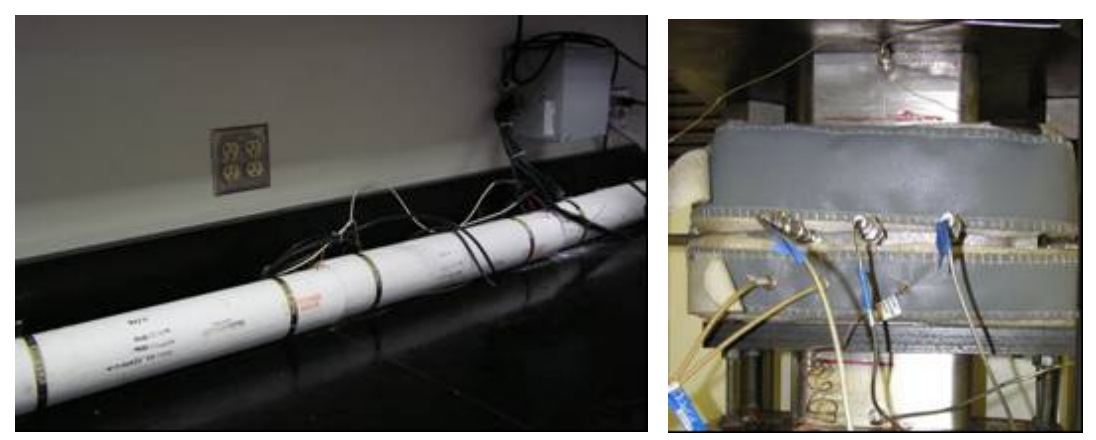

Figure 20 Cylindrical heaters and heating jacket 


\subsubsection{API modified conductivity cell}

The fracturing fluid is injected through a modified API (American Petroleum Institute) fracture conductive cell [Zou, 2006]. The conductivity cell is made of stainless steel and consists of the cell body, two side pistons and two flow inserts (Figure 21). Dimension of the cell body is 10 " $\times 3-1 / 4$ " $\times 8$ ". One side of the cell body has three pressure access ports for pressure measurement. The side pistons are used to confine cores in the cell center and maintain a desired pressure inside the cell body during the experiments. The side piston cross-section area is 12.5 squire inch. There is an access port in each piston to allow leak off fluids and nitrogen flow through rock samples. The two flow inserts on both ends of the cell body are inlet and outlet for the flow through the conductivity cell. The side pistons and the flow inserts are sealed with Viton $\mathrm{O}$ rings.

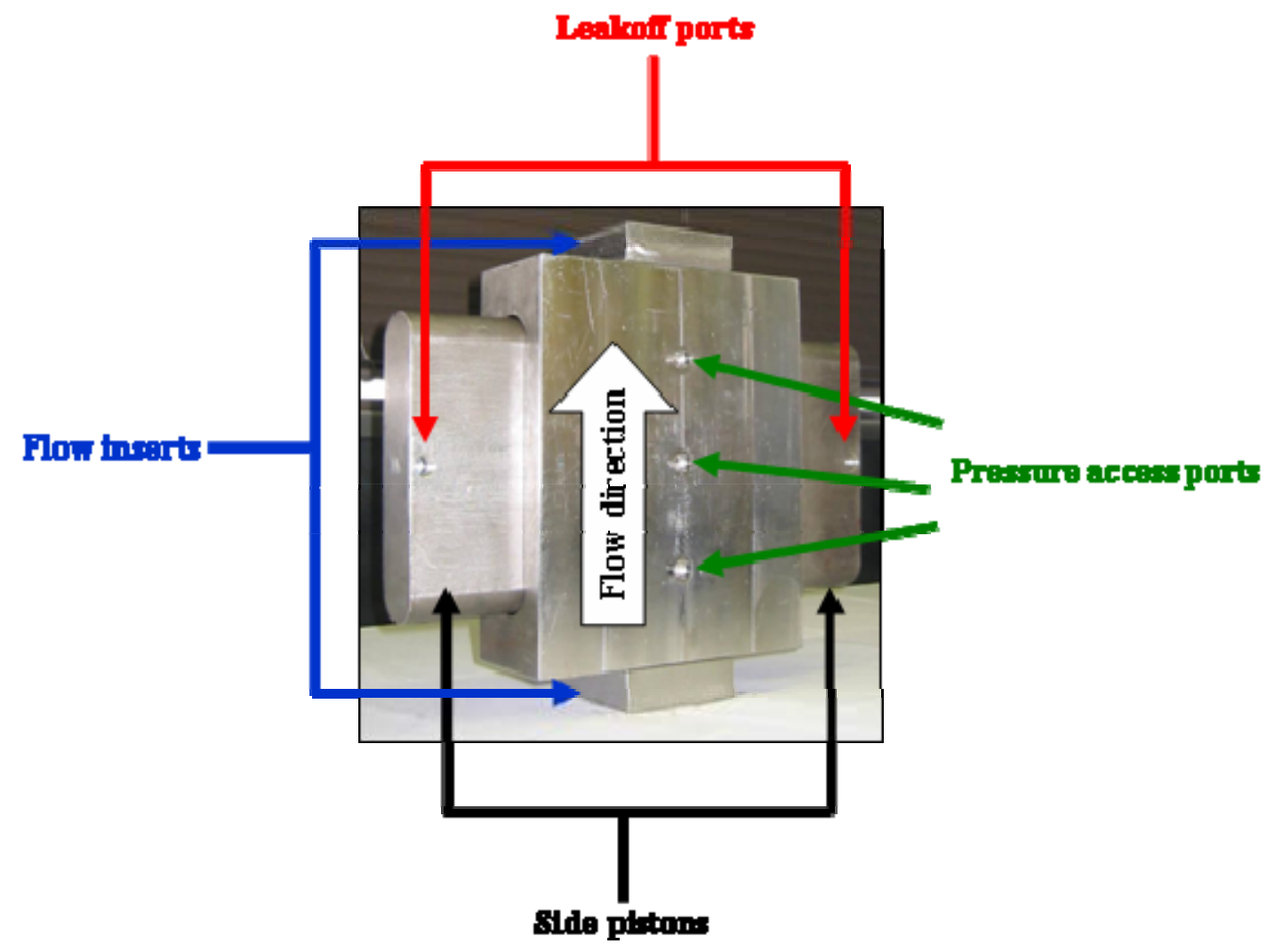

Figure 21 Conductivity cell

\subsubsection{Load frame, back pressure regulator, and pressure transducers}

Figure 22 shows load frame, back pressure regulator, and pressure transducers. Closure stress is produced with the load frame CT-250, manufactured by Structure Behavior Engineering Laboratories, Inc. An AP-1000 pump system is used to pressurize hydraulic oil for the load frame. The pump is operated by compressed air. The specification of the load frame is 125 square inches ram area and maximum capacity of 250,000 lbm force. The conductivity cell is supported by a rack on the load frame to properly space out the core samples in the cell. A back pressure regulator (Grove, model SD90W) is installed in the leakoff line to control the leakoff pressure. Two pressure transducers from Foborox (model IGP 10) are used to measure the cell pressure and leakoff pressure during fluid injection. Three pressure transducers (STC944, STD930, and STD974) from Honeywell are used to measure the cell pressure, front pressure drop and back pressure drop along the fracture. 


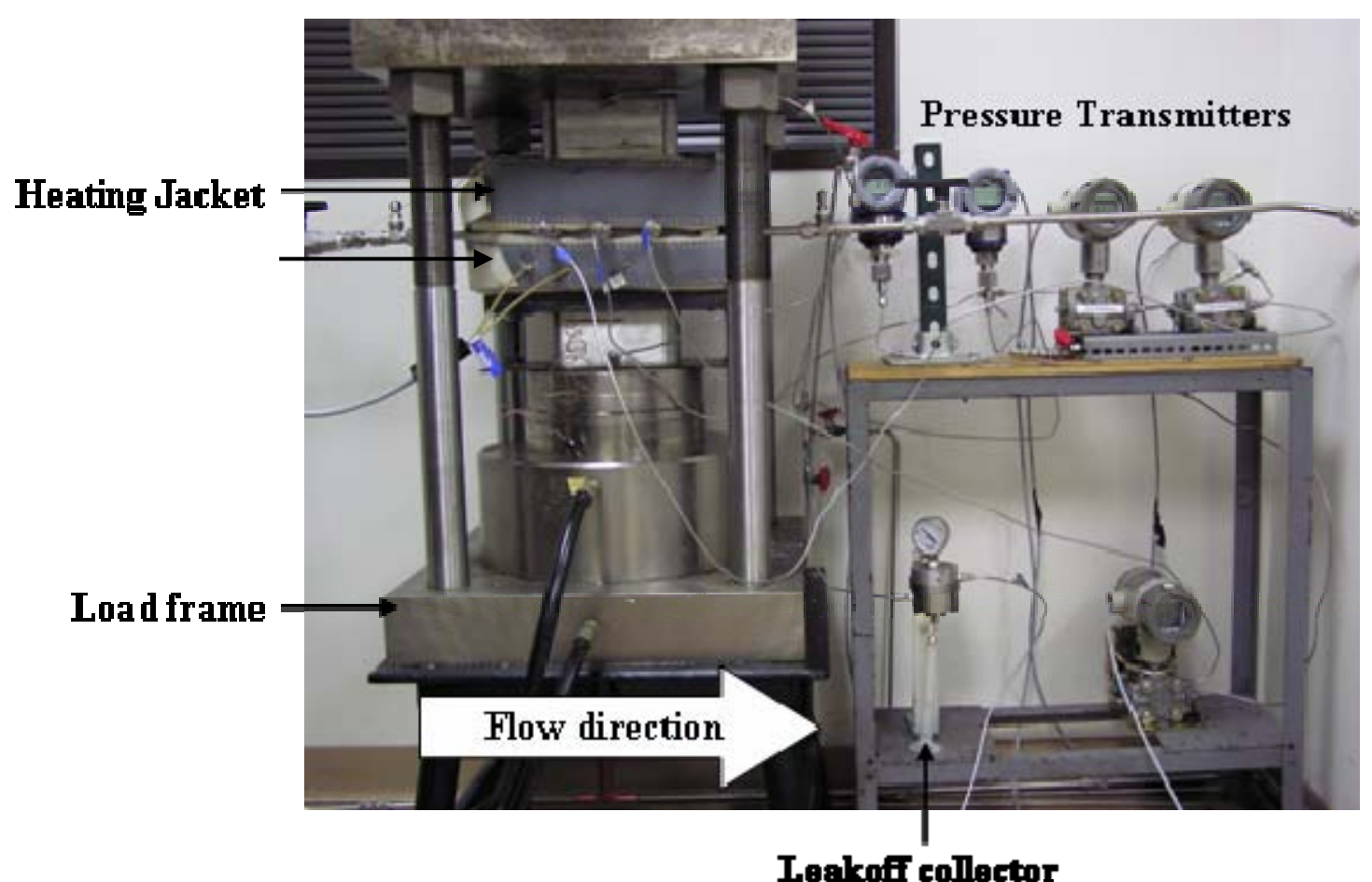

Figure 22 Load frame, back pressure regulator, and pressure transducers

\subsubsection{Displacement pots}

Two tanks are installed in the downstream of the conductivity cell to control cell pressure (Figure 23). Currently no back pressure regulators in the market are available to handle particles at high pressure condition. The tanks are served as displacement pots. The dimension of the tank is 5.7 inch i.d. with 35 inch length. Small diameter tubing of 1/8" o.d. with a needle valve is installed in the outlet of the tank and the flow rates can be adjusted to achieve high cell pressure. One tank is a back up in case proppant plugs the lines in the other tank.

\subsubsection{Fracture conductivity measurement experimental setup}

The fracture conductivity is measured by flowing nitrogen through the proppant pack. The conductivity measurement system is available in Petroleum Engineering department at Texas A\&M University from acid fracture studies. Figure 24 shows the actual experimental setup for fracture conductivity measurement. The major components are nitrogen supply, nitrogen mass flow controller, water tank, conductivity cell, load frame, pressure transmitters, and back pressure regulator. The nitrogen flow rate is adjusted and measured with Abalborg GFC Mass Flow Controller model 47. The nitrogen bubbles through a water tank to wet the gas. One-way check valves are installed to prevent water from flowing back to the mass flow controller. Fracture conductivity tests are conducted when a closure stress is applied to simulate field downhole fracture closure pressure after pumping stops. The closure stress is applied by a heavy duty load frame. An APCO back pressure regulator is installed on the nitrogen effluent line from the conductivity cell to achieve constant conductivity cell pressure. The cell pressure and the pressure drop along the fracture are recorded. 


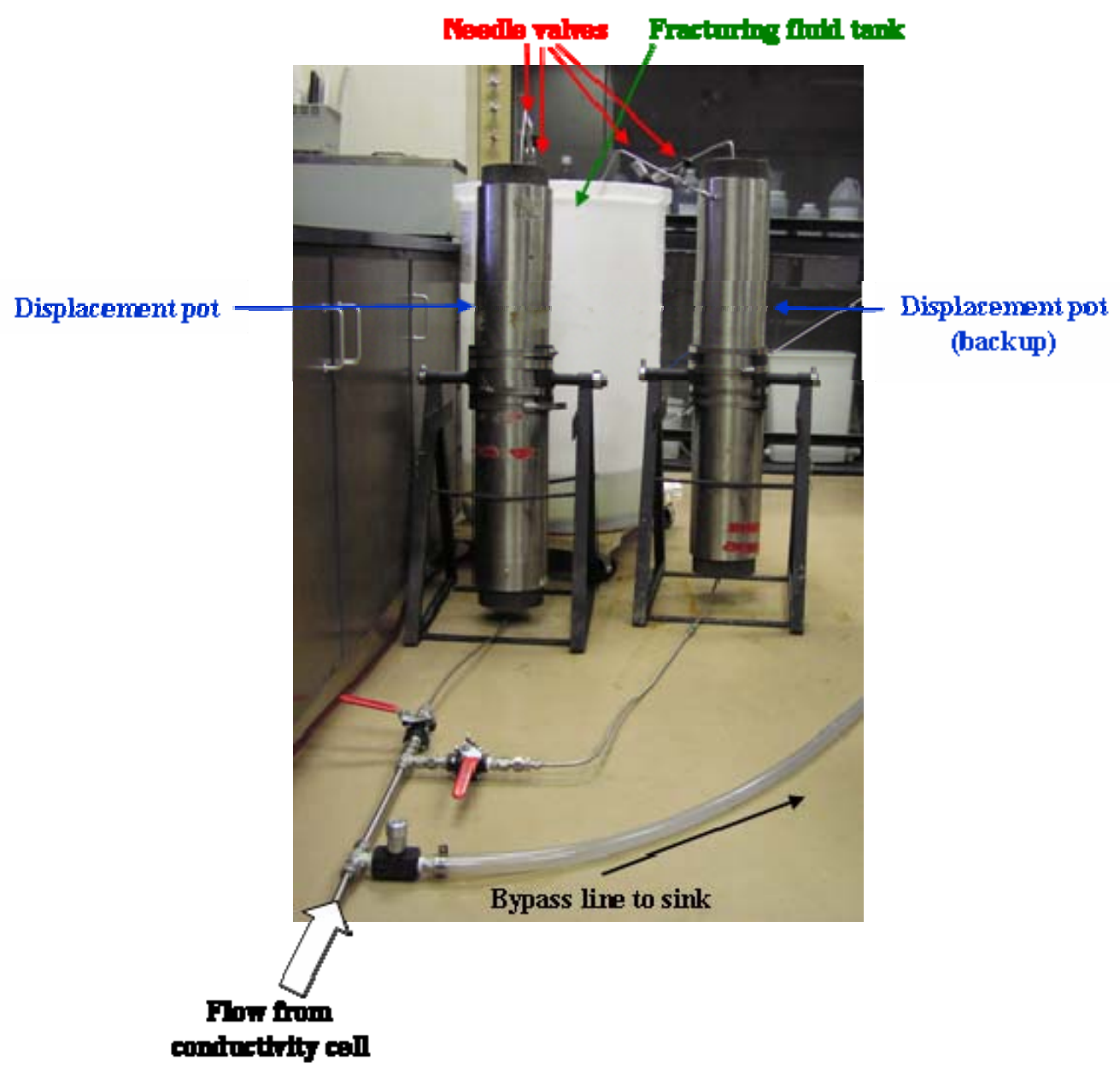

Figure 23 Displacement pots

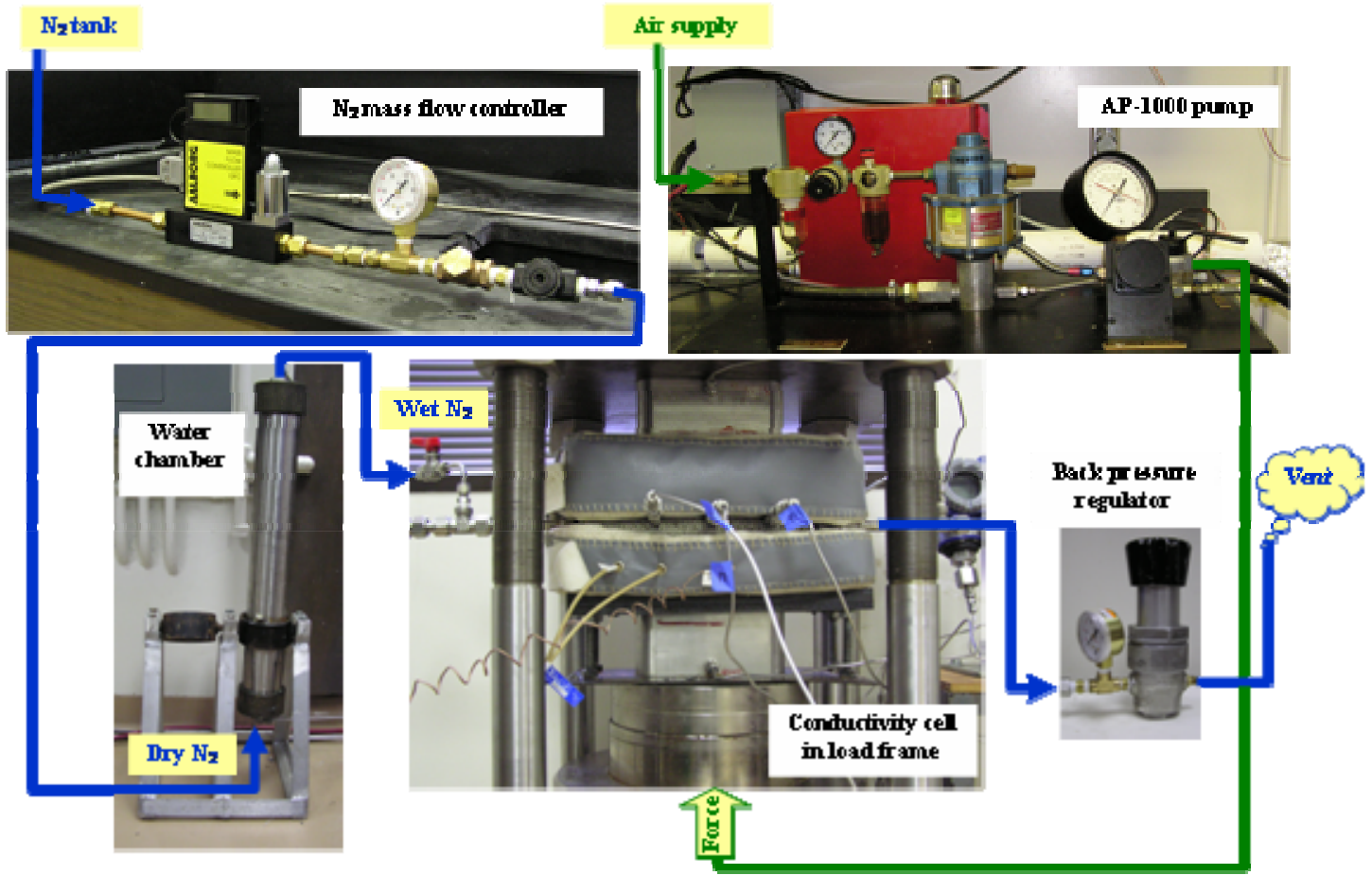

Figure 24 Fracture conductivity measurement experimental setup 


\subsubsection{Data acquisition}

The experimental variables for slurry injection, including conductivity cell pressure, gauge pressure in the leakoff side and the variables for conductivity measurement, including cell pressure and differential pressure along the fracture, are digitalized with sensors and recorded. Acromag modbus TCP/IP module is utilized to transfer signals to computer. It has a direct network interface, processes $\mathrm{I} / \mathrm{O}$ signals up to twelve channels, and handles power conversion. Data acquisition in computer is programmed with LabVIEW software. Figure 25 and 26 show the block diagram and front panel of the LabVIEW program.

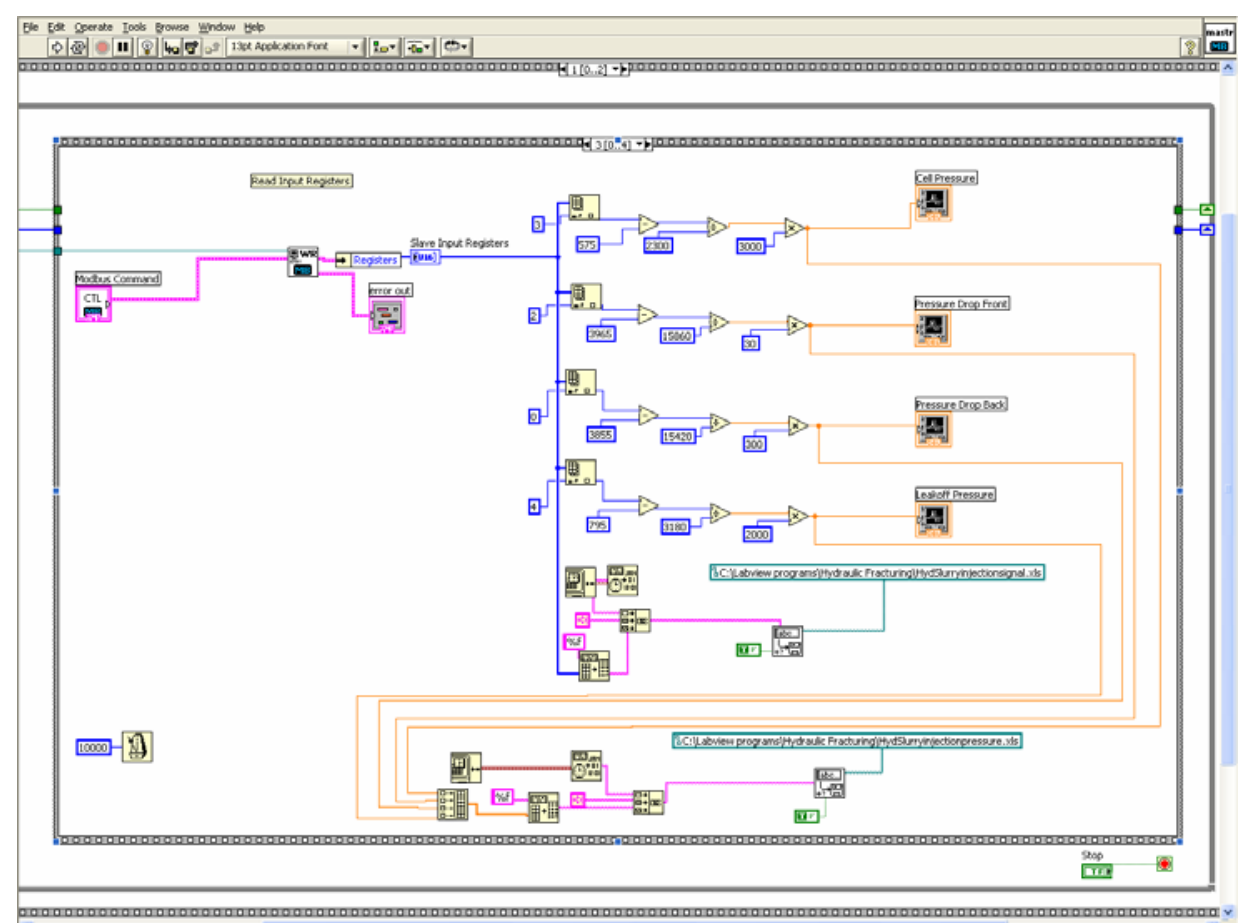

Figure 25 Data acquisition LabVIEW program (block diagram)

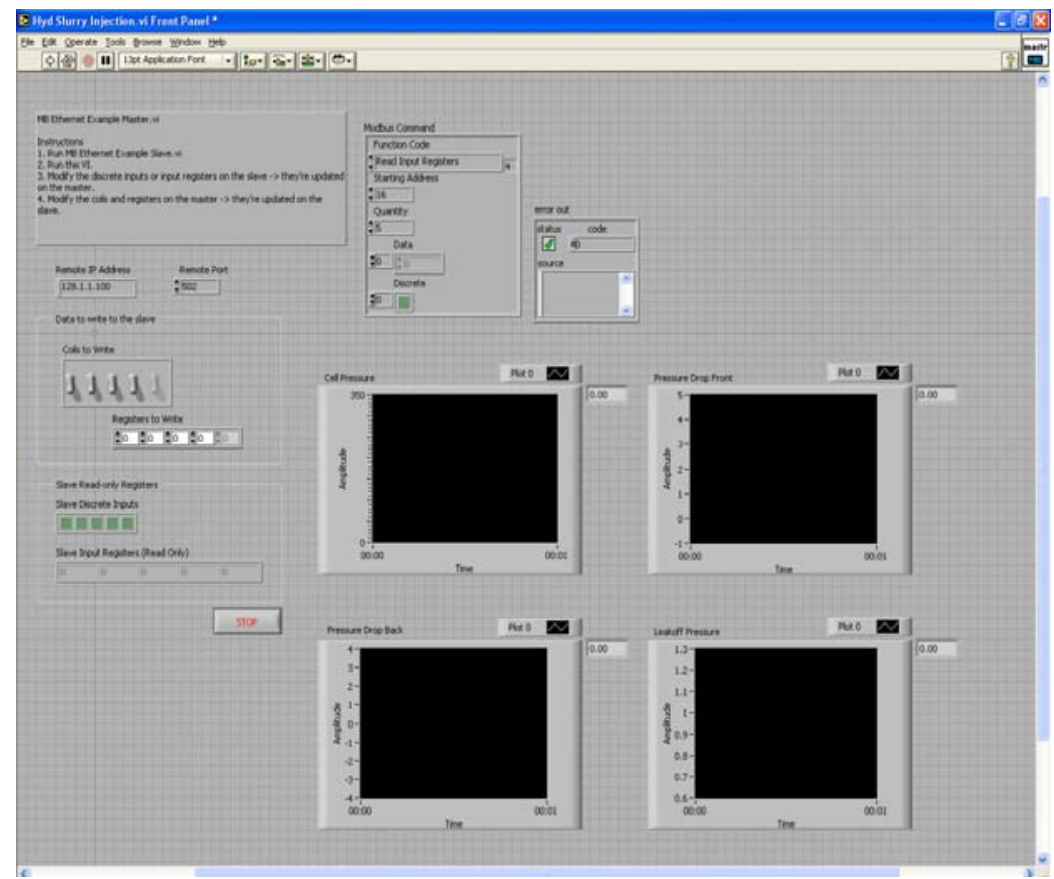

Figure 26 Data acquisition LabVIEW program (front panel) 


\subsubsection{Chemicals and proppants}

Halliburton has supplied the chemicals and receipt for the experiments. The postdoctoral research associate and three graduate students had a trip to Halliburton Duncan Technology Center, OK in September, 2006. They visited Conductivity Lab and had a good discussion about the project with several researchers there. The principal technician in Halliburton also demonstrated the detailed procedures to prepare hydraulic fracturing fluids.

Sixty 50 pound bags of 30/50 Econoprop were provided by Carbo Ceramics for the experimental study. This is the actual proppant used in the field for hydraulic fracturing jobs.

\section{Subtask 4.2 Preliminary Tests}

\subsubsection{Experimental procedures}

The experimental apparatus was assembled, preliminary tests were conducted to test the equipment.

The general experimental procedure for hydraulic fracturing fluid injection is shown in the following:

- Prepare the core samples by molding with a high temperature RTV silicone rubber.

- Assemble the core samples into conductivity cell as per designed fracture width by using a hydraulic hand pump.

- Connect all lines to the conductivity cell including the inlet and outlet tubing and the lines to the pressure transducers to measure the cell pressure, leakoff pressure and the differential pressure transducers.

- Measure the permeability of the rocks.

- Prepare fracturing fluid based on the recipe provided by Halliburton.

- Pump the heated base gel solution into the conductivity cell followed by the heated slurry.

- Shut-in the cell and apply closure stress of 2000 psig and leave the heated conductivity cell for 18 hours and excess fluid in the cell is allowed to bleed off through leakoff lines.

- Clean the pumping equipment.

The general experimental procedure for fracture conductivity measurement is shown in the following:

- Conductivity measurements are made by flowing wet nitrogen gas through the conductivity cell at flow rates of 2 to $10 \mathrm{~L} / \mathrm{min}$. Four to six flow rates are used. Record data at different flow rates.

- When not making measurements, the flow rate is set to a desired flow rate.

- Measure the conductivity after certain time period until the measured conductivity is relatively stable.

- Process data to get the conductivity by using the Forchheimer's equation.

- Disassemble the unit. The nature and condition of the filter cake and proppant pack are visually inspected.

- Proppant and filter cake residue are dried and weighed to quantify exactly the proppant concentration that is present in the test. 


\subsubsection{Core sample preparation}

Core samples are custom cut to fit the conductivity cell with about 0.07 inch less in all dimensions. Each core sample is then put in a mold and potted with silicone potting compound. The silicone rubber around the rocks provides seal between the core and the conductivity cell. Following is a preparation procedure:

1. Cut the rock sample into half by the rock-cutting machine.

2. Mark the rock samples as XA and XB.

3. Weight the rock samples.

4. Put duct tapes on top and bottom surface, cut edges with an exacto knife.

5. Brush the rock with silicone primer (SS4155 01P from GE) 3 times, 15 minutes apart.

6. Clean the metal molds and bottom plastic plates with Acetone by using cloths. Make sure it is very clean otherwise, the silicone will not be perfectly attached to the rock sample.

7. Spray Sprayon S00315 on the metal molds and bottom plastic plates 3 times (2 minutes apart). Make sure all surface areas are covered especially the curves.

8. Assemble the molds and put the rock samples in the center of the molds.

9. Mix $75 \mathrm{cc}$ of silicone potting compound (gray) and $75 \mathrm{cc}$ of silicone curing agent (white)-RTV 627022 kit. Stir it thoroughly.

10. Pour the silicone mixture into a syringe barrel. Assemble the injection system.

11. Slowly inject the mixture into the gap between the core sample and the mold until reach the top of the rock sample.

12. Remove the duct tapes and put the molds into the oven at $60^{\circ} \mathrm{C}$ for 15 minutes.

13. Refill the mixture to the top of the rock and put in the oven for 2-4 hours.

14. Leave the molds to cool down for at least 3 hours.

15. Carefully remove the samples from the molds.

16. Cut the excess silicone at the edges.

17. Label and weight the rock samples.

\subsubsection{Conductivity cell assembly procedure}

We conducted several preliminary tests and recognized that putting the rock samples into the conductivity cell is an important part of the experiment. Lack of carefulness when assemble the cell may lead to experiment failure as revealed in Table 1.

Table 1: Problems caused by carelessness conductivity cell assemble

\begin{tabular}{|l|l|}
\hline \multicolumn{1}{|c|}{ Actions } & \multicolumn{1}{c|}{ Results } \\
\hline $\begin{array}{l}\text { If not carefully wrap rock samples with a } \\
\text { Teflon tape }\end{array}$ & $\begin{array}{l}\text { Fluid flows between the rubber and the } \\
\text { cell }\end{array}$ \\
\hline If not carefully put the rock into the cell & Damage the rubber \\
\hline If the rocks touch too tight & The shim can not be removed \\
\hline If the piston does not touch the rock & $\begin{array}{l}\text { The test result is bias because of the gap in } \\
\text { between }\end{array}$ \\
\hline
\end{tabular}

The following guideline to assemble the conductivity cell is therefore created:

1. Select core samples for the experiment. Make signs for front, back, top and bottom sides.

2. Trim the silicone rubbers in positions that will be attached to the pressure recording lines after applying closure stress to prevent obstructions of pressure reading.

3. Wrap each core sample with a Teflon tape to prevent flow between the rubber and the conductivity cell. 
4. Apply Dow Corning high vacuum grease to the rubber and the Teflon tape.

5. Carefully insert the core samples into the conductivity cell by using the hydraulic jack. Be sure the fracture faces are lined up with the inlet and outlet flow insert ports.

6. Put a shim in the middle of the cell. The shim thickness is the designed fracture width.

7. Apply o-ring grease to the piston o-rings and the flow insert o-rings.

8. Use the hydraulic jack to push the pistons into the cell until touch the rocks.

9. Remove the shim and install the flow inserts.

10. Install the support rack and adjust the bolts to fit the bottom piston.

11. The samples are ready to be tested.

\subsubsection{Rock permeability measurement}

Follow is a guideline to measure rock permeability:

1. Adjust the mass flow controller to the close position. Calibrate to a zero value. Then, connect to the dry gas line.

2. Plug outlet of the cell and open the leakoff valve. Plug one side of the leakoff access port to measure the permeability of each rock sample separately. Flow nitrogen from inlet of the cell through the rock sample to the leakoff line.

3. Open the nitrogen regulator to flow gas into the system. Open the mass flow controller.

4. Check the gas flow line to ensure no leakage.

5. Control the gas flow rate by adjusting the mass flow controller.

6. Record the gas flow rate, the cell pressure and the leakoff pressure. Vary the gas flow rates between 1 to 5 liters/minute to receive five data sets.

7. Calculate the rock permeability by using the Forchheimer's equation.

\subsubsection{Fracturing fluid mixing procedure}

The mixing procedure is provided along with all chemicals from Halliburton. Table 2 shows the fracturing fluid mixing recipe for temperature $150{ }^{\circ} \mathrm{F}$. General mixing procedure is as follows:

1. Propose pumping volume, temperature and polymer concentration for an experiment.

2. Measure amount of chemicals required.

3. Add a measured volume of tap water into the mixing tank.

4. Turn on the centrifugal pump and the mixer.

5. Add polymer and $\mathrm{pH}$ buffer\#1 to $\mathrm{pH}$ 6.5.

6. To ensure hydration, mix the base gel for at least 30 minutes.

7. Measure and record the fluid $\mathrm{pH}$, temperature and viscosity of the base gel.

8. Transport a volume of pad fluid to the Polyethylene drum.

9. Add $\mathrm{pH}$ buffer\#2 and $\mathrm{pH}$ buffer\#3 to the slurry tank until the target $\mathrm{pH}$ is reached.

10. Add gel stabilizer, breaker and breaker activator.

11. Add proppant to the slurry tank.

12. Mix crosslinker and crosslink accelerator in a bottle and connect to the metering pump. 
Table 2: Fracturing Fluid Mixing Recipe

\begin{tabular}{|l|c|}
\hline \multirow{2}{*}{ Chemical } & $\begin{array}{c}\text { Temperature } \\
\text { (degree } \mathrm{F} \text { ) }\end{array}$ \\
\cline { 2 - 2 } & 150 \\
\hline Polymer, lb/Mgal & 30 \\
\hline $\mathrm{pH}$ buffer\#1 to $\mathrm{pH}$ & 6.5 \\
\hline $\mathrm{pH}$ buffer\#2 to $\mathrm{pH}$ & 10.0 \\
\hline $\mathrm{pH}$ buffer\#3 to $\mathrm{pH}$ & None \\
\hline Gel stabilizer, gal/Mgal & 0 \\
\hline Breaker, gal/Mgal & 10 \\
\hline Breaker activator, gal/Mgal & 1.0 \\
\hline Crosslinker, gal/Mgal & 0.9 \\
\hline Crosslink accelerator, gal/Mgal & 0.1 \\
\hline
\end{tabular}

\subsubsection{Hydraulic fracturing treatment procedure}

A very detailed procedure for hydraulic fracturing treatment is descried here:

1. Assemble the core samples into the conductivity cell followed the guideline.

2. Put the conductivity cell in the center of the hydraulic load frame.

3. Use a horizontal level meter to make sure that load frame top plate, the conductivity cell and load frame bottom ram are all in horizontal level.

4. Move the load frame to the neutral position by opening the air supply valve to activate the AP-1000 hydraulic oil pump. Carefully operate the air pressure regulator and the hydraulic oil pressure regulator to pump hydraulic oil to the load frame. The bottom ram of load frame will move up. Monitor the top piston to just touch the top plate. Do not apply more pressure to the load frame, otherwise the fracture will be closed and cannot run the experiment. Reset the test gauge to zero.

5. Turn on the laboratory exhaust system.

6. Connect the conductivity cell to the system lines, including the inlet line, the outlet line, two leakoff lines and three pressure recording lines.

7. Make sure all connections are tightened and all valves are in close positions. Check also all connections for leakoff backpressure line from a Nitrogen tank to the backpressure regulator.

8. Connect the dry gas line to the conductivity cell's inlet line.

9. Measure the rock permeability followed the measurement guideline.

10. Open the valves in order to fill tap water into the mixing tank. The water volume is calculated based on pumping time for both pad and slurry injections, and the dead volume in the system.

11. Wrap the heating jacket around the conductivity cell.

12. Set the temperature controllers of the cylindrical heaters and the heating jacket to the desired temperature. Turn on the switches to preheat the cylindrical heaters and the heating jacket. Flow water continuously for at least half an hour to preheat the cylindrical heaters. The temperature sensor of the cylindrical heaters detects the fluid temperature after heated. Failure to flow water may cause the cylindrical heaters temperature infinite increase and result in tubing burning. The temperature controllers are set $5^{\circ} \mathrm{F}$ higher and lower than the desired temperature for the upper and lower ranges, respectively.

13. Switch the proper valves in order to flow tap water directly to the high pressure pumps, through the cylindrical heaters but bypass the conductivity cell and dump into a sink. 
14. Turn on the high pressure pumps. Check the connections to confirm no leakage at high pumping pressure.

15. While wait for the heaters to warm up, mix the fracturing fluid followed the procedure.

16. Apply backpressure to the leakoff side by opening the nitrogen regulator to $300 \mathrm{psi}$ less than the desired pumping pressure. Tests proved that the Teflon tape can prevent a leakage if the differential pressure is less than 300 psi. Put a graduated cylinder under the outlet line to collect the leakoff fluid.

17. Open the leakoff valve and the displacement pots' outlet valves.

18. Open the LabVIEW file named "Hyd Slurryinjection.vi" from the laboratory computer linked to the pressure transducers. Calibrate a zero valve; then run the program. This file is used to record the pumping pressure and leakoff pressure.

19. Turn on the centrifugal pump used to feed base gel into the high pressure pump's suction but the valve connected to the high pressure pump remains close. The base gel therefore circulates into the Polyethylene drum.

20. When the fluid temperature reaches the proposed temperature, close tap water valve, switch the Polyethylene drum discharge valves in order to feed the base gel into the high pressure pumps. In the meantime, switch the discharge valve at the outlet of the conductivity cell to flow through one of the displacement pots (the other one is a backup in case of plugging) then into the waste drum.

21. Monitor the cell pressure increasing as the fluid filled in the displacement pot. When the fluid start flow into the waste drum, adjust the discharge valve until the cell pressure raises to the desired pressure.

22. Use a stopwatch and two liters beaker to measure the flow rate after the discharge valve. In the meantime, record the leakoff rate if there is any fluid leakoff.

23. After getting the pumping rate, calculate the crosslinker pumping rate to obtain the desired concentration based on the recipe. Adjust the metering pump to feed the crosslinker at the calculated rate but not turn on the metering pump.

24 . Flow the base gel continuously for ten minutes.

25 . Switch the proper valves to change from the base gel to the slurry pumping. Open the metering pump to inject the crosslinker as the slurry fed in.

26. Flow the slurry for one minute. It may cause proppant screen out if flowing the slurry for too long and thus wide fracture width after applying closure stress. If the slurry is injected for too short time, it may not yet enter into the conductivity cell.

27. Close the inlet and outlet valves of the conductivity cell. Open the bypass valve and continue to flow the slurry. Turn off the metering pump.

28. Fill in water in the mixing tank and continue to flow in order to clean the mixing system. Then, switch to the base gel reservoir and pump all remaining gel.

29. Switch the proper valves to flow tap water directly into the high pressure pumps and continue to flow for one hour in order to clean the high pressure pumps. Failure to clean the pumps properly may cause the proppant settle down and damage the pumps. During the pumps cleaning process, observe the discharge fluid. If only water comes out, switch the valve to discharge water into the sink.

30. After the high pressure pumps are cleaned. Turn off the pumps. Disconnect the metering pump and clean by pumping water for ten minutes.

31. Disconnect and clean the displacement pot.

32. Load the chemical wastes into a proper tank for disposal.

33. Record the leakoff volume during pumping. Then, clean the graduated cylinder and prepare to collect fluid after applying closure stress.

34. Apply the closure stress by gradually increasing the air pressure regulator, $100 \mathrm{psi}$ closure stress in every one minute. Monitor the gauge pressure. Slowly increase to 
obtain the desired fracture closure pressure. The gauge pressure of 200 psi means the closure stress of $2,000 \mathrm{psi}$. In the mean time, slowly release the leakoff backpressure by closing the nitrogen regulator and bleeding off the pressure.

35. Leave the heated conductivity cell for 18 hours. Secure the test area to prevent any incidents.

36. After 18 hours, stop the LabVIEW program and save the excel file in the test result folder. Close the leakoff valve. Record the leakoff volume.

37. Take off the filters for cleaning and reconnect. Failure to clean the filters may result in no pressure reading.

38. Connect the wet gas line to the conductivity cell's inlet line. Nitrogen will flow through the water chamber before entering the conductivity cell.

39. Measure the fracture conductivity followed the procedure.

40. Release the hydraulic load frame pressure. Lower the bottom ram of the load frame.

41. Disconnect all lines from the conductivity cell.

42. Disconnect the conductivity cell assemble by using the hydraulic jack. Disassemble two pistons first; then carefully push the rock samples out together. Measure the fracture width. Open the samples and observe proppant distribution inside the fracture.

43. Clean all components of the conductivity cell.

44. Fill in the experiment data sheet and analyze the experimental result.

\subsubsection{Results and discussion}

After setting up the new laboratory to perform dynamic fracture conductivity tests, we conducted several dry runs to test the operating range of each apparatus. Then, we performed several preliminary experiments for various conditions. Two completed experiments are discussed. Table 3 presents the parameters in the preliminary tests. The fracturing fluids were mixed following the recipe with the desired polymer concentration and injected into the conductivity cell at the desired temperature. The cell was then shut in for 18 hours to represent the shut-in period. After that, we flowed nitrogen gas through the proppant pack at the desired flow rate to simulate the cleanup period. We repeatedly measured the fracture conductivity at various times until it stabilized.

Table 3 Parameters used in the preliminary experiments

\begin{tabular}{|lcc|}
\hline Parameters & Experiment A & Experiment B \\
\hline Desired fracture width, inch & 0.25 & 0.25 \\
Proppant loading, ppg & 2 & 2 \\
Polymer loading, lb/Mgal & 30 & 30 \\
Pumping pressure, psi & 320 & 320 \\
Pumping rate, gal/min & 0.75 & 0.75 \\
Temperature, ${ }^{\circ} \mathrm{F}$ & 70 & 150 \\
Nitrogen flow rate, standard L/min & 1 (dry gas) & 1 (wet gas) \\
Cell pressure during the & 50 & 50 \\
conductivity measurement, psig & & \\
\hline
\end{tabular}


To ensure the pumping condition in the laboratory is comparable to that of field fracturing jobs, the flux along the fracture in the laboratory is calculated by using Eq.1:

$$
\begin{aligned}
q_{\text {lab }} & =v_{\text {lab }} w_{f, l a b} h_{\text {lab }} \\
v_{l a b} & =\frac{(0.75 \mathrm{gal} / \mathrm{min})}{\left(\frac{1.75}{12} \mathrm{ft}\right)\left(\frac{0.25}{12} \mathrm{ft}\right)}\left(0.1337 \mathrm{ft}^{3} / \mathrm{gal}\right)=33.0 \mathrm{ft} / \mathrm{min}
\end{aligned}
$$

The result in Table 4 shows that the flux in the laboratory and the flux calculated from field fracturing jobs are similar.

Table 4 Comparison between the field and our laboratory conditions

\begin{tabular}{|lcc|}
\hline Parameters & Field & Our Lab \\
\hline Injection rate & $25 \mathrm{bbl} / \mathrm{min}$ & $0.75 \mathrm{gal} / \mathrm{min}$ \\
Fracture height & $100 \mathrm{ft}$ & $1.75 \mathrm{in}$ \\
Fracture width & $0.25 \mathrm{in}$ & $0.25 \mathrm{in}$ \\
Flux & $33.3 \mathrm{ft} / \mathrm{min}$ & $33.0 \mathrm{ft} / \mathrm{min}$ \\
\hline
\end{tabular}

To ensure the experimental results were in reasonable ranges, we calculated some variables as references.

\section{Surface concentration and fracture width after closure}

$$
\begin{aligned}
& C_{s}=C_{p} w_{f, \text { before closure }} \\
& C_{s}=\left(2 \frac{l b}{g a l} \times \frac{7.48 \mathrm{gal}}{f t^{3}}\right)\left(\frac{0.25}{12} f t\right)=0.312 \frac{\mathrm{lb}}{f t^{2}} \\
& W_{p}=C_{s} A \\
& W_{p}=\left(0.312 \frac{l b}{f t^{2}}\right)\left(\frac{12}{144} f t^{2}\right)=0.026 l b \\
& V_{p}=W_{p} V_{p, a b s o l u t e}
\end{aligned}
$$

Since the absolute volume of proppant is $0.044 \mathrm{gal} / \mathrm{lb}$,

$$
V_{p}=(0.026 \mathrm{lb})\left(0.044 \frac{g a l}{l b}\right)=0.00114 \mathrm{gal}
$$

Assuming proppant porosity of 0.38 yields:

$$
V_{f}=\frac{0.00114 \mathrm{gal}}{(1-0.38)}=0.00184 \mathrm{gal}
$$




$$
w_{f, \text { after closure }=} \frac{V_{f}}{A}=\frac{(0.00184 \mathrm{gal})\left(\frac{f t^{3}}{7.48 \mathrm{gal}}\right)}{\left(\frac{12}{144} \mathrm{ft}^{2}\right)}=0.00295 \mathrm{ft}=0.0355 \mathrm{in} .
$$

Therefore, the expected surface concentration is $0.312 \mathrm{lb} / \mathrm{ft}^{2}$ and the expected fracture width after closure is 0.0355 in.

\section{Fracture permeability}

The permeability at $250^{\circ} \mathrm{F}$ under 2,000 psi closure stress of $30 / 50$ Econoprop is reported by CARBO Ceramics to be 230 Darcies. This permeability is used as an upper limit because the proppant permeability was tested with no gel damage. Additionally, the expected permeability was calculated by using Kozeny-Carman's equation [Carman, 1956]

$$
k_{f}=\frac{\phi^{3}}{C S_{0}^{2}(1-\phi)^{2}}
$$

where $S_{0}=\frac{6}{d}$, and $C$ is the Kozeny-Carman constant.

Since the median particle diameter is 0.020 in. or 512 micron, $C$ equals 5 for flow through unconsolidated porous media, and the assumed proppant porosity is 0.38 , the expected permeability using the Kozeny-Carman equation is:

$$
k_{f}=\left[\frac{(0.38)^{3}}{5\left(\frac{6}{512 \times 10^{-6}}\right)^{2}(1-0.38)^{2}} m^{2}\right]\left(\frac{\text { Darcies }}{9.869 \times 10^{-13} m^{2}}\right)=210.65 \text { Darcies }
$$
200 Darcies.

Both reference permeabilities indicate that the expected permeability should be about

\section{Fracture conductivity}

From the reference permeability of 230 Darcies and the expected fracture width after closure of 0.0355 in., the expected fracture conductivity should be a maximum of $680 \mathrm{md}-\mathrm{ft}$.

Experiment A was conducted at room temperature and the water chamber was not used to wet the nitrogen before it entered the cell. Figs. 27 and 28 revealed that the experimental conductivity and permeability are higher than expected. The picture of the core samples (Fig. 29) shows that the proppant was not uniformly placed in the fracture. The surface concentration is just about $0.2 \mathrm{lb} / \mathrm{ft}^{2}$. We believe that this was caused by the inlet and outlet valves of the conductivity cell were leak during pump cleaning. Therefore, the line system was modified to prevent water from flowing into the conductivity cell during the pump cleaning. 


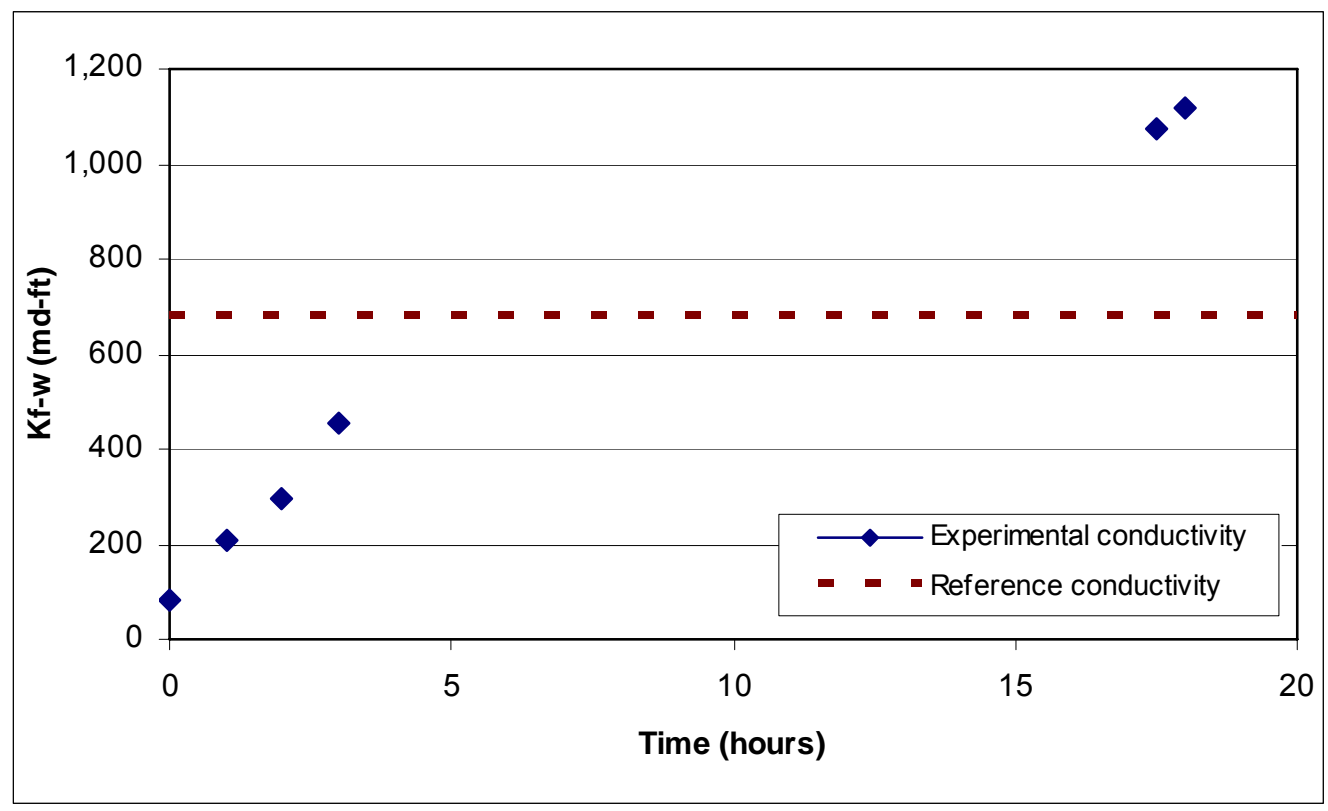

Figure 27 Fracture conductivity over time of Experiment A.

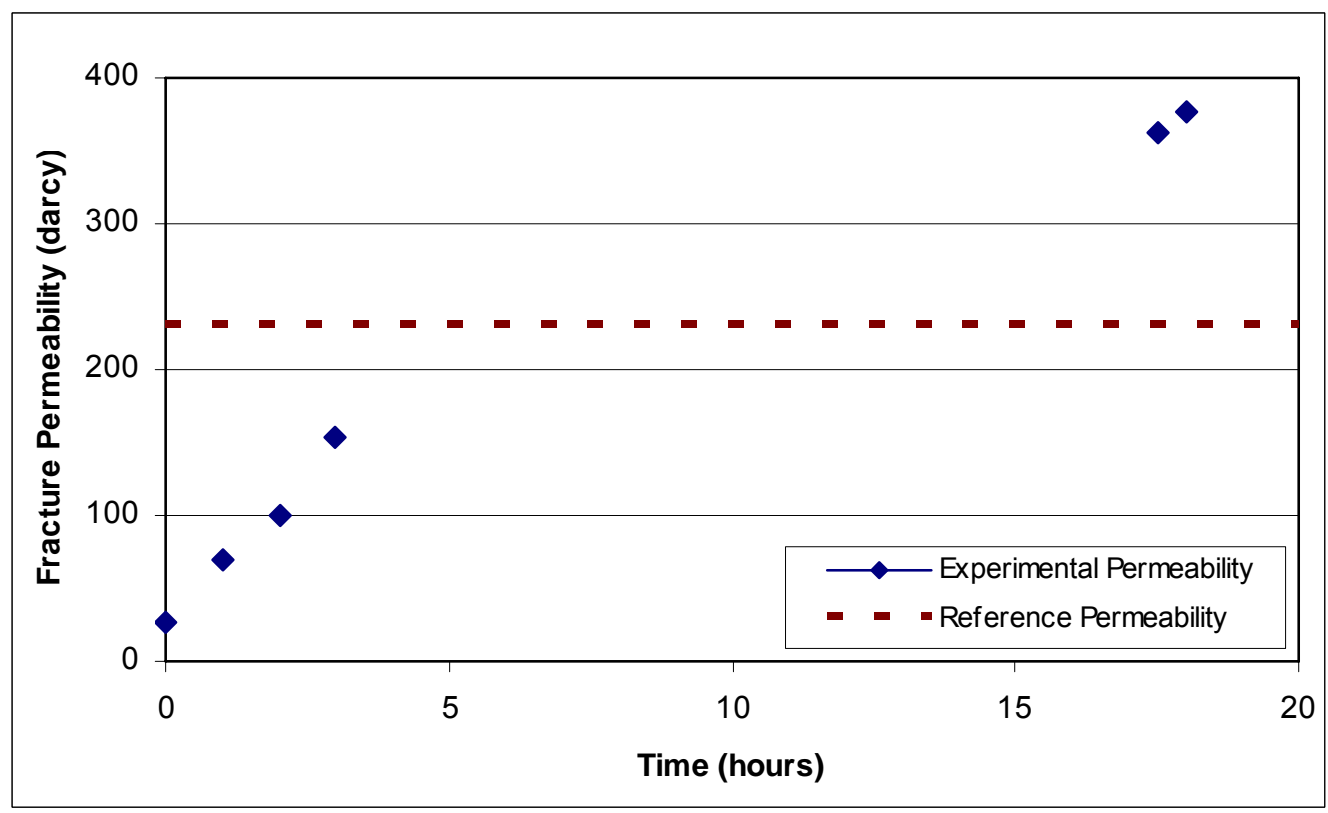

Figure 28 Fracture permeability over time of Experiment A. 


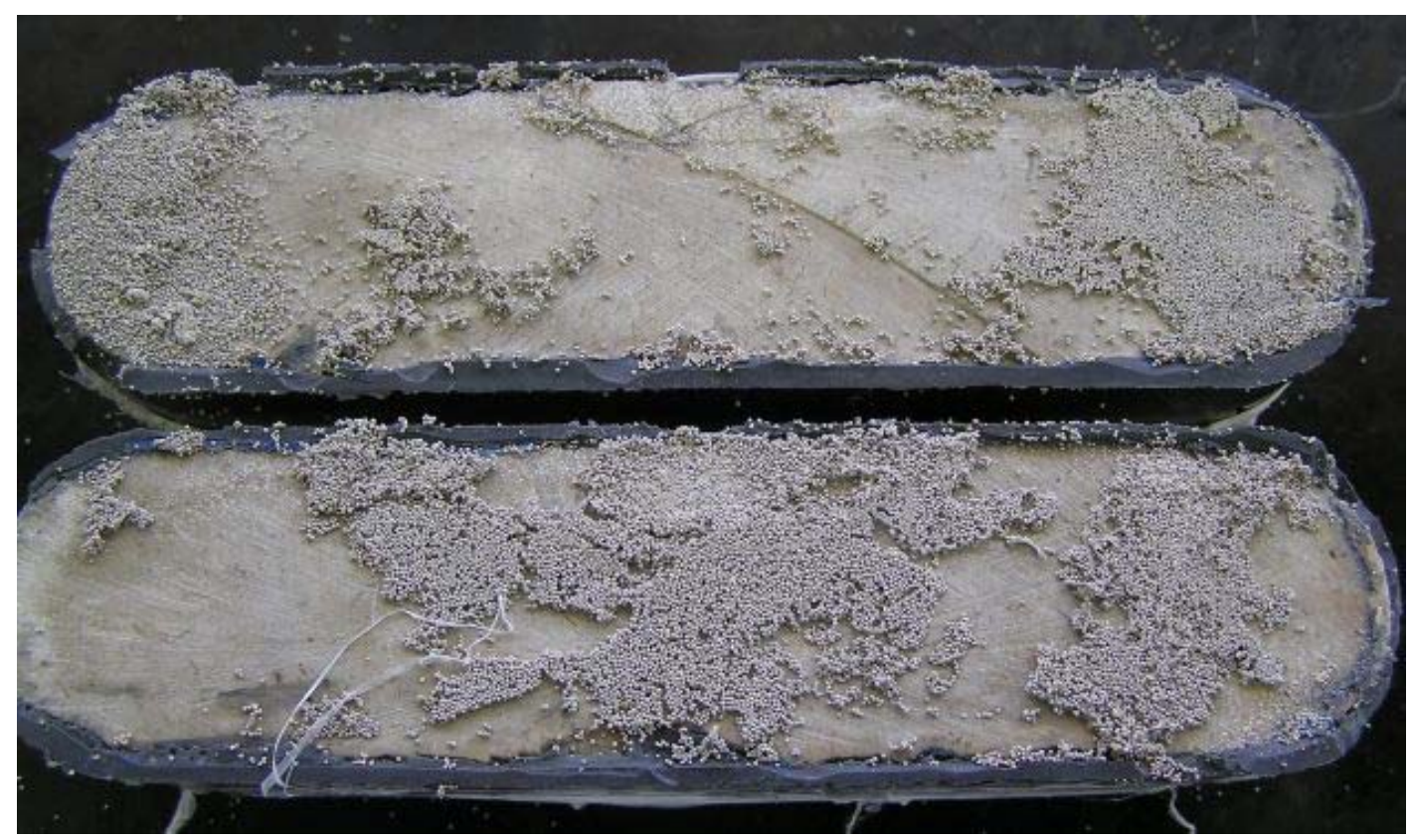

Figure 29 Proppant placement of Experiment A.

After modifying the flow system, we successfully conducted Experiment B at a temperature of $150^{\circ} \mathrm{F}$ with nitrogen flowing through the water chamber. Figs. 30 and 31 show that the experimental conductivity and permeability are in reasonable ranges. The picture of the core samples (Fig. 32) indicated that the proppant was uniformly placed. The surface concentration of $0.39 \mathrm{lb} / \mathrm{ft}^{2}$ is comparable to the expected surface concentration of $0.31 \mathrm{lb} / \mathrm{ft}^{2}$.

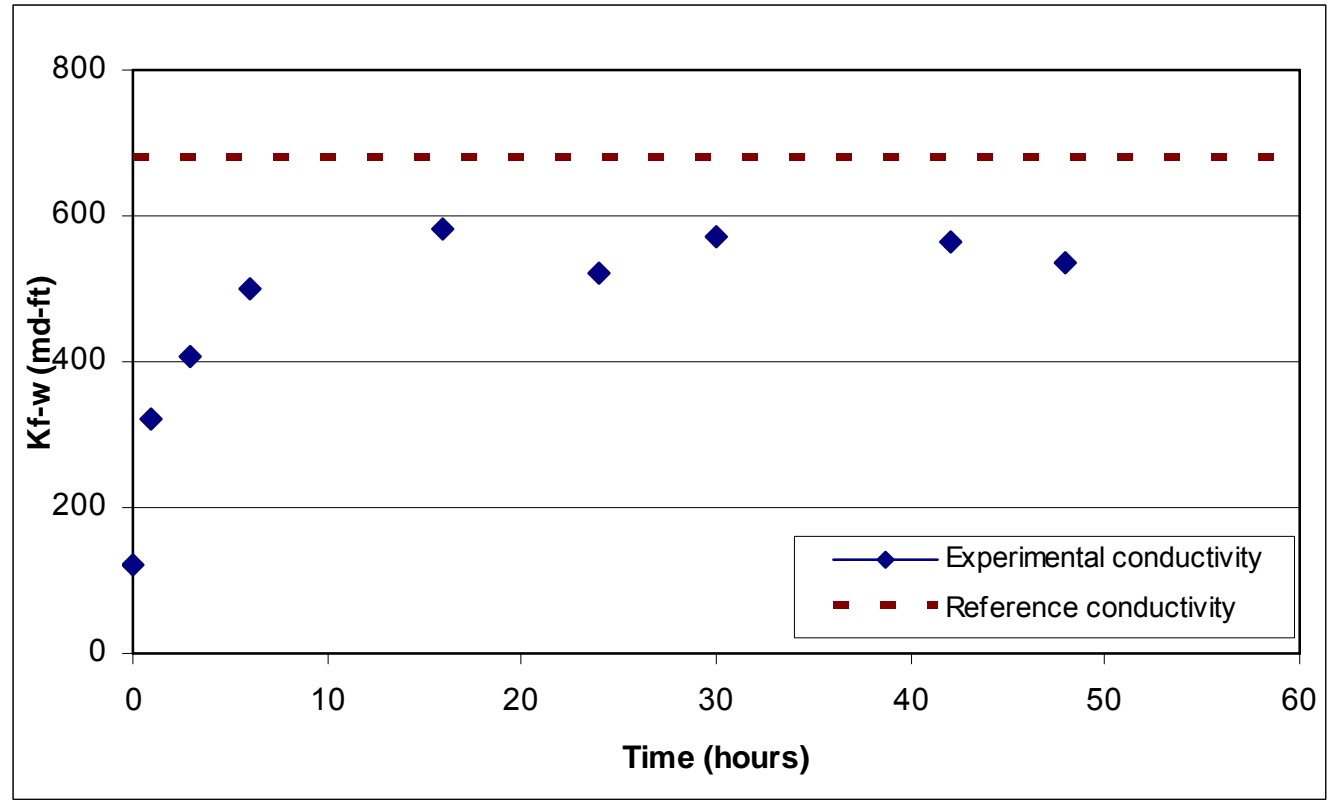

Figure 30 Fracture conductivity over time of Experiment B. 


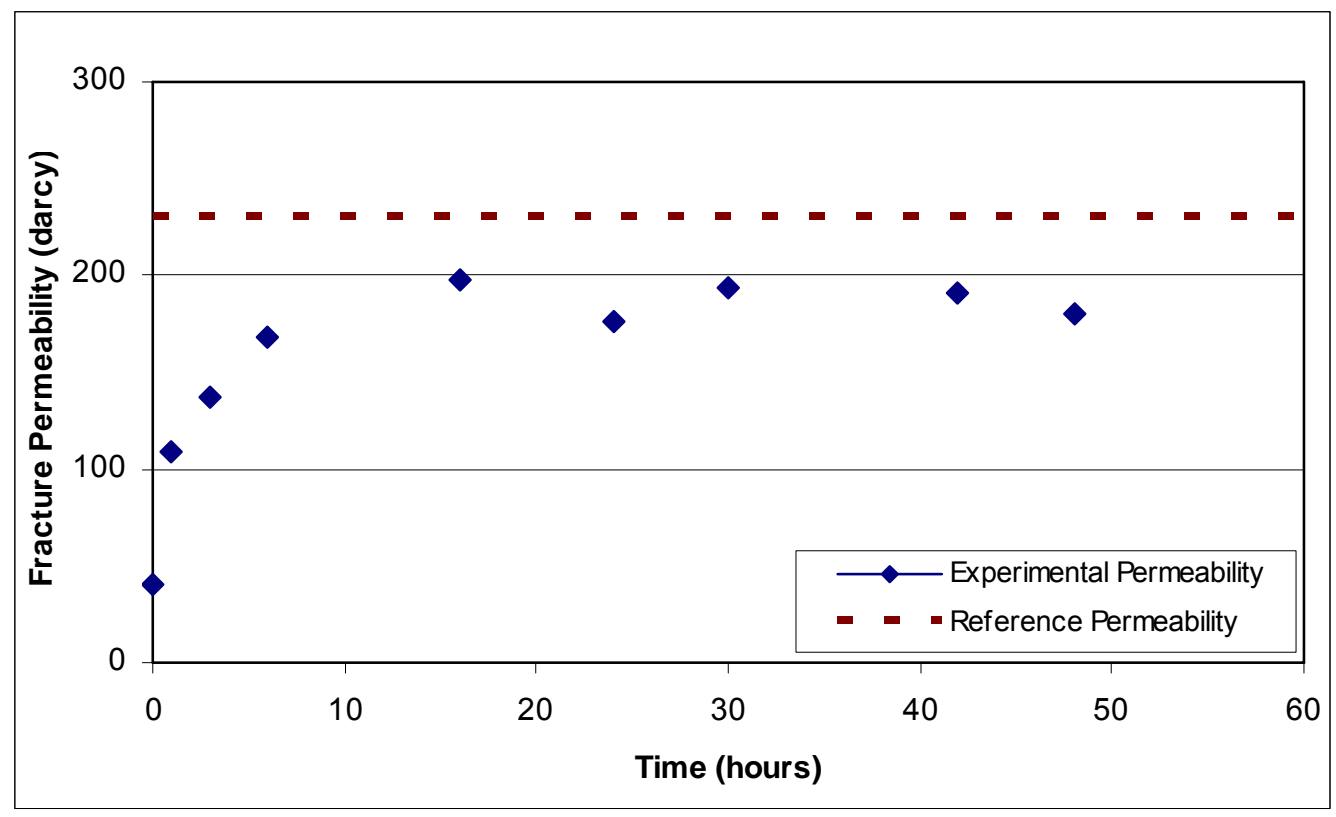

Figure 31 Fracture permeability over time of Experiment B.

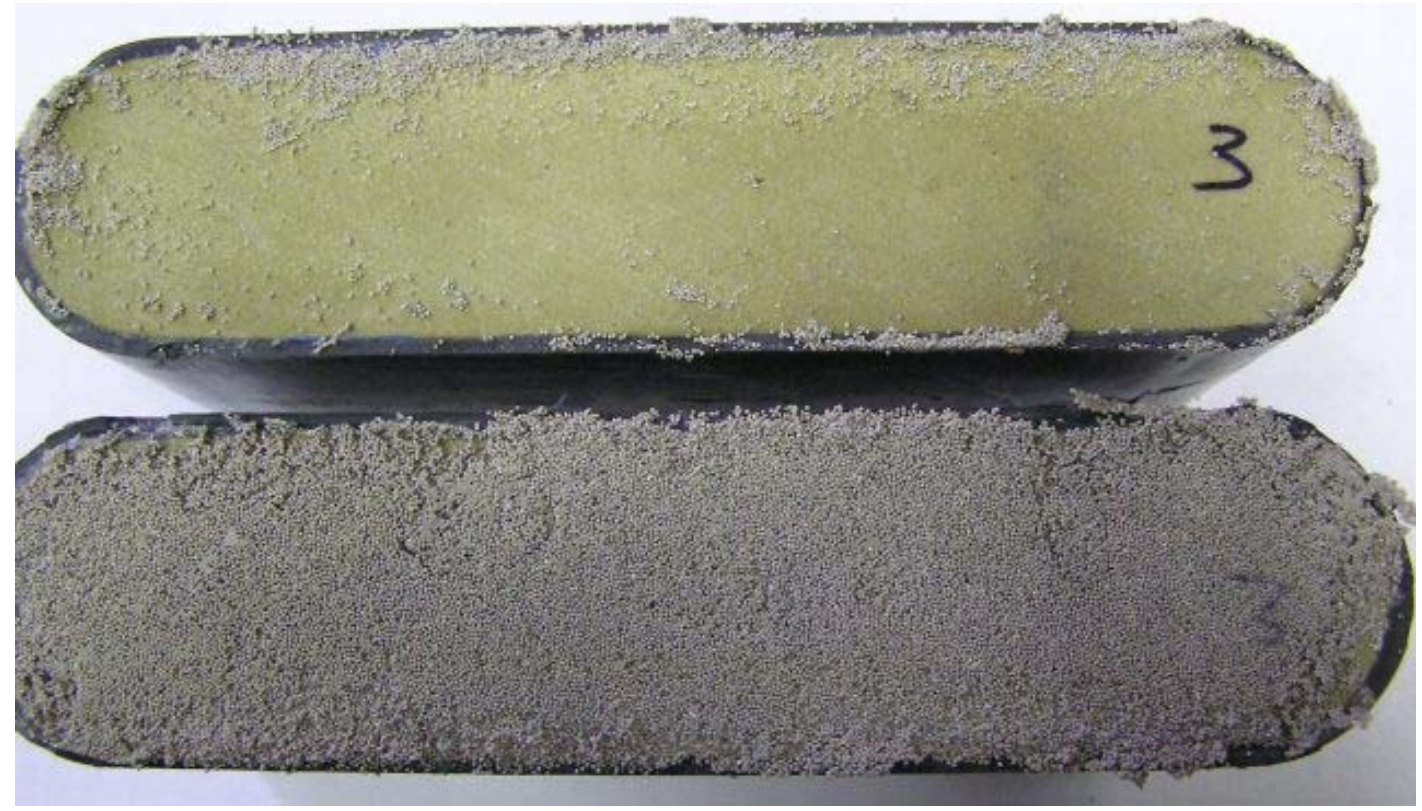

Figure 32 Proppant placement of Experiment B.

In the following several months, a series of experiments should be conducted to compare the conductivity measured with dynamic conductivity tests with the results obtained with standard static conductivity tests conducted with the same proppant loading. Differences in results between the standard static conductivity tests and the newly developed dynamic conductivity tests shall be documented. Based on these differences, a recommendation on whether to proceed to Phase II of the project shall be made. 


\section{Task 5 Gel Damage Investigation}

It is well documented in the literature that hydraulic fractures for tight gas sands, although successful, often under-perform. Hydraulic fracture completions show discrepancies between the placed propped length and the effective production fracture length. Ineffective fracture cleanup is often cited as a likely culprit.

We have been surveying the literature on laboratory investigations of gel damage in tight gas sands. The objectives of the study are to investigate gel damage effect on fracture conductivity, develop guidelines and recommendations for dynamic fracture conductivity experiments, and guidelines for proppant concentration/polymer loading to minimize gel damage.

\subsection{Description of the problem}

The properties that a fracturing fluid should possess are low leak off rate, the ability to carry a propping agent, and low pumping friction loss. The fluid also needed to be easy to remove from the formation. It should be compatible with natural formation fluids and should cause minimum damage to the formation permeability.

First hydraulic fracture treatments used viscous oils as the base for the fracturing fluid. Later, the industry began to use low viscosity water based fluids pumped at high injection rate to overcome the disadvantage of the oil water dispersion. There are three materials used to prepare water base thickened fluids. There are guar gum, a cellulose derivative and a synthetic polymer. All are able to swell in water. Each has its own advantages and imparts different fluid characteristics when used as a thickener for water.

Guar gum has been the most commonly used polymer to increase the viscosity of fracturing fluids. It is a polysaccharide as it is a branched copolymer with a mannose backbone and a galatose branch which both are simple sugar. For the natural polymers, guar has the highest weight percent insoluble residue content (8-12\%) and degraded guar gum is not completely water soluble. Treatment of guar with propylene oxide in alkaline medium results in formation of guar gum derivatives such as hydroxypropyl guar (HPG) form and sequential treatment of guar can result in the formation of a double derivative such as Carboxymethyl-hydroxypropyl guar (CMHPG). Guar derivatives have previously been considered to be "cleaner polymer" than natural guar gum, some test results indicate that the resulting damage is about the same for guar gum and guar gum derivatives. The weight percent insoluble residue content of HPG and CMHPG are 1-4\% and 1-2\% respectively [Rae and Lullo, 1996]. HPG solutions have better thermal stability than guar solution, but HPG is slightly more expensive. The primary advantage of CMHPG is the reduction in residue upon degradation, but its advantage is outweighed by higher cost relative to guar and HPG.

The cellulose derivative is prepared by reacting with a naturally occurring cellulose material with synthetic chemicals to form remarkable pure materials. The cellulose derivative or synthetic polymers form high viscosity solutions and have no residue after complete degradation; however, they are relatively expensive compared to the guar and guar derivative polymers. Hydroxyethyl cellulose (HEC) is not easily crosslinked and, currently, has limited hydraulic fracturing applications. While Carboxymethyl cellulose (CMC) can be crosslinked, its higher cost and salt sensitivity limit its use. Carboxymethylhydroxyethyl cellulose (CMHEC), which can be crosslinked and does not have the salt sensitivity of CMC, has been used to viscosify acid systems. The amount of residue left by this polymer is much less than from guar.

The synthetic polymer, polyacrylamide, is made by reacting with synthetic chemicals. It is a completely polymer that leaves no residue after degradation. The synthetic polymer is for high temperature application. 
The high viscosity of the fluids can be achieved by crosslinking with metal ions, such as, titanium, zirconium, aluminium, chromium, and boron to form complex three dimensional network structures (gels). Viscosity increases in the magnitude of eight to ten folds. Crosslinked gels will provide stable viscosity at high temperature, reduced fluid loss, and near perfect proppant suspension due to gel network structure. Fracturing fluid should degrade rapidly after the fracture treatment to allow the fluid to be easily removed from the formation and to prevent plugging of the proppant pack with higher viscosity fluids. A large number of the water soluble polymers used in fracturing may leave an insoluble material (residues) after breaking. This insoluble material may influence flow in both the fracture and formation by simply blocking or restricting pore space. During the fracture operation, the high pressure fracturing fluid leaks away to the formation. The filter cake is formed. The filter cake is determined by the particular fracturing fluid used, the formation characteristics, the fracture-to-reservoir pressure difference, and the erosional effects caused by slurry being pumped along fracture face. During fracture closure, the proppant is embedded into the filter cake, making it difficult to remove the cake during production.

There are several factors involved in the degradation of the polymers which could potentially affect the amount of gel residue remaining from each polymer: breaker type, breaker concentration, break time and break temperature. The formation of an immobile residue arising from the concentration of gelling agent due to fluid loss and fracture closure and the result of breaking mechanisms has been determined to be the major source of permeability reduction. Proppant permeability is dramatically reduced due to filter cake deposition from polymer after breaking residue and long term exposure effects. Fracturing fluid damage or gel damage can easily result in an additional 50\% damage. Although design engineer cannot alter the time effects, they can impact the effect of fluid damage. It is minimized by use of an effective viscosity breaker. An inadequate breaker can lead to virtually complete loss of proppant pack concentration. On the other hand, aggressive breaker schedules, short break times can produce high retention factor in excess of $80 \%$ which can result in excessive proppant settling in the fracture before closure [Daview and Kulper, 1988].

\subsection{Literature review}

Cooke [1975] investigated the effect of fracturing fluids on fracture conductivity and found that the volume of polymer residues presenting in the pore space of the fracture reduced the permeability of the proppant (or fracture conductivity). His test also indicted that this reduction would be in long term testing, the residues would not be displaced from the fracture by production and would be degraded slowly. This reduction in fracture conductivity by the gel residue has a significant effect on production. The results indicated that when the residues volume is increased (guar gum $>$ cellulose derivative $>$ polyacrylamide), the amount of reduction in fracture conductivity is also increased.

Almond [1982] presented the factors involved in the degradation of fracturing polymers with results in amount of residue remaining in the proppant pack are breaker type, breaker concentration, break time, and temperature. Crosslinker type and crosslinker concentration could affect the enzyme activity. Finally, it was shown that a solution viscosity reduction to 2-3 cp could still result in flow impairment through packs.

Volk et al. [1983] published a study of the extent of formation damage due to invasion of fracturing fluids during the hydraulic fracturing process. The results indicated that unbroken HPG polymer would not pass through the rock permeability of 0.0006 to $0.115 \mathrm{md}$ and broken HPG polymer would flow through the core and filter cake.

Almond and Bland [1984] determined the relative residue volumes for fracturing fluids and compared to their actual flow impairment values. The experiment used enzyme breakers at $120^{\circ} \mathrm{F}$, oxidizing breakers at $180^{\circ} \mathrm{F}$, and high temperature breakers at $275^{\circ} \mathrm{F}$. 
They found that the flow impairment can be determined by the breaker temperature or break mechanism and the least flow impairment resulted from high temperature breakers, followed by enzyme breakers, and finally oxidizing breaker. Higher polymer concentrations result in more residues in the fracture and greater flow restriction through the sandpack.

Gal and Raible [1985] used size exclusion chromatography (SEC) to investigate degradation of HPG and HEC polymers. A reduction in solution viscosity did not eliminate the possibility of proppant damage. Additionally, increases in temperature resulted in increasing the rate of HPG degradation caused by the breaker. The degree of degradation was also found to depend on the oxidative breaker concentration.

Kim and Losacano [1985] compared the reduction in sand permeability due to the residue volumes from guar, HPG, and CMHEC polymers. The guar borate and HPG titanate gels result in about the same damage to $20 / 40$ mesh sand permeability after break. While broken CMHEC trivalent aluminium gels give the least damage.

Roodhart et al. [1986] presented the clean up at a highly concentrated proppant by water saturated gas was studied. Substantial permeability reduction was found. The authors suggested that only $10 \%$ of the permeability measured without fracturing fluid could be assumed.

Much and Penny [1987] concluded from their study that gel damage to the created proppant pack reduced effective conductivity by as much as 10-90\%. Proppant pack conductivity is defined as the product of permeability and width. The majority of the impairment occurs at the formation/proppant interface where the residual filter cake and fines act to reduce the pack width. Gel becomes more concentrated within the center of the pack increasing in an order of 5 to 7 times of the original gel concentration. The degree of impairment becomes severe at lower proppant loadings and critical at concentrations below $0.5 \mathrm{lb} / \mathrm{sq}-\mathrm{ft}$, where the filter cake could grow to fill a major portion of the pack. Because of the damage potential to the hydraulic fracture and natural fracture systems, the ability to remediate damage caused by unbroken gelled fluids would be invaluable in restoring or improving gas productivity in fracture-treated wells.

Penny [1987] later presented the dynamic fluid loss test, building the filter cake on the face of two core wafers, and then injecting the proppant as a gelled slurry. This was followed by applying closure stress and measuring fracture conductivity. The impact of gel damage is a function of the gel concentration in the fracture, clean up process, and the presence of multi-phase flow. Increasing gel concentration within the fracture will reduce the retained conductivity. The final gel concentration within the proppant pack prior to flowback depends upon the initial gel loading, leak-off, pumping width, and proppant concentration at closure. Figure 33 is SEM photos of the proppant pack between cores. It shows that the majority of the damage occurs at the core proppant interface where the residual filter cake and fines act to diminish the pack width. 

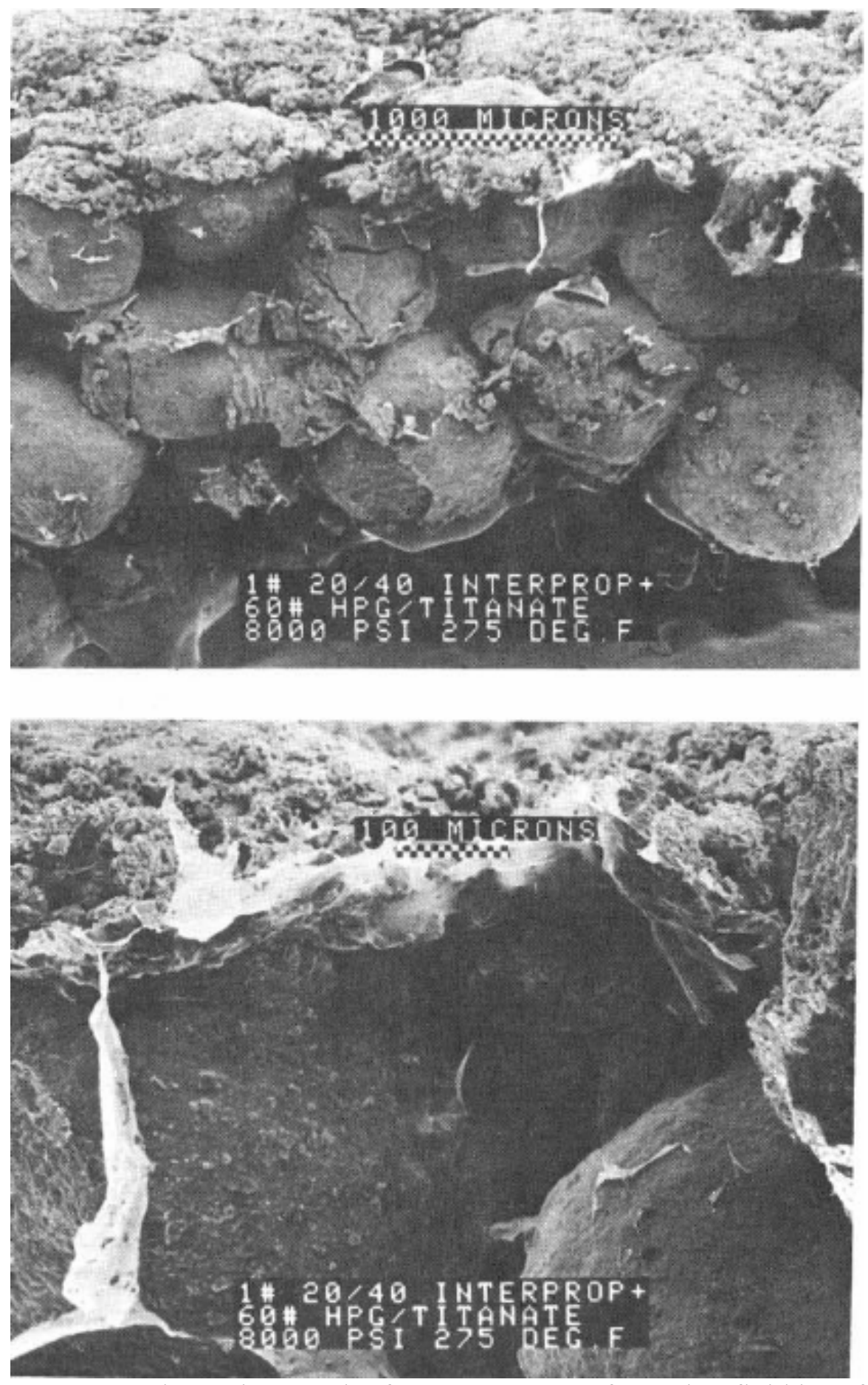

Figure 33 SEM photomicrograph of a proppant-core-fracturing fluid interface is showing filter cake, gel residue, and formation fines. Bottom photo is a closeup of the top surface [Penny, 1987].

Thomas [1989] conducted an experimental study for fracture conductivity with the titanate crosslinked HPG and the result yields up to $81 \%$ damage, whereas the borate crosslinked HPG yields $12 \%$ and $32 \%$ damage, dependent on the type of breaker, at a temperature of $100{ }^{\circ} \mathrm{F}$. The severe damage caused by the titanate fluid is attributed to the poor degradation on characteristics of its filter cake.

Brannon and Puisinelli [1990] published the test results from their study indicating that proppant pack damage can be significantly reduced by the addition of elevated breaker 
concentrations. An understanding of the effects of breaker concentration on proppant pack damage can be very useful in the effective design of gel fracturing treatments. High polymer concentrations are the result of filtration process that occurs during fracture closure. If formation pore sizes are too small to allow invasion by guar polymers, the guar concentration in the fracture may increase dramatically. High breaker concentration is necessary to remove damage effect.

Voneiff et al. [1993] conducted a study of damage mechanisms resulting from hydraulic fracturing in tight gas well. The results suggested that the two primary damage mechanisms by hydraulic fracturing are 1) damage to the proppant pack, and 2) damage to the natural fractures. The authors assumed Newtonian fluid behavior and concluded that unbroken fracture fluids can decrease gas reserves in a tight gas well by $30 \%$, reduce initial production rate up to $80 \%$, delay fracture fluid cleanup and increase the amount of fracture fluid filtrate remaining in the formation.

Palisch et al. [2007] presented that engineers usually only consider the residual fracture damage and assumes $50 \%$ gel damage or greater. Generally, the authors concluded that gel damage can divide into three ways which are residual fracture damage, loss of width due to filter cake and loss of length due to static gel at the tip. Figure 34 shows what left in proppant pack after 35 ppt of gel breaking in the conductivity cell and Figure 35 shows the filter cake build on the fracture face during the fracture stimulation.

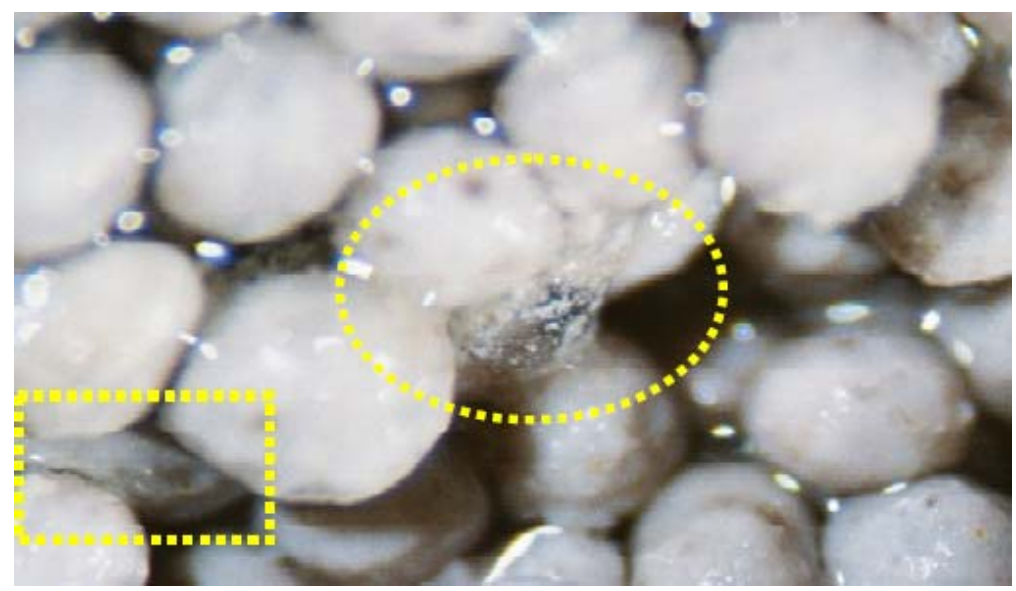

Figure 34 Residual gel damage of 35 ppt CMHPG fluid, with breaker, in conductivity cell after measuring long term conductivity [Palisch et al., 2007]

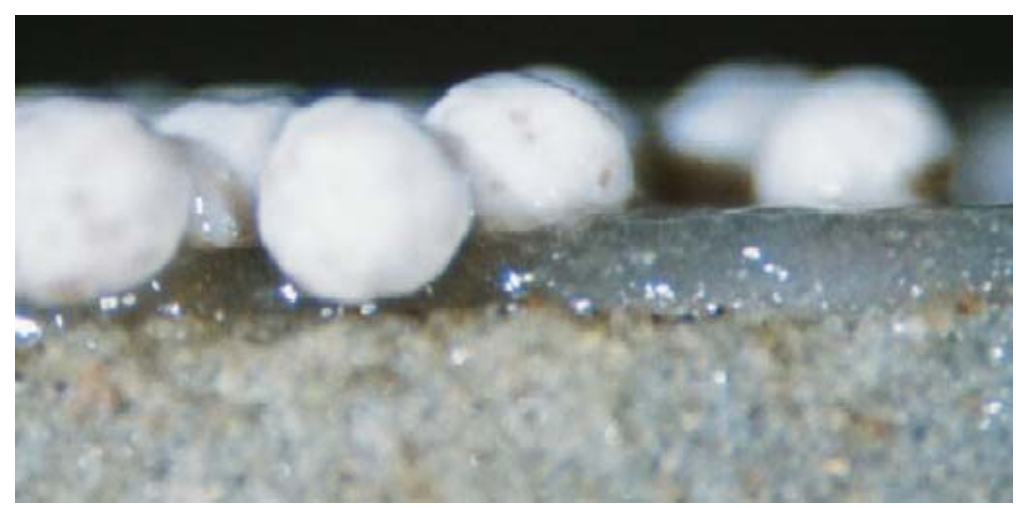

Figure 35 Filter cake buildup after 35 ppt CMHPG fluid with breaker [Palisch et al., 2007] 
5.3 Alternatives of fracturing in tight gas formations

5.3.1 Water fracturing treatment

Using gelled fracturing treatment in low permeability reservoirs can cause damage to the formation due to viscosified fluid residues. The residues can severely restrict gas flow through the fractures, so the gas productivity is decreased. There are many approaches to reduce the gel damage in hydraulic fracturing treatment. One of the approaches is water fracturing treatment which was developed as a less expensive way than conventional gel treatments.

Water fracturing or "water frac" were initially designed to generate fractures by injecting low viscosity fluid carrying little or no proppant. "Slick water frac" added linear gels or friction reducers to the water as only friction reducer is added to the fracturing fluid to reduce the required hydraulic horsepower needed to pump the treatment. High injection rates, anywhere from 40 to $100 \mathrm{bbl} / \mathrm{min}$, are used to minimize pumping time, minimize leak-off time, and maximize proppant transport. A pad fluid without any proppant is pumped. Pad volumes are typically about $50 \%$ of the total fluid volume pumped. Depending on the job size, low volume, low proppant concentration stages are pumped following the pad. The proppant stages are alternated with proppant-free, slick water stages commonly called sweeps. Sweeps function is primarily to push away the proppant that is settled in the fracture near the wellbore to keep the perforations from plugging. The proppant concentrations of the proppant stages are gradually increased as the treatment progressed. Proppant concentrations typically are around $0.25 \mathrm{ppg}$ (pounds per gallon) and gradually increase to around 2.0-3.0 ppg during the final stages of the treatment.

There are many studies comparing the water fracs with conventional gel. Water fracs generate similar or sometimes better production responses [Jennings, 2006]. Even when conventional gel treatments generate longer propped fracture lengths than a water frac, the presence of damaging gels may adversely affect well performance. The advantages of the water frac treatment over the conventional gel fracturing treatment are

- Treatment cost is lower. Since less total proppant treatment is used, the costs for proppant are also reduced.

- Less fracture damage. Less fracturing fluid residue remains in the fracture due to the limited amount of fluid additives used.

- Fewer screen-outs and proppant placement problems because of the relatively large pad volume pumped, the very low proppant concentrations used (especially early in treatment), the "sweep" volumes (containing no proppant) pumped between stages, and the high injection rates used, screen-outs ( or drastic increases in treating pressure exceeding the maximum allowable) are comparatively rare.

Some potential problems with water frac treatments include low conductivity and poor proppant transport. In low permeability formations, low fracture conductivity is not a major limitation to production, as long as the conductivity is not too low. The poor proppant transport is caused by the low viscosities of the water frac fluids and results in rapid settling of the proppant particles. This inability to carry proppant a significant distance away from the wellbore can severely limit the effective fracture length. Fracture length is the key variable for initial production potential and ultimate recovery from very low permeability formations. Therefore, if the proppant does not get transported towards the tip of the fracture, the success of the water frac treatment will depend entirely on the conductivity created by surface asperities or some other mechanisms.

\subsubsection{Hybrid and reverse hybrid fracturing treatment}


Water and hybrid frac are common stimulation methods. The hybrid frac combines the advantages and benefits of both conventional gel and water-frac treatments. The proppant is carried into the fracture either with a gelled fluid (hybrid frac) or slick water (water frac). In theory, low viscosity pad fluid allows creation of more confined fractures. On average, a hybrid frac treatment seems to generate longer effective fracture half-lengths and larger effective fracture conductivities than conventional water frac. However, the low viscosity promotes proppant settling and, therefore, can lead to poor proppant placement and also leads to narrower fractures, which in some cases can cause proppant bridging.

Rushing and Sullivan [2003] presented a comparison between water frac and hybrid frac. They concluded that hybrid fractures generate longer effective lengths than conventional frac. Pumping higher proppant concentrations in conventional water frac does not lead to longer and more conductive fractures due to proppant settling. The effective conductivity for hybrid frac was not consistently higher than for water frac.

Liu and Sharma [2006] presented another treatment, reverse hybrid fracturing treatment, for the efficient placement of proppant deep into created fractures while minimizing gel induced damage. The sequence of the fluid injection is the reverse of hybrid fracturing treatment. Experiments were conducted in a simulated fracture (slot cell) to study the transport of proppant. Slick water was injected first into the slot, followed by gel. Finally slick water containing proppant was injected to displace the gel. The water that carried the proppant quickly formed viscous fingers through the gel. The gel was observed to form long thin layers which effectively hindered proppant settling and helped transport the proppant further into the slot. This resulted in the formation of proppant packs above the gel layer. The advantage of this treatment is the proppant placing deeper in the fracture because of reduced settling rates and faster propagating in viscous fingers. Proppant pack is also placing in slick water that has the potential to minimize gel induced damage to the proppant pack.

\subsubsection{Ultra-lightweight proppants}

The last approach is using ultra-lightweight proppants in hydraulic fracturing. Increasing proppants density can lead to increasing degree of difficulty with proppant transport and the difficulty of placing the particle evenly throughout the created fracture geometry. Excessive settling can often lead to bridging of the proppant in the formation before the desired stimulation is achieved. Lesser density proppant would be easier to transport, reduce fracturing fluid complexity and minimize proppant pack damage.

Ultra-Lightweight proppants(ULWP) [Rickards et al., 2003] which is described as a resin-impregnated and coated chemically modified walnut hull with a varied specific gravity and bulk density lesser than sand. The low specific gravity allows for excellent transport in very low viscosity fracturing fluids, namely slick water, due to its near neutral buoyancy. When using a lower viscosity transport fluid, this lower settling rate allows the Ultra Lightweight proppant to be transported further into the fracture when compared to a higher density proppant. The lower viscosity slick water transport fluid was less damaged to reservoir permeability and the proppant pack when compared to higher viscosity crosslinked gelled fluids necessary to carry higher density proppants. Slick water is also more cost effective, improving the economics of the well. The ease of placing ULWP eliminates the need for high pump rates needed to overcome the high settling rate of high density proppants.

\subsection{Experimental study of gel damage}

Most of the hydraulic fracturing treatments currently pumped throughout the world still use some conventional gelled fluid treatment as this type of fluid has proven itself to provide better stimulation results than those given by ungelled fluids. Even though recent laboratory testing is showing a very significant degree of gel filter cake damage to the 
proppant bed, it is recognized that viscous fluids are necessary to open the fracture and suspend the proppants. This makes the successful design of fracturing treatment a challenge task.

To study the gel damage in tight gas formation, an experimental approach is recommended. Fracture conductivity is used to optimize the treatment design. The conductivity of the fracture $\left(\mathrm{C}_{\mathrm{fD}}\right)$ is defined as the product of the permeability of the fracture $\left(\mathrm{k}_{\mathrm{f}}\right)$ and the fracture width $\left(\mathrm{w}_{\mathrm{f}}\right)$.

$$
\mathrm{C}_{\mathrm{fD}}=\mathrm{k}_{\mathrm{f}}^{*} \mathrm{~W}_{\mathrm{f}}
$$

\subsubsection{Conventional gel damage study}

Cooke [1974] designed a test apparatus capable of measuring proppant conductivity versus closure stress. He indicated that elevated test temperatures and brine test fluids should be used in conductivity testing. Most of the data were generated at ambient temperature and held the proppant pack at each stress level for only short time period (typically 0.1 to 0.5 hour). McDaniel [1986] published the two procedures for conductivity testing at high temperatures and long test times. The first one removed oxygen from the brine water which was used as the flowing medium and presaturating test fluids with silica to simulate the condition of fluid in sandstone reservoirs. Roodhart et al. [1986] later published the first laboratory simulation where a gel filter cake was incorperated into a fracture conductivity test. Kim [1985] added short time stress conditions but did not incorporate any gel filter cake. Much and Penny [1987] presented a dynamic fluid loss test. They first built a filter cake from a crosslinked hydroxypropyl guar (HPG) gel on the face of two core wafers, and then injected the proppant as gelled slurry, then followed by applying closure stress and measuring the fracture conductivity using $\mathrm{KCl}$ brine flow for several days.

The general procedures for fracture conductivity test incorperated the use of a modified API conductivity test. The conductivity cell has a 10 square inches flow path which allows for leak off through core slabs and filter cake development. 63.1 grams $\left(2 \mathrm{lb} / \mathrm{ft}^{2}\right)$ proppant is loaded and leveled. Closure pressure and temperature is increased. The system is evacuated and saturated with water. After the desired closure pressure is reached, the proppant is allowed to equilibrate and also all transducers and thermocouples. The flow rate, pressure differential and average width are measured in order to calculate conductivity and permeability. The cells are shut in and temperature is increased to the test temperature and allowed to equilibrate. The pressure is then increased in 1000 or 2000 psi increments and the proppant is allowed to equilibrate at each pressure. The flow rates are set and the conductivity and permeability are monitored continuously at the test temperature and closure for the duration of test. 


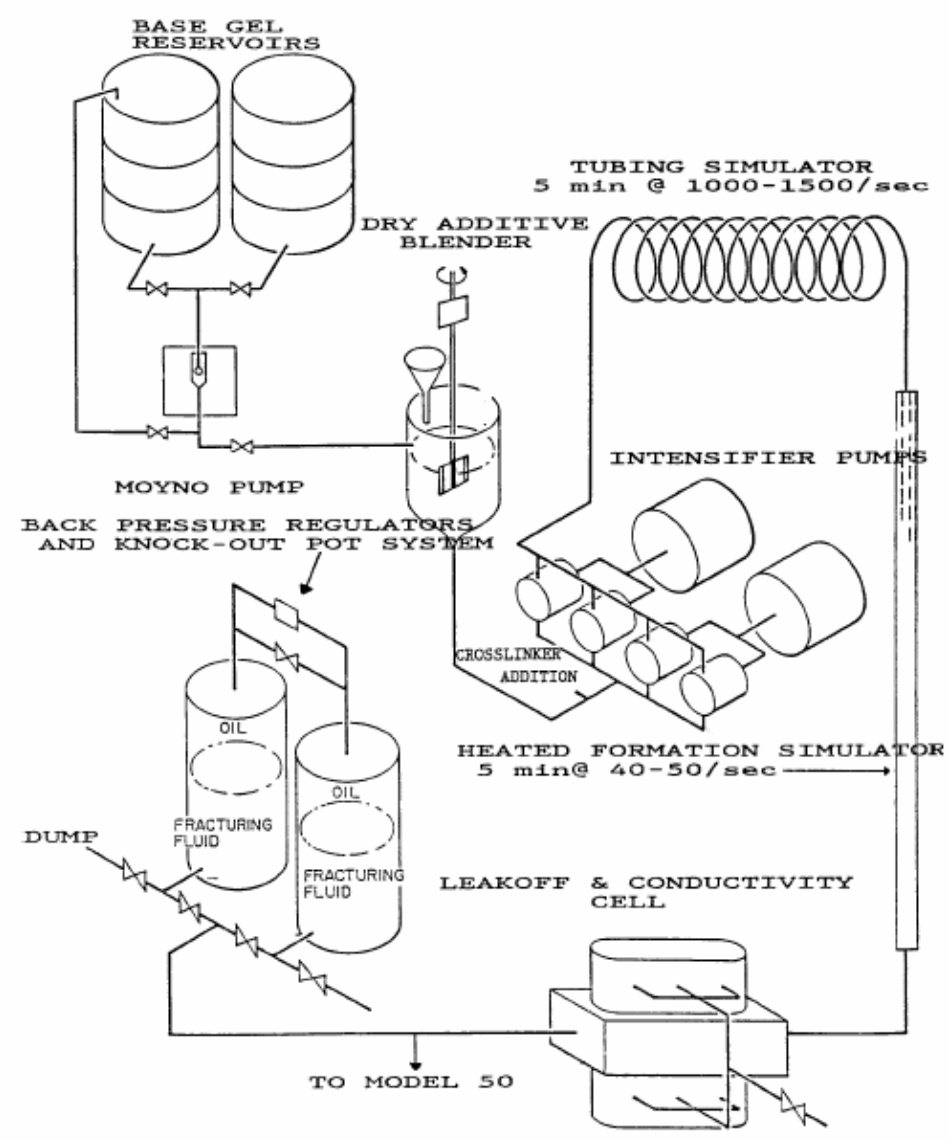

Figure 36 Schematic for fracturing treatment simulator [Penny, 1987]

Figure 36 shows the schematic of the fracture treatment simulator. The two fracturing fluid containers connected together, the base gel is then mixed by adding gel and additives to the drum while circulating with a pump. Crosslinker is injected as the fluid is fed to a series of intensifier pumps which increase the pressure to cell pressure and provide a rate which is designed for obtaining shear rate in the tubing and fracture simulator.

The fluid now enters a tubing surrounded by heat jacket. The fluid is heated when it flows. The fluid flows in between two core slabs which have been saturated with $\mathrm{KCl}$. The leak off rate through each core is monitored. A pumping time of 240 minutes was performed on all reported tests in the order of $\mathrm{KCl}$, base gel, complex gel pad, 1 ppg proppant, $3 \mathrm{ppg}$ of proppant, up to $5 \mathrm{ppg}$ of proppant, and slurry to pack cell. The final slurry is flowing slowly into the cell and then shut in.

The development of the experiments to improve fracturing methods for tight gas sands are a series of dynamic fracturing conductivity tests. By injecting the proppant slurry into the fracture under conditions similar to actual fracture, the effects such as erosion of the fracture faces and non-uniform proppant distribution that do not occur in standard static fracture conductivity tests can be studied. The procedure is described above.

\subsubsection{Test conditions of gel damage study}

\subsubsection{Polymer}

- Polymer type - guar and hydropropyl guar (HPG) are recommended to use in this study because of their competitive price, wide availability and overall performance flexibility. Guar and HPG are the most common material in use today as gellant. While the residue from guar is the highest on a mass percentage basis (Figure 37), the main reason for the use of guar more than guar derivatives in the field is the 
temperature range of borate system. The borate system has been extended up to as high as $350{ }^{\circ} \mathrm{F}$. Gel residue from organometal crosslink system is extremely damaged and difficult to remove.

- Polymer concentration - The increasing in polymer concentration generates proportionally higher gel residues. However the damage to the sand permeability is not proportional. Different concentrations of polymer should be tested and the effect of the polymer concentration should be studied.

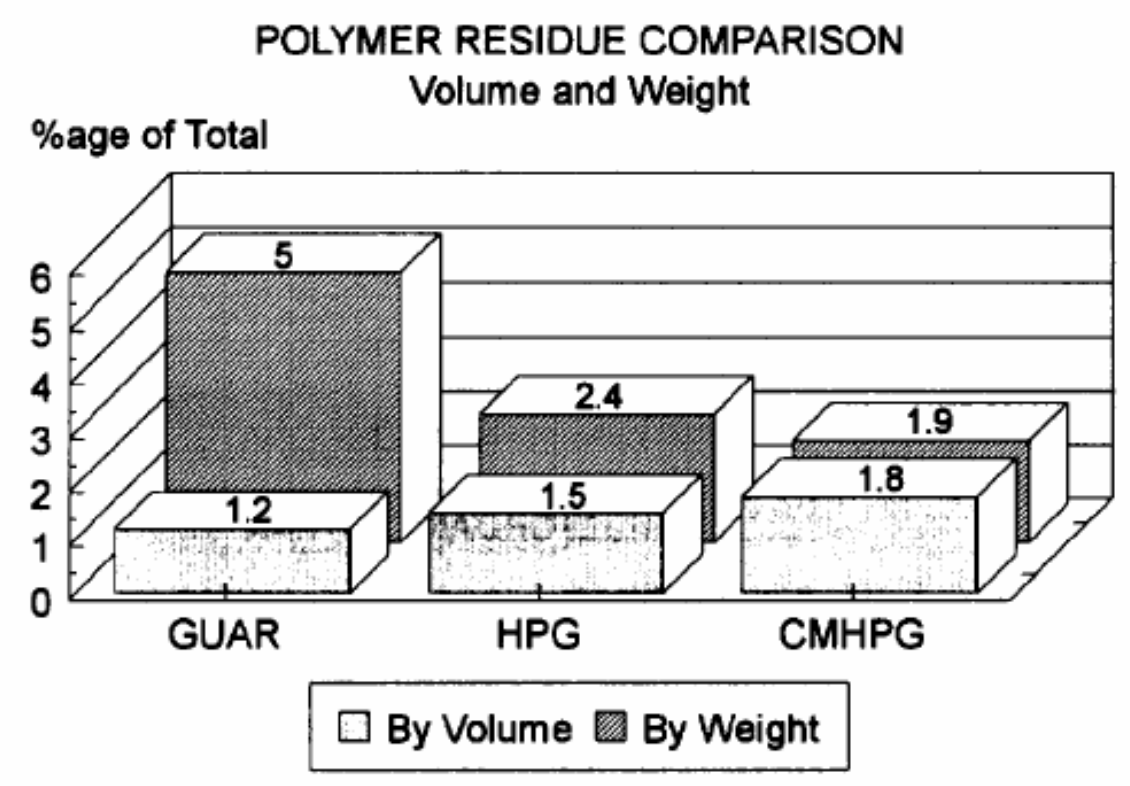

Figure 37 Comparison of residues by volume and weight of guar and its derivatives [Phil and Gino, 1996]

\subsubsection{Proppants}

Two types of proppants are suggested in this study: sand and CARBOLITE proppant. The function of a proppant is to hold the fracture open after the hydraulic treatment has been completed. The reservoir fluids then can flow through the conductive path created by the proppant pack in the fracture. Silica sand is by far the most commonly used proppant in the U.S. today. The availability and low cost of high-quality sands that can provide good fracture conductivity for a wide range of conditions make them very attractive for fracture stimulation. API has established sand-quality specifications for use in fracturing treatment. These basically cover size distribution, sphericity and roundness, solubility in acid, silt and clay content, and crush resistance. CARBOLITE proppant is lightweight proppant designed for use in gas wells of moderate depth and shallower oil wells. CARBOLITE proppant is approximately the same density as sand, but is more spherical, so higher production rates can be achieved due to the product's uniform size and spherical shape.

\subsubsection{Crosslinker}

Each crosslink agent is restricted within certain $\mathrm{pH}$ limits and temperature ranges as shown in Figure 38 and 39. Most widely used groups of crosslinkers for high $\mathrm{pH}$ fluids and temperature are the borates. In this study, delayed borate crosslink is suggested because delayed borate crosslink fluids give much less damage to the proppant pack permeability than 
conventional organometallic crosslink fluids and also can be used with wide temperature range from 100 to $350{ }^{\circ} \mathrm{F}$ and with $\mathrm{pH}$ in the range of 8-12.

\section{CROSSLINKERS \& pH}

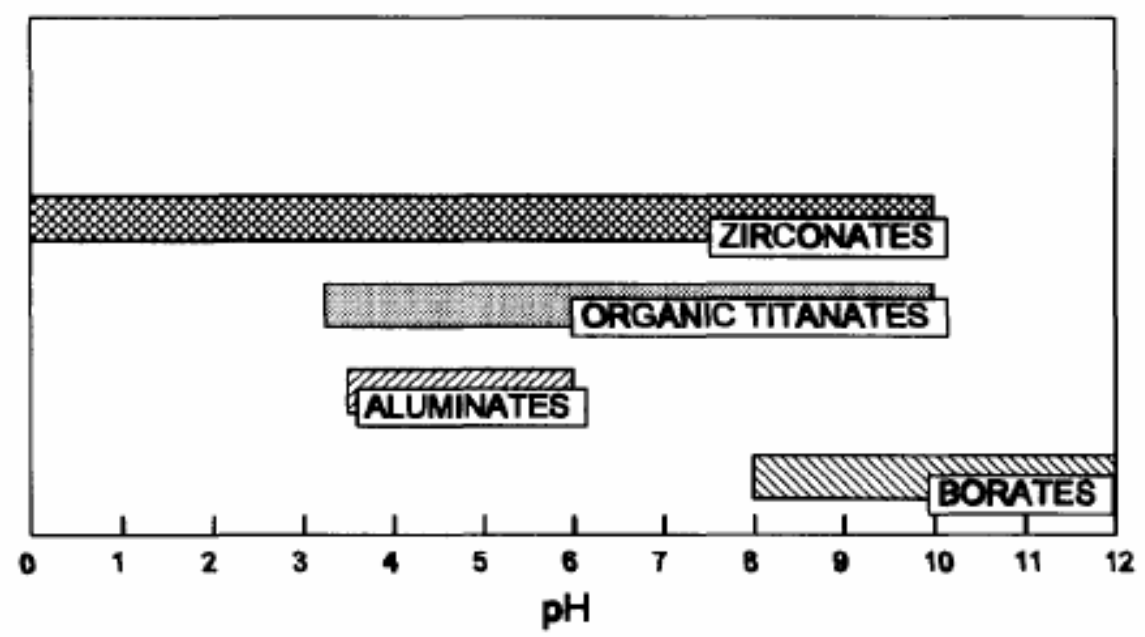

Figure $38 \mathrm{pH}$ ranges for various crosslinkers [Phil and Gino, 1996]

CROSSLINKERS \& TEMPERATURE

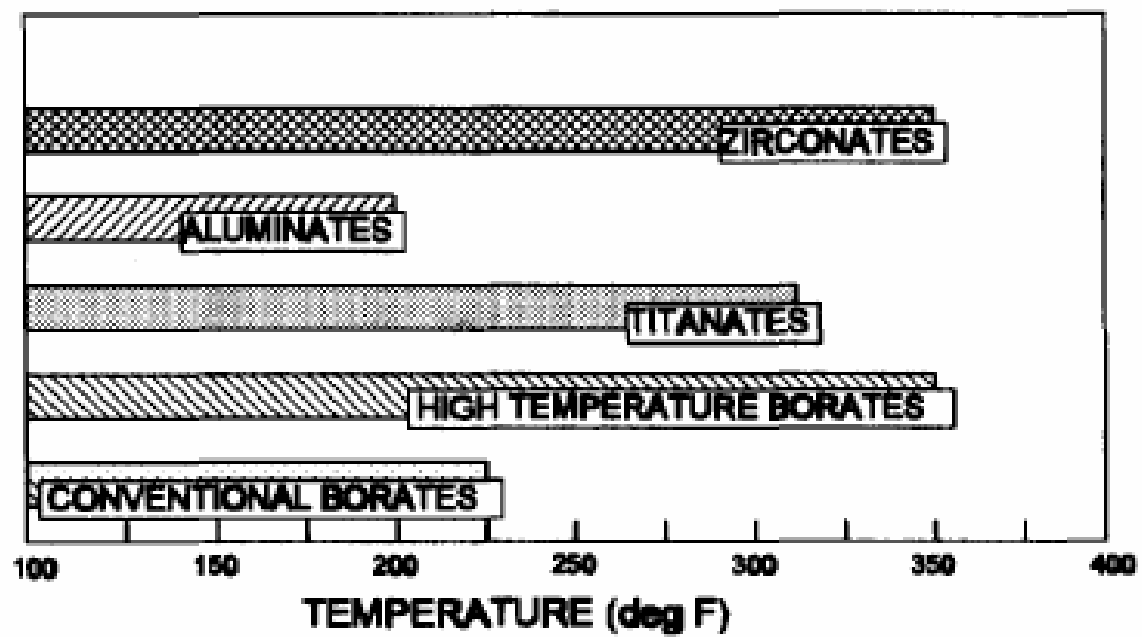

Figure 39 Temperature for various crosslinkers [Phil and Gino, 1996]

\subsubsection{Breaker}

Proppant permeability damage by crosslinked fluids substantially depends on the filter cake buildup. It is minimized by use of an effective viscosity breaker. An inadequate breaker leads to virtually complete loss of proppant pack conductivity. On the other hand, aggressive breaker schedules, short break time can provide high retention factor in excess of $80 \%$, and can result in excessive proppant setting in the fracture before closure. The most common 
breakers are oxidizing agents like peroxides and persulfates. These reactive species decompose to produce free radicals which attack the polymer chains and bring about degradation. Enzymes have also been used for many years to break fracturing fluids. These enzymes attack the guar molecules and reduce its molecular weight. But, unlike oxidizing agents they are not consumed in the process. Borate crosslinked fluids with persulfate/amine breakers yield less conductivity impairment than borate crosslinked fluids with enzyme breaker (12\% vs. $32 \%)$. In this study, persulfates and oxidizing agent are used for low and high temperature application respectively. Persulfate can not be used when fluid temperature is greater than $200^{\circ} \mathrm{F}$, so high temperature oxidizing agent is used instead.

\subsubsection{Time and Temperature}

Temperature alone has little effect on the degree of sandpack permeability reduction for uncrosslinked fluids. Borate crosslinked fluids yield minimal damage (23\%) at high temperature. Conductivity data generated at low temperature indicated metal crosslinked fluids yield minimal conductivity impairment. Borate crosslinked 30 and $40 \mathrm{lb}$ HPG placement fluids yielded 5 and $12 \%$ impairment respectively; while a titanate crosslinked 40 lb HPG placement fluid yields $81 \%$ conductivity impairment at low temperature. The severe damage caused by the titanate fluid is attributed to the poor degradation on characteristics of its filter cake. Delayed borate crosslinked fluids can be used to treat low and high temperature wells, where the fluid is not exposed to greater than $300{ }^{\circ} \mathrm{F}$. Permeability decreased dramatically with increasing shut in time. Different temperature and time should be tested and the effects of temperature and time should be studied.

\subsubsection{Closure stress}

The fracture conductivity depends on effective closure stress (minimum in-situ stress minus pore pressure). The high closure stresses encountered in deeper wells require the use of artificial (intermediate- or high-strength) proppants to improve fracture conductivity. The recent long-term measurements discussed show a technical need for these stronger (and therefore more conductive) proppants at lower closure stresses (shallower depth). This is also true if coarser proppant sand grades are used in an attempt to increase fracture conductivity because crushing occurs at lower closure stress. Different closure stress should be tested and the effect of closure stress should be studied.

Based on these findings, a series of experiments to systematically identify the conditions that lead to gel damage under dynamic conditions will be conducted. A range of temperatures from 150 to $250 \mathrm{~F}$ will be studied. The fracture fluid/proppant slurry will be heated up to the desired temperature before going through the conductivity cell. A series of experiments with different proppant concentrations and polymer concentrations will be conducted. The suggested study condition is summarized in Table 5. 
Table 5 Conditions for gel damage experiments

Note: Conc. $=$ Concentration per 1000 gal of clean fluids

$\mathrm{HPG}=$ Hydropropyl guar $\quad \mathrm{Br}=$ Borate

\begin{tabular}{|c|c|c|c|c|c|c|c|c|c|c|}
\hline polymer & conc. & crosslink & proppant & $\begin{array}{l}\text { Conc. } \\
\left(\mathrm{lbm} / \mathrm{ft}^{2}\right)\end{array}$ & $\begin{array}{c}\mathrm{pH} \\
\text { adjust } \\
\text { additive }\end{array}$ & $\begin{array}{l}\text { Oxidative } \\
\text { breaker }\end{array}$ & $\begin{array}{l}\text { Conc. } \\
\text { lbm }\end{array}$ & $\begin{array}{c}\text { clossure } \\
\text { stress } \\
(\mathrm{psi})\end{array}$ & $\begin{array}{l}\text { temp } \\
\left({ }^{0} \mathrm{~F}\right)\end{array}$ & $\begin{array}{l}\text { flow rate } \\
\text { (liter/min) }\end{array}$ \\
\hline Guar & 40 & $\begin{array}{c}\mathrm{Br} \\
\text { delayed }\end{array}$ & $\begin{array}{c}\text { Carbolite or } \\
20 / 40 \text { mesh sand }\end{array}$ & 2 & $\begin{array}{l}8.0- \\
12.0\end{array}$ & Persulfate & 0.1 & 1000 & 180 & 1.3 \\
\hline Guar & 40 & $\begin{array}{c}\mathrm{Br} \\
\text { delayed }\end{array}$ & $\begin{array}{c}\text { Carbolite or } \\
20 / 40 \text { mesh sand }\end{array}$ & 2 & $\begin{array}{l}8.0- \\
12.0\end{array}$ & $\begin{array}{l}\text { High Temp. } \\
\text { Oxidizer }\end{array}$ & 0.1 & 6000 & 250 & 1.3 \\
\hline Guar & 50 & $\begin{array}{c}\mathrm{Br} \\
\text { delayed }\end{array}$ & $\begin{array}{c}\text { Carbolite or } \\
20 / 40 \text { mesh sand }\end{array}$ & 2 & $\begin{array}{l}8.0- \\
12.0\end{array}$ & Persulfate & 0.1 & 1000 & 180 & 1.3 \\
\hline Guar & 50 & $\begin{array}{c}\mathrm{Br} \\
\text { delayed }\end{array}$ & $\begin{array}{c}\text { Carbolite or } \\
20 / 40 \text { mesh sand }\end{array}$ & 2 & $\begin{array}{l}8.0- \\
12.0\end{array}$ & $\begin{array}{l}\text { High Temp. } \\
\text { Oxidizer }\end{array}$ & 0.1 & 6000 & 250 & 1.3 \\
\hline Guar & 60 & $\begin{array}{c}\mathrm{Br} \\
\text { delayed }\end{array}$ & $\begin{array}{c}\text { Carbolite or } \\
20 / 40 \text { mesh sand }\end{array}$ & 2 & $\begin{array}{l}8.0- \\
12.0\end{array}$ & Persulfate & 0.1 & 1000 & 180 & 1.3 \\
\hline Guar & 60 & $\begin{array}{c}\mathrm{Br} \\
\text { delayed }\end{array}$ & $\begin{array}{c}\text { Carbolite or } \\
20 / 40 \text { mesh sand }\end{array}$ & 2 & $\begin{array}{l}8.0- \\
12.0\end{array}$ & $\begin{array}{l}\text { High Temp. } \\
\text { Oxidizer }\end{array}$ & 0.1 & 6000 & 250 & 1.3 \\
\hline HPG & 40 & $\begin{array}{c}\mathrm{Br} \\
\text { delayed }\end{array}$ & $\begin{array}{c}\text { Carbolite or } \\
20 / 40 \text { mesh sand }\end{array}$ & 2 & $\begin{array}{l}8.0- \\
12.0\end{array}$ & Persulfate & 0.1 & 1000 & 180 & 1.3 \\
\hline HPG & 40 & $\begin{array}{c}\mathrm{Br} \\
\text { delayed }\end{array}$ & $\begin{array}{c}\text { Carbolite or } \\
20 / 40 \text { mesh sand }\end{array}$ & 2 & $\begin{array}{l}8.0- \\
12.0\end{array}$ & $\begin{array}{l}\text { High Temp. } \\
\text { Oxidizer }\end{array}$ & 0.1 & 6000 & 250 & 1.3 \\
\hline HPG & 50 & $\begin{array}{c}\mathrm{Br} \\
\text { delayed }\end{array}$ & $\begin{array}{c}\text { Carbolite or } \\
20 / 40 \text { mesh sand }\end{array}$ & 2 & $\begin{array}{l}8.0- \\
12.0\end{array}$ & Persulfate & 0.1 & 1000 & 180 & 1.3 \\
\hline HPG & 50 & $\begin{array}{c}\mathrm{Br} \\
\text { delayed }\end{array}$ & $\begin{array}{c}\text { Carbolite or } \\
20 / 40 \text { mesh sand }\end{array}$ & 2 & $\begin{array}{l}8.0- \\
12.0\end{array}$ & $\begin{array}{l}\text { High Temp. } \\
\text { Oxidizer }\end{array}$ & 0.1 & 6000 & 250 & 1.3 \\
\hline HPG & 60 & $\begin{array}{c}\mathrm{Br} \\
\text { delayed }\end{array}$ & $\begin{array}{c}\text { Carbolite or } \\
20 / 40 \text { mesh sand }\end{array}$ & 2 & $\begin{array}{l}8.0- \\
12.0\end{array}$ & Persulfate & 0.1 & 1000 & 180 & 1.3 \\
\hline HPG & 60 & $\begin{array}{c}\mathrm{Br} \\
\text { delayed }\end{array}$ & $\begin{array}{c}\text { Carbolite or } \\
20 / 40 \text { mesh sand }\end{array}$ & 2 & $\begin{array}{l}8.0- \\
12.0\end{array}$ & $\begin{array}{l}\text { High Temp } \\
\text { Oxidizer }\end{array}$ & 0.1 & 6000 & 250 & 1.3 \\
\hline
\end{tabular}


The conclusions from the literature reviews about gel damage effect on fracture conductivity are summarized as following:

1. There are several factors affect the amount of residues after breaking of fracturing fluids: breaker types, breaker concentration, break time and break temperature.

2. Gel damage can divided into three ways which are residual fracture damage, loss of width due to filter cake and loss of length due to static gel at the tip.

3. Water fracturing treatments can reduce gel damage in hydraulic fracturing treatment but it does not result better conductivity than gel fracturing treatments. They may be much cheaper and thus a better economic alternative.

4. Hybrid fracturing treatments is increasing in effective fracture lengths and well productivity but can also increase the possibility of tip screen out.

5. Fracture conductivity reduction from a fracturing fluid can be determined by concentration of proppant, amount of residue in the fluid, porosity of the proppant, and fraction of residue retained in the fracture after leaks off.

6. Gel residues can result in significant conductivity reduction.

\subsection{Static leakoff tests}

In order to investigate the fracture cleanup mechanism, we will use a modified permeability plugging apparatus (Figure 40) for our static fracture fluid leakoff test. Ceramic disks with permeability of less than $1 \mathrm{md}$ will be used as the filter medium (Figure 35). The experiments will be conducted at pressures and temperatures approximating those prevailing downhole. A range of different fracture fluids with different additives of different concentrations will be tested in order to simulate the real fracturing leakoff.

We plan to conduct experiments in which we perform the following steps:

1. Prepare the fluid samples.

2. Preheat the heating jacket to the proposed test temperature.

3. Fill in the filtration cell with the fluid sample prepared in step 1.

4. Load the filtration cell.

5. Pressurize the cell using a hydraulic hand pump.

6. Conduct the filtration tests using the graduate cylinder to collect filtrate and use stopwatch to measure the time.

The data collected in these tests will provide us an insight of the crucial role played by polymer concentration via leakoff, which could be either avoided through adequate design or used to estimate the resulting productivity loss. The data collected in these tests will also be incorporated into our fracture fluid cleanup simulator. 


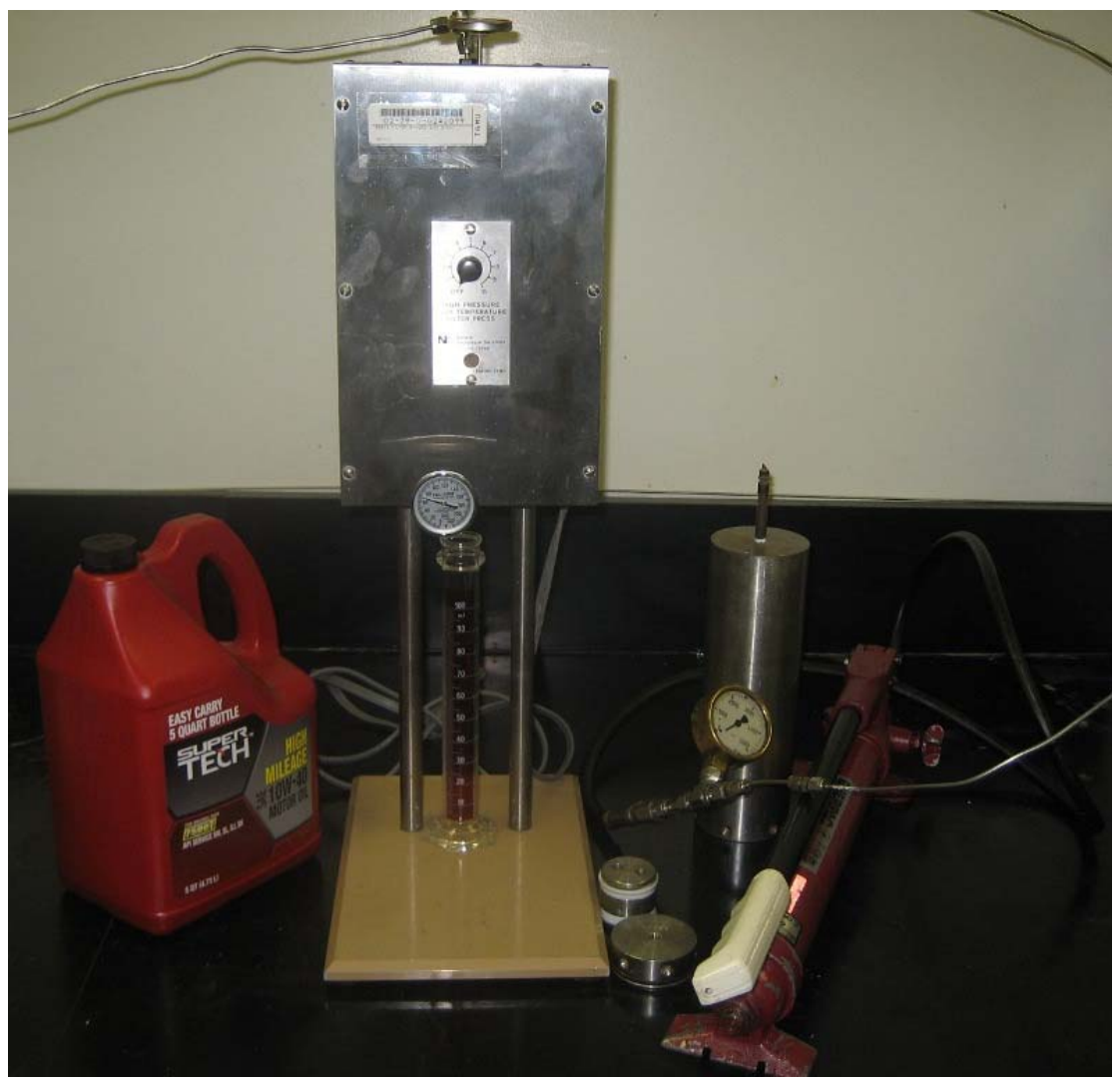

Figure 40 Modified permeability plugging apparatus

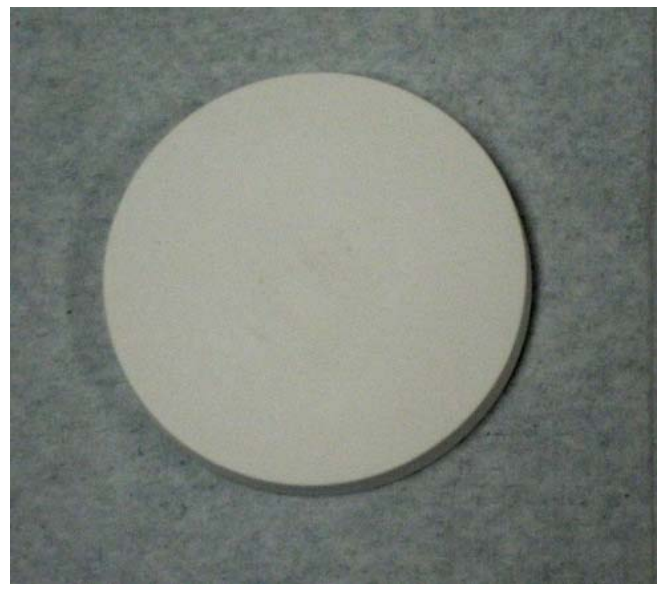

Figure 41 Filter medium (ceramic disk)

\subsection{Model development}

A new comprehensive 3D, 3-phase simulator to investigate fracture fluid cleanup problem and its effect on long term recovery in tight gas reservoirs is under development. We are investigating all factors affecting the cleanup process such as pressure drawdown, fracture geometry, non-Darcy flow effect, fracture conductivity, clay swelling, heterogeneity, formation temperature, fracture fluid viscosity, viscous fingering, gel residue, breaker and operational procedures. A comprehensive literature study on fracture fluid damage and the cleanup process has been done. Several mathematical models charactering the cleanup 
process has been understood and will be improved for the tight gas reservoir. A couple of simulations have been run to look at the fracture fluid cleanup process. We find out that we need to implement the yield stress effect into our simulator to model the long term gas production more accurately. So far, we have incorporated the yield-power law model and the polymer residue vs. proppant permeability model into our simulator FFSIM. Simulations have been run to study the effect of the yield stress and polymer residue on the cleanup process and long-term gas production. Polymer effect has been compared and quantified based on the analysis of three cases: Newtonian facture fluid, non-Newtonian fracture fluid (with yield stress of 0 to 50pa), and non-Newtonian fracture fluid (the yield stress model plus the polymer residue model), at fracture conductivity of $\mathrm{F}_{\mathrm{CD}}=12.5$ and $\mathrm{F}_{\mathrm{CD}}=1250$.

Figures 42 and 43 show the water and gas saturation after a treatment. The fracture fluid has displaced the gas further into the reservoir formation and created a block zone abound the fracture. Before fracturing, the water saturation is 0.2 , and gas saturation is 0.8 . After treatment, the saturations are shown above, with $100 \%$ gel inside the fracture. We assume the initial formation water is immobile to study the cleanup. It is the initial condition for simulation runs.
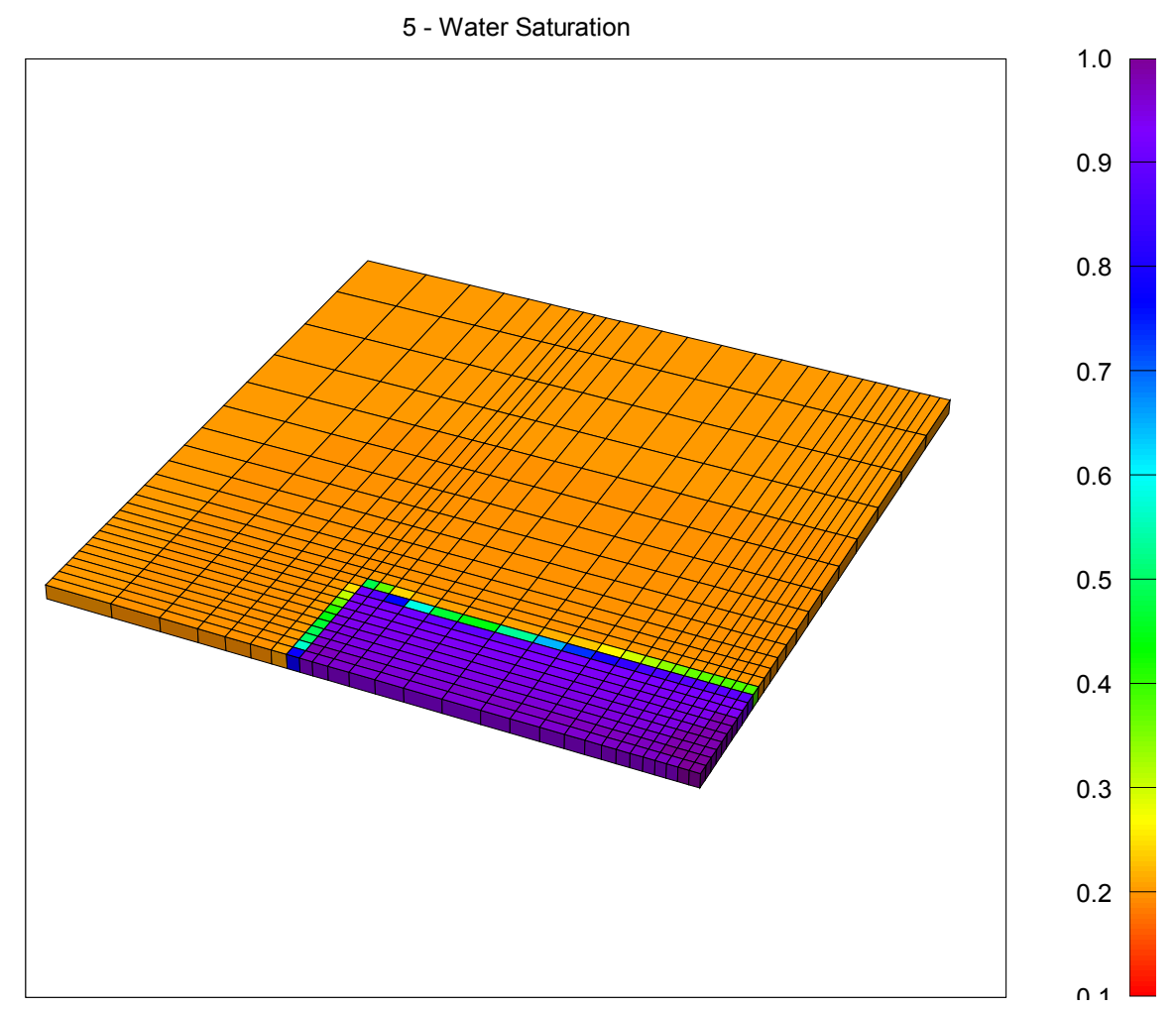

Figure 42 Water saturation map after a fracture treatment of 252,000 gallons of fracture fluid 

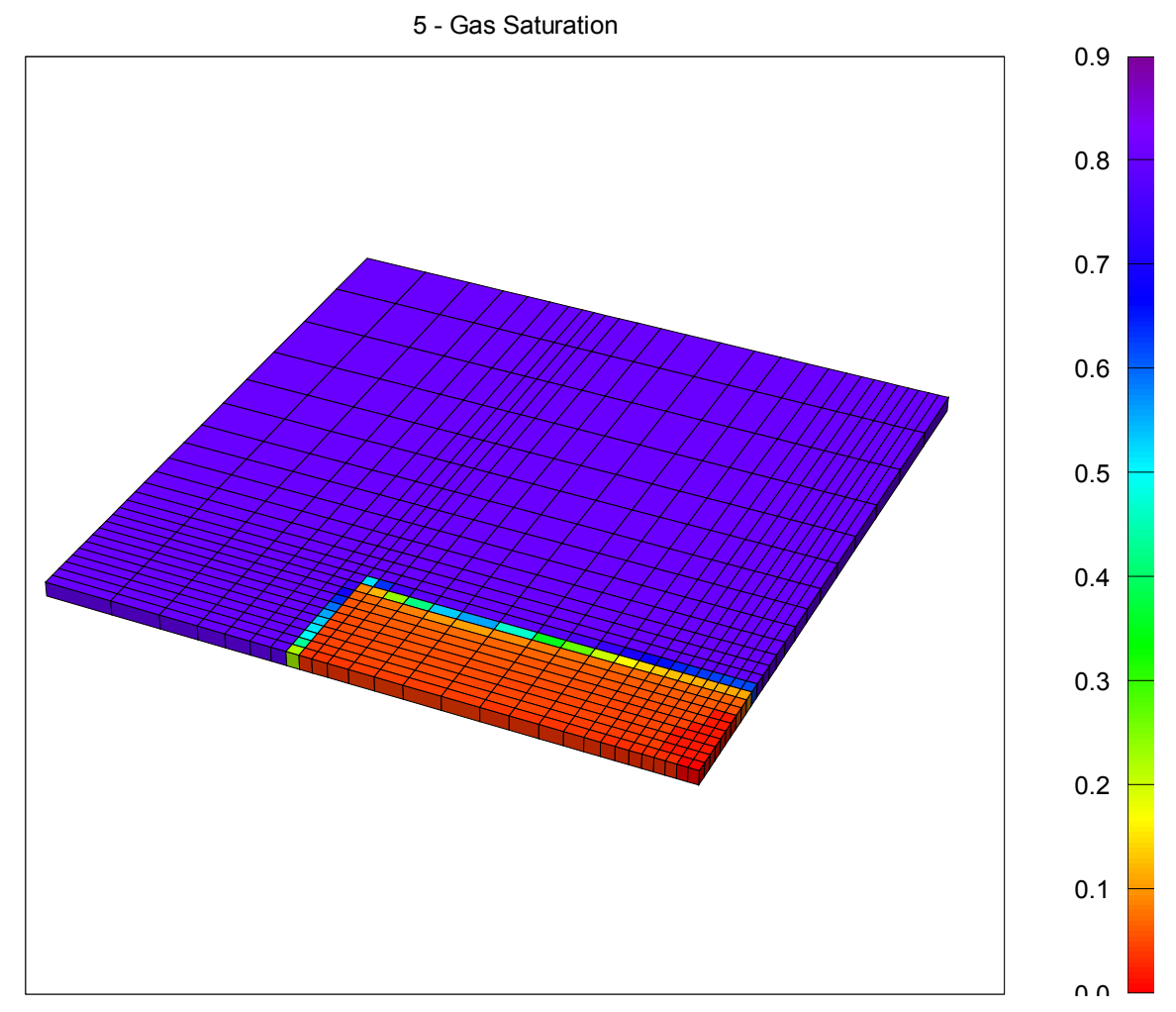

Figure 43 Gas saturation map after a fracture treatment of 252,000 gallons of fracture fluid

Then, the well is completed at the cell $(1 \times 1 \times 1)$, and will be operated at constant bottom hole pressure (BHP) or constant production rate. Figures 44 and 45 show the relative permeability curves for the reservoir formation and for the fracture, respectively. Then during simulation, the three-phase permeability will be calculated by using Stone II method.

Gas - Fracture fluid curve 1

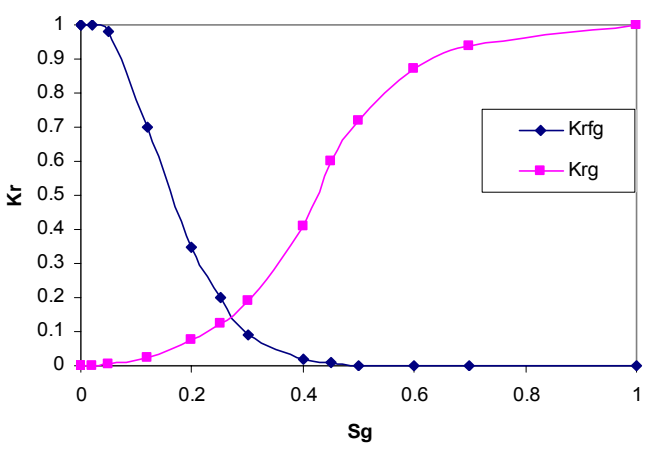




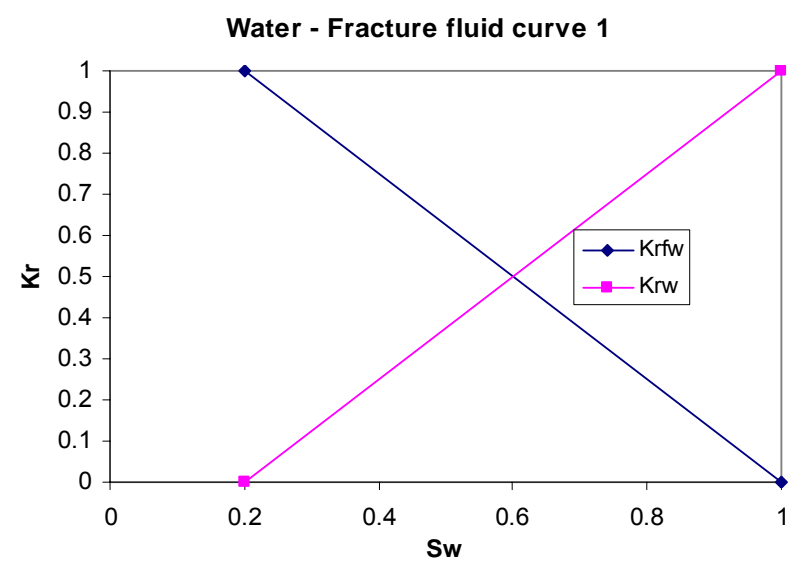

Figure 44 Relative permeability curves in the reservoir formation

Gas- Fracture fluid curve 2

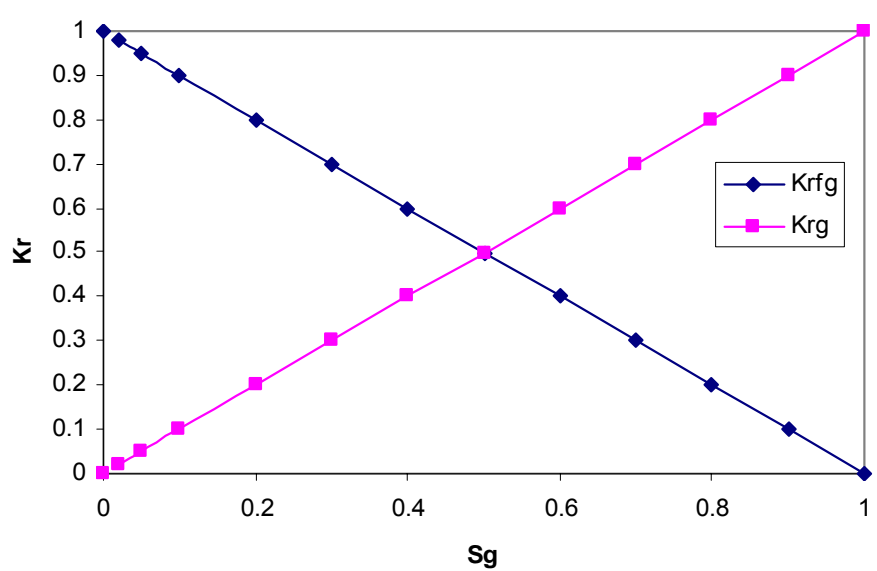

Water - Fracture fluid curve 2

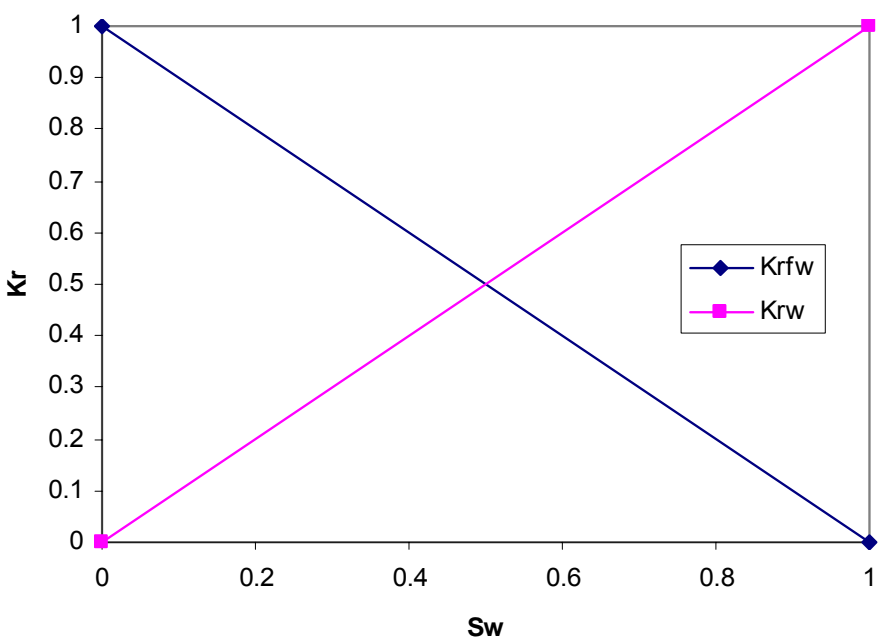

Figure 45 Relative permeability curves inside the fracture 
The following figures show the saturation maps during the cleanup process for Newtonian fracture fluid and non-Newtonian fracture fluid (the yield stress model plus the polymer residue model) with a yield stress of 50pa.
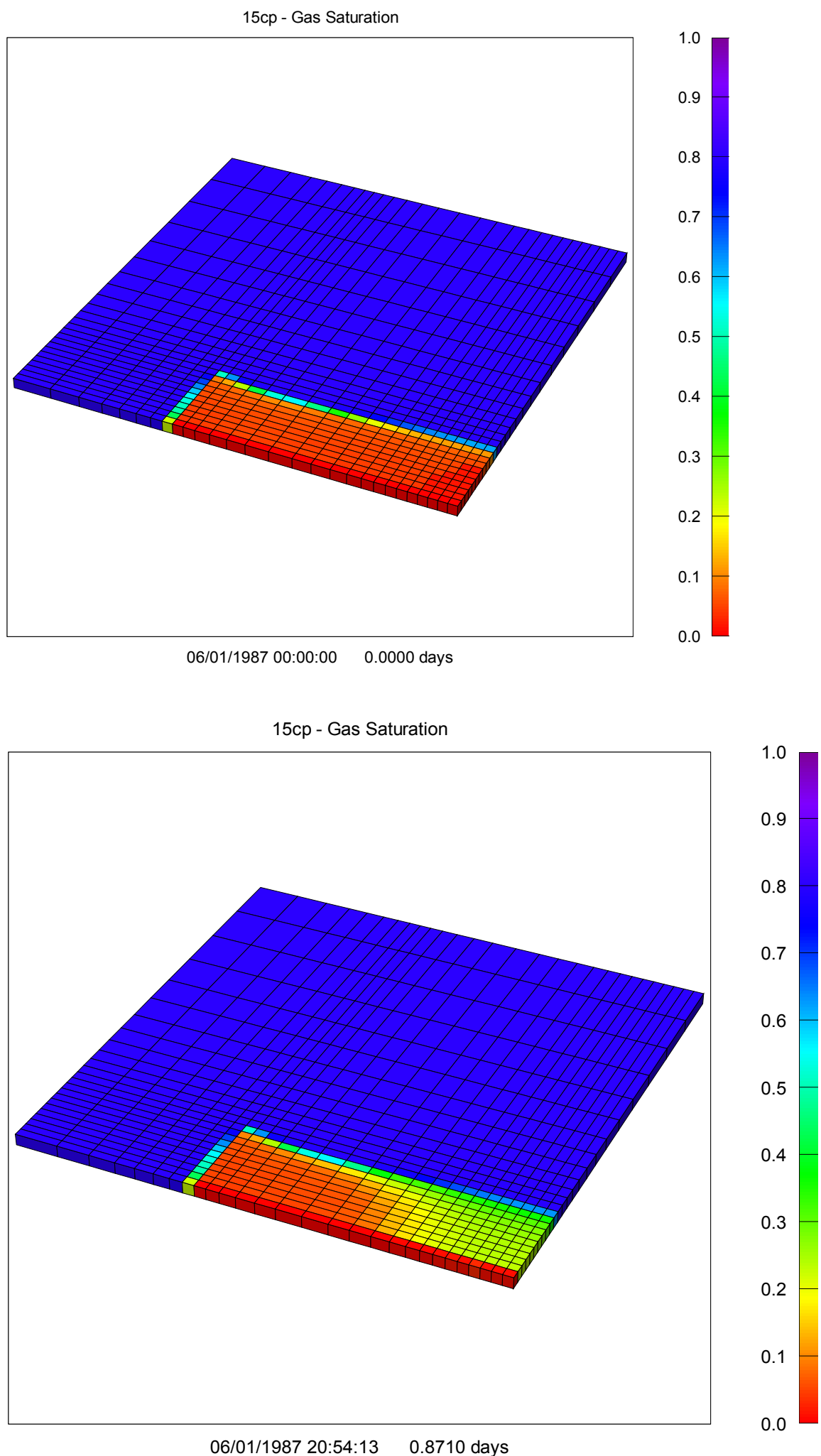

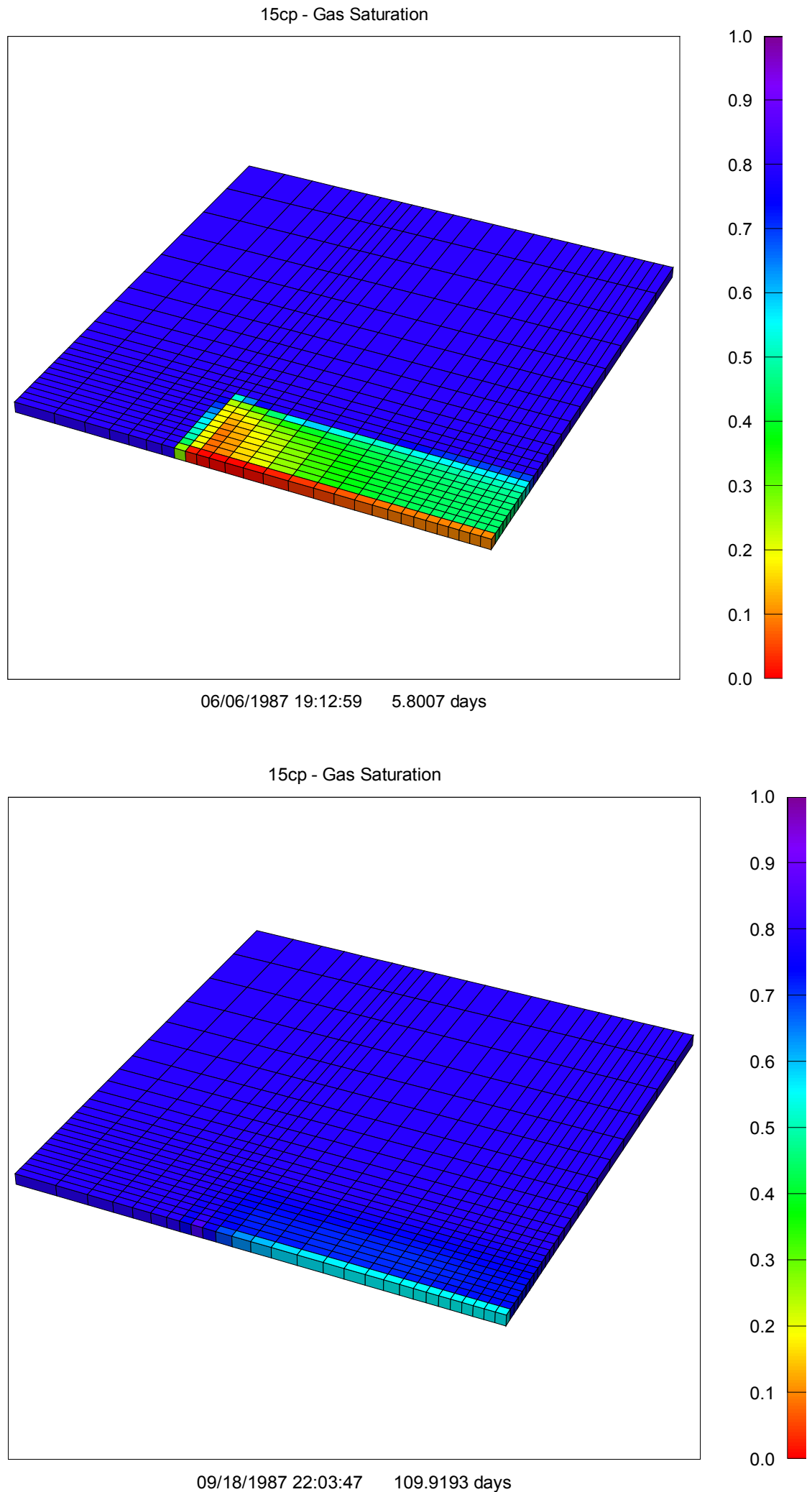

Figure 46 Saturation map for fracture fluid of $15 \mathrm{cp}$ 
Yield50pa - Gas Saturation
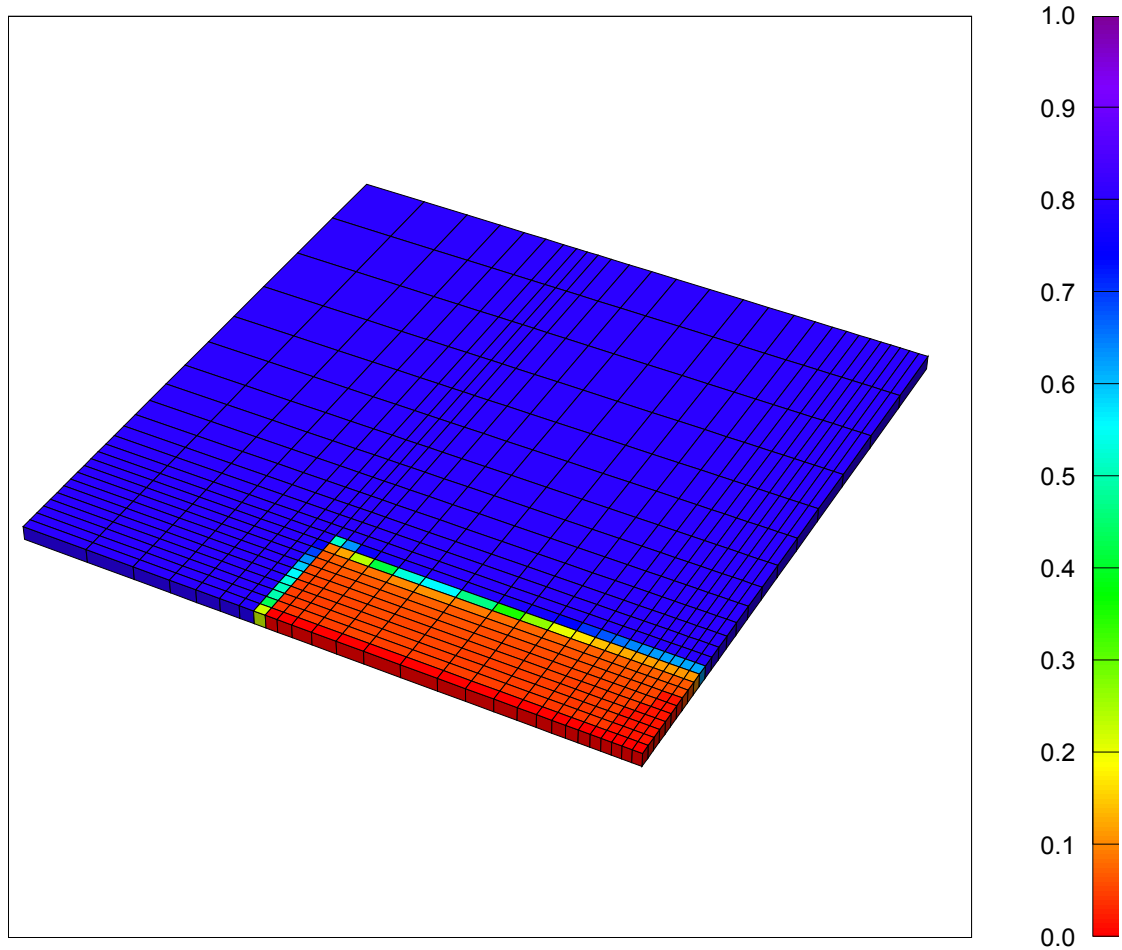

06/01/1987 00:00:00 $\quad 0.0000$ days

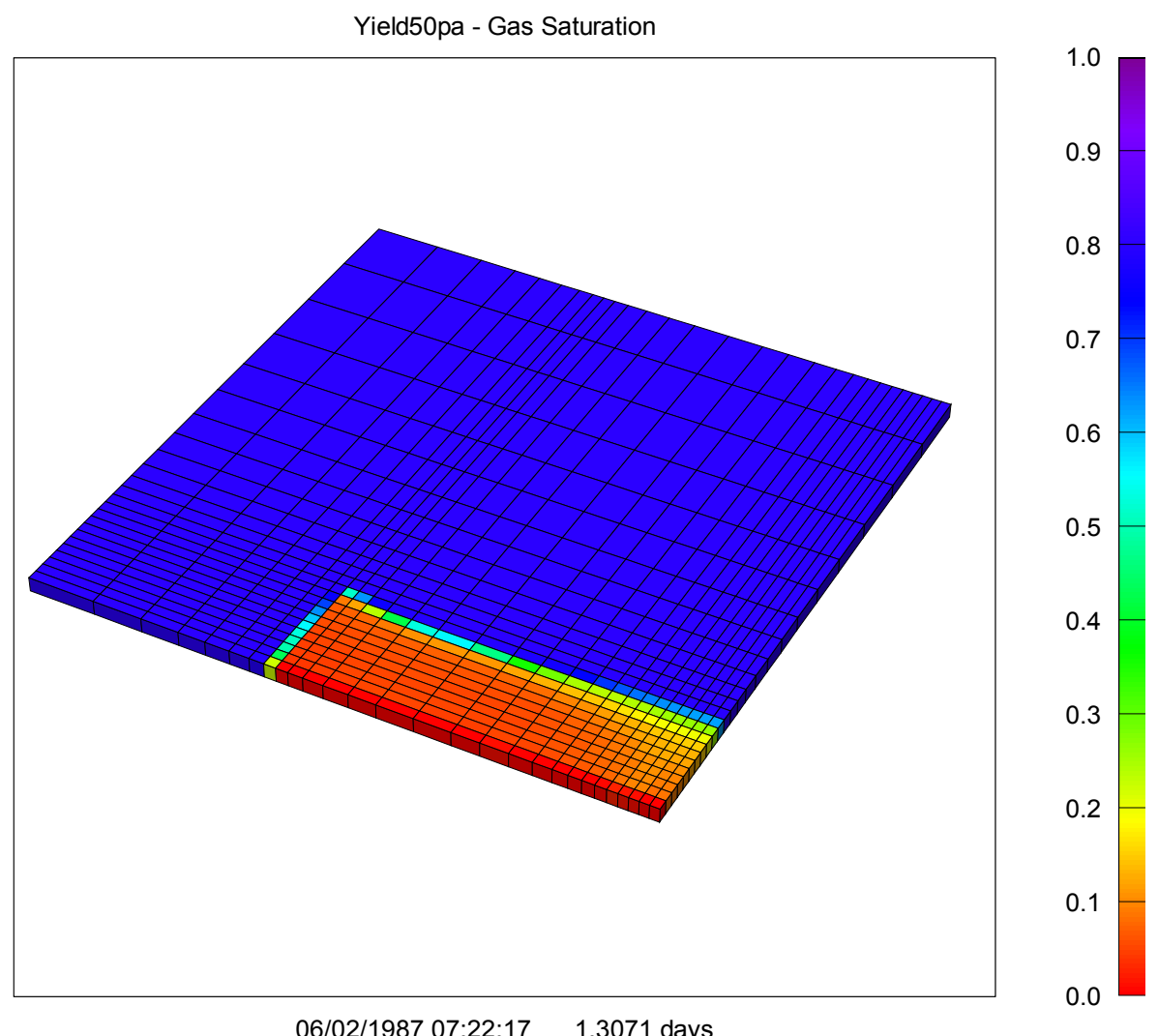



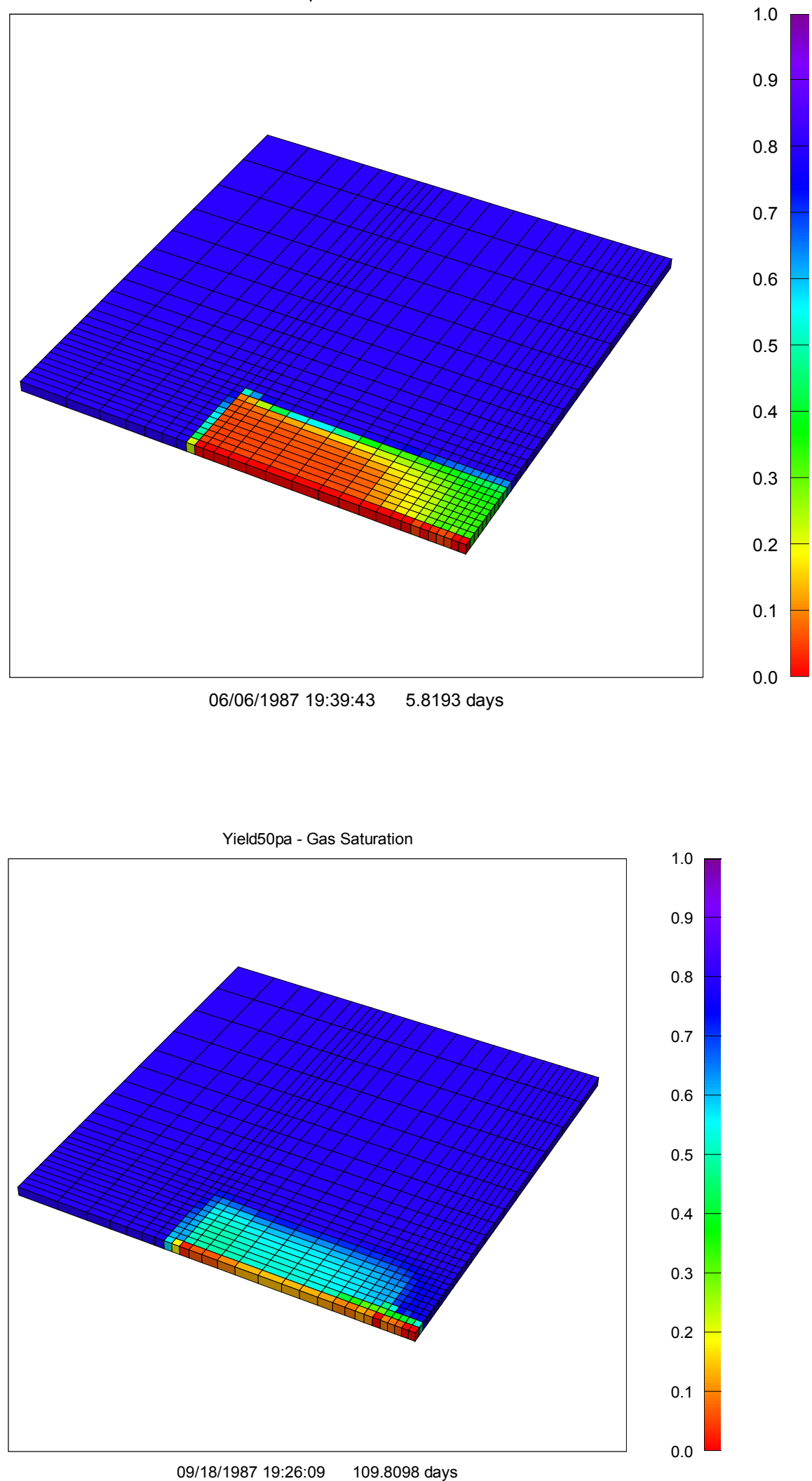

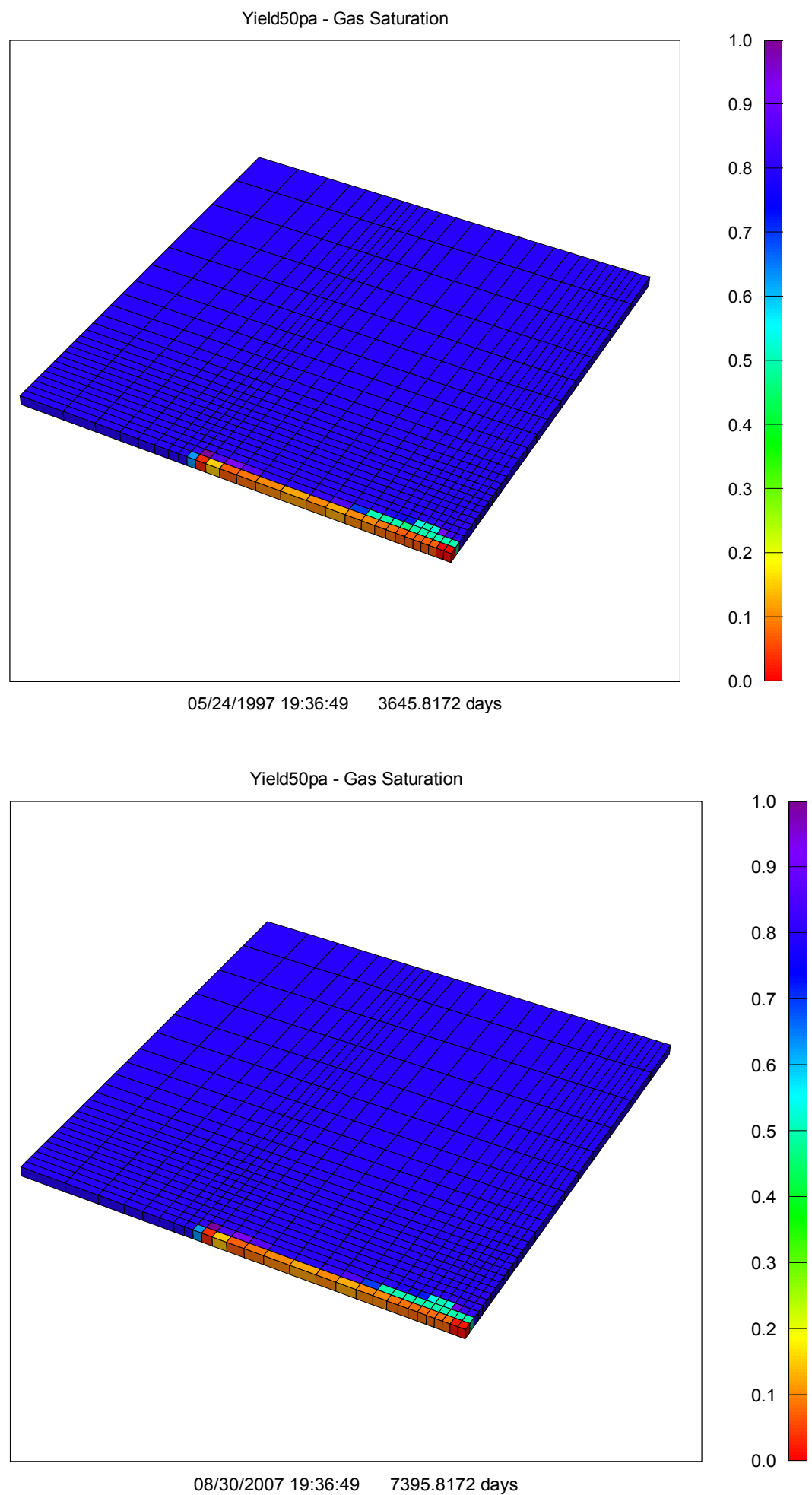

Figure 47 Saturation map for the case with yield stress of 50 pa 
Fracture Fluid Cleanup Process for yield stress of 0.01pa

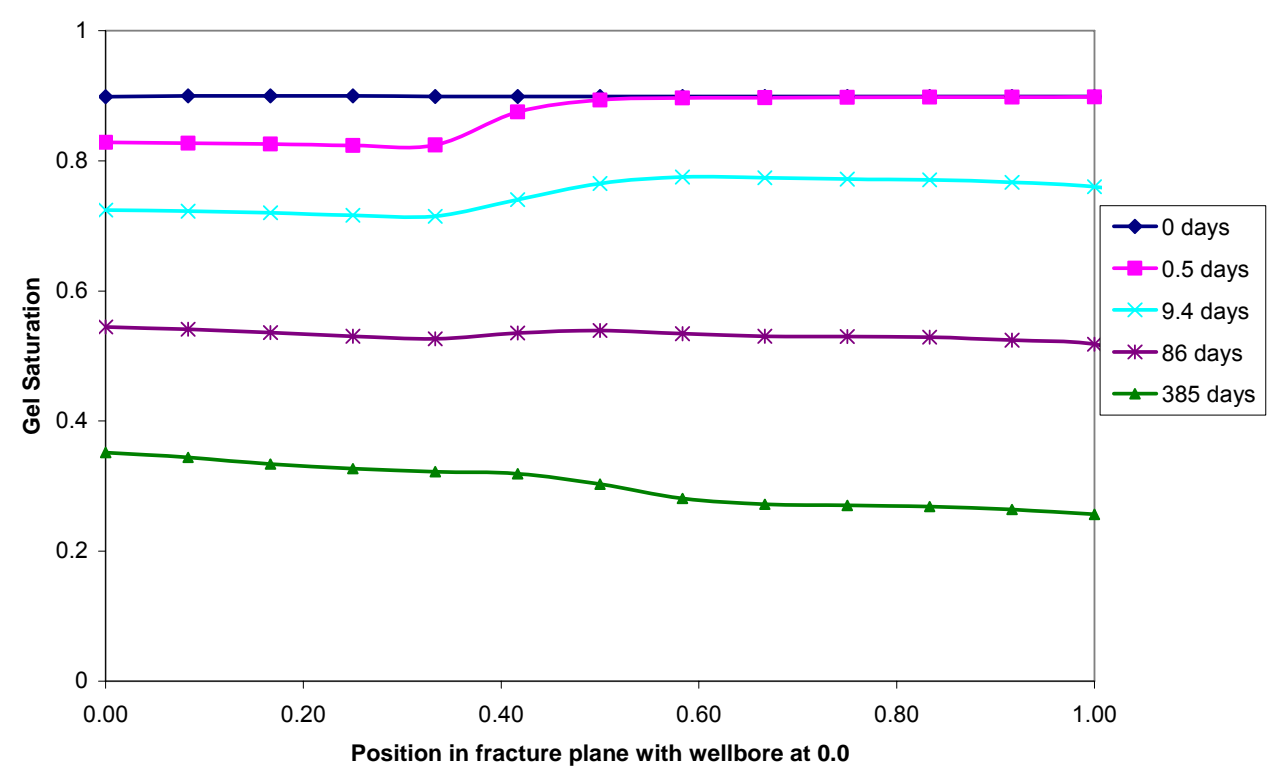

Figure 48 Saturation map for the case with yield stress of 0.01 pa

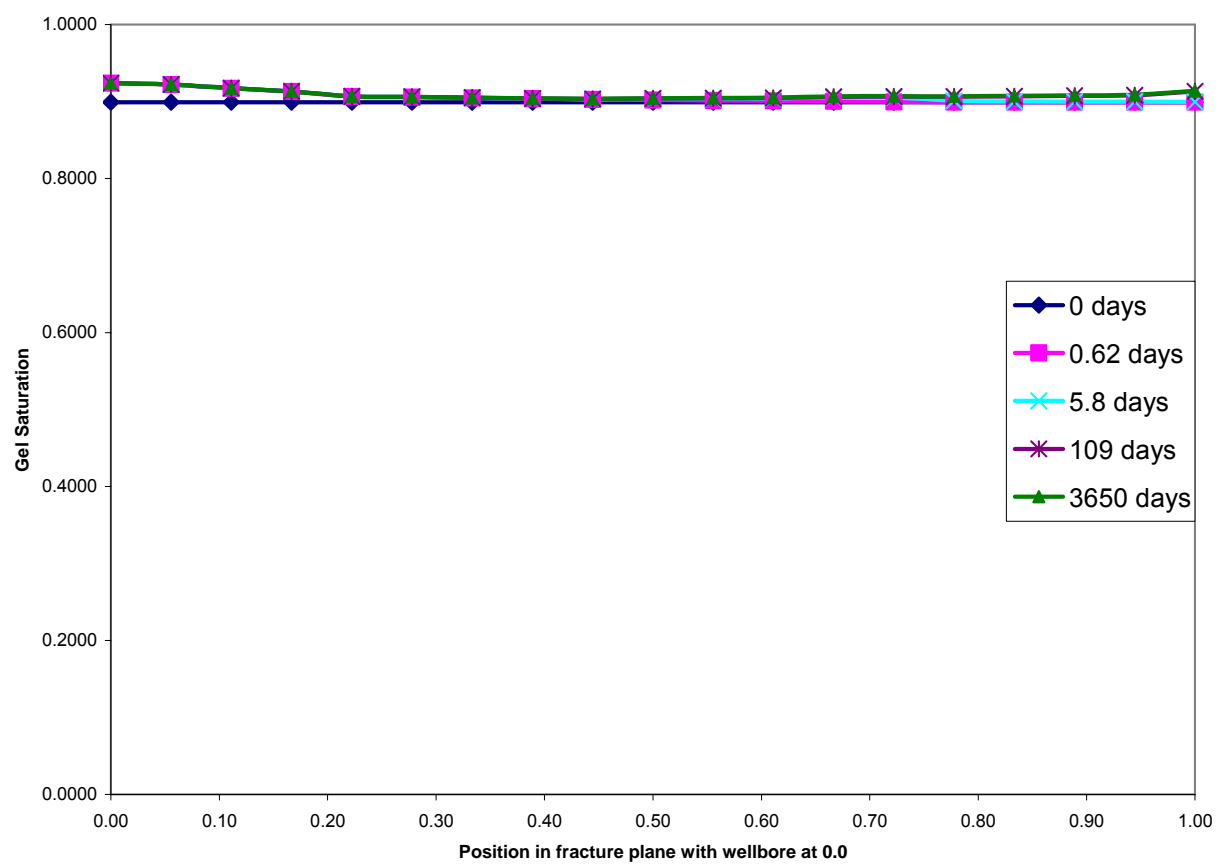

Figure 49 Saturation map for the case with yield stress of 50 pa

Figure 46 and 47 show the saturation map during the cleanup process for two different kinds of fracture fluids. Figures 48 and 49 show the saturation profile inside the fracture plane during the cleanup process for two different fracture fluids. As we can see, the fracture will eventually clean up if the fracture fluid behaves like Newtonian fluid after the treatment. However, if the fracture fluid does not degrade enough and behave like non-Newtonian fluid with a yield stress, the fracture can not clean up effectively and the gel will stay inside the 
fracture even after 10 years. So it is recommended for the industry to design some fracturing fluids which can degrade effectively after the treatment, so the productivity of the well can be increased.

\section{Information Exchange with Industries}

To exchange the technology with industrial experts, a Crisman Institute Workshop on fracture fluid damage was held in College Station on September 6, 2006. Attending were 10 industry representatives from 7 different companies (all Crisman Institute sponsors). The purpose of the meeting was to review with the industry representatives our plans for the DOE-sponsored project "Advanced Hydraulic Fracturing Technology for Unconventional Tight Gas Reservoirs," and to receive their feedback on these plans.

Professors Hill and Zhu overviewed the two tasks in the first year of the project - an assessment of current field practices in the U. S. for hydraulically fracturing tight gas wells, and the development of an experimental apparatus and methodology to conduct fracture fluid damage studies in a way that is representative of actual fracturing conditions. Professor Holditch reviewed the work that has been done to date to statistically assess the current tight gas hydraulic fracturing practices. Dr. Holditch's students have collected hundreds of papers from the SPE literature and other sources, and are inputting data about the fracturing treatments described in these papers into a searchable database.

Valuable suggestions have been given by the industrial people about the experimental apparatus and experimental procedures. Based on this feedback, we are modifying some of the planned apparatus to address concerns about slurry mixing and transport to the cell. The final topic of the meeting was modeling fracture fluid cleanup. Professor Holditch described our plans for modifying an existing three-phase reservoir simulator to model fracture fluid cleanup. Instead of oil-water-gas flow, the simulator will model gas, water, and frac fluid gel as the 3 phases. The fracture fluid will be modeled as behaving as a Bingham-type fluid with a yield stress. Again, the industry representatives offered a number of suggestions to guide this work, particularly concerning previous work on relative permeability relationships for such modeling.

Based on the work performed during this project, the following conclusions are presented:

There have been numerous technical reports about tight gas reservoirs by SPE eLibrary, DOE, Gas Research Institute (GTI), Bureau of Economic Geology, IHS Energy, USGS, AAPG, and CIM. Among them, SPE eLibrary, DOE, Gas Research Institute (GTI), Bureau of Economic Geology, and IHS Energy contain most useful information for this study. So far the SPE eLibrary is considered as a main source of technical information. Over 350 SPE papers about the productivity of hundreds of tight gas wells that have been hydraulically fractured have been downloaded. We are using the information from these papers to build a database that will contain field treatment data, organized by geographic location, and hydraulic fracture treatment design data, organized by the treatment type. MSSQL is used as the language for the database. From the information got from our study of the petroleum literature, we developed various flow charts. These flow charts group the diversion techniques, based on certain reservoir parameters. We have developed a VBA program that covers the flow charts. This program will assist engineers in making decisions concerning the appropriate diversion technique(s) to be used in fracture treating a tight gas formation.

The experimental apparatus for dynamic fracture conductivity tests has been assembled and we developed the dynamic fracture conductivity testing procedure. We have done several preliminary tests to test the setup. We have been surveying the literature on laboratory investigations of gel damage in tight gas sands. A comprehensive 3D, 3-phase 
simulator to investigate fracture fluid cleanup problem and its effect on long term recovery in tight gas reservoirs is under development. The yield stress effect should be implemented into the simulator to model the long term gas production more accurately.

\section{4. $\quad$ Products Developed}

Even though there are no final products developed from this project, the project has been extremely productive and has achieved many of the objectives of the project. The original project was designed for three years of study, and one year of field application. At the end of Phase I (the end of the first year of the project), we have met all the proposed tasks for the Phase I period. Unfortunately, the project has been terminated, so there is no plan to deliver any products to the Department of Energy. We have built a preliminary database, and a preliminary version of the advisory system based the collected data, which will provide the industry strategies of effective hydraulic fracture design and execution. We have designed and built a dynamic conductivity experimental apparatus which is the most comprehensive facility in the industry today, and further experimental study will bring the industry critical understanding about stimulation of tight gas formation. We have started modeling of gel damage problem using a black oil simulation model, which will explain the causes of gel damage, and provide the solutions of successful hydraulic fracture treatments in tight gas formation. We plan to continue the project with industry funding, and we believe that the final products of the project will add the extremely valuables to efficiently and effectively produce natural gas from unconventional formations. 


\section{Bibliography}

Almond, S.W.: "Factors Affecting Gelling Agent Residue under Low Temperature Conditions," SPE 10658 presented at SPE Formation Damage Control Symposium, Lafayette, LA, March 24-25, 1982.

Almond, S.W., and Bland, W.E.: "The Effect of Break Mechanism on Gelling Agent Residue and Flow Impairment in 20/40 Mesh Sand," SPE 12485 presented at Formation Damage Control Symposium, Bakersfield, CA, Feb, 13-14, 1984.

Brannon, H.D. and Pulsinelli, R.J.; "Evaluation of the Breaker Concentrations Required to Improve the Permeability of Proppant Packs Damaged by Hydraulic Fracturing Fluids," SPE 19402 presented at the SPE Formation Damage Control Symposium, Lafayette, Louisiana, February 22-23,1990

Carman, P.C.: "Flow of gases through porous media," New York, Academic Press, 1956.

Cooke, C.E.: "Effect of Fracturing Fluids on Fracture Conductivity," SPE 5114 presented at the SPE-AIME $49^{\text {th }}$ Annual Fall Meeting, Houston, October 6-9,1974.

Coulter, Gerald R., Benton, Edward G., and Thomson, Clifford L.: "Water Fracs and Sand Quantity: A Barnett Shale Example," SPE 90891 presented at the SPE Annual Technical Conference and Exhibition, Houston, Texas, September 26-29, 2004.

Davies, D.R. and Kulper, T.O.H.: "Fracture Conductivity in Hydraulic Fracture Stimulation," SPE 17655, May 1988.

Fisher, M. K., Wright, C. A., Davidson, B. M., Goodwin, A. K., Fielder, E. O., Buckler, W. S., and Steinsberger, N. P.: "Integrated Fracture Mapping Technologies to Optimize Stimulations in the Barnett Shale," SPE 77441 presented the SPE Annual Technical Conference and Exhibition, San Antonio, Texas, Sept. 29 - Oct. 2, 2002.

Gall, B.L. and Raible, C.J.: "Molecular Size Studies of Degraded Fracturing Polymers," SPE 13566 presented at International Symposium on Oilfield and Geothermal Chemistry, Phoenix, Arizona, April 9-11, 1985.

Grieser, Bill, Hobbs, Jimmie, Hunter, Jeff, and Ables, Jerry: "The Rocket Science Behind Water Frac Design, "SPE 80933 presented at the SPE Production and Operations Symposium, Oklahoma City, OK, March 23-25, 2003.

Holditch, S. A., and Ely, J.: "Successful Stimulation of Deep Wells Using High Proppant Concentrations," Journal of Petroleum Technology, August 1973, p959-964.

Jennings Jr., A.R, Westerman, C.W., Tadlock, D.W., Westerman, R., and Anderson, M.:” A Systematic Approach to Improved Success with Hydraulic Fracturing Applications," SPE 101837 presented at SPE Annual Technical Conference and Exhibition, San Antonio, Texas, September 24-27, 2006.

Kim, C.M. and Losacano, J.A.: "Fracture Conductivity Damage Due to Crosslinked Gel Residue and Closure Stress on Propped 20/40 Mesh Sand," SPE 14436, Annual Technical Conference, Las Vegas, NV, September, 1985.

Maxwell, S. C., Urbancic, T. I., Steinsberger, N. P., and Zinno, R.: "Microseismic Imaging of Hydraulic Fracturing Complexity in the Barnett Shale," SPE paper 77440 presented the SPE Annual Technical Conference and Exhibition, San Antonio, Texas, Sept. 29 Oct. 2, 2002.

Liu, Y., Gadde, P.B., and Sharma, M.M.; "Proppant Placement Using Reverse-Hybrid Fracs," SPE 99580 presented at the 2006 SPE Gas Technology Symposium, Calgary, Alberta, Canada, 15-17 May 2006.

McDaniel, B.W.; "Conductivity Testing of Proppants at High Temperature and Stress," SPE 15067 presented at the $56^{\text {th }}$ California Regional Meeting of the Society of Petroleum Engineers, Oakland, CA, April2-4, 1986.

Mayerhofer, M. J., Richardson, M. F., Walker, R. N., Jr., Meehan, D. N., Oehler, M. W., and 
Browning, R. R., Jr.: “Proppants? WE Don't Need No Proppants, “ SPE 38611 presented at the SPE Annual Technical Conference and Exhibition, San Antonio, Texas, Oct. 5-8, 1997.

Much, M.G. and Penny, G.S.: "Long Term Performance of Proppants under Simulated Reservoir Conditions," SPE/DOE 16415 presented at the DOE Symposium on Low Permeability Reservoirs, Denver, May 18-19, 1987.

Palisch, T., Duenckel, R., and Bazan, L.; "Determining Realistic Fracture Conductivity and Understanding Its Impact on well Performance - Theory and Field Examples," SPE 106301 presented at the 2007 SPE hydraulic Fracturing Technology Conference, College station, Texas, 29-31 January 2007.

Penny, G.S.: "An Evaluation of the Effects of Environmental Conditions and Fracturing Fluids Upon the Long-Term Conductivity of Proppants," SPE 16900 presented at the 1987 SPE Annual Technical Meeting, Dallas, TX, Sept. 27-30.

Rickards, A.R., Brannon, H.D., Wood, W.D., and Stephenson, C.J.; "High Strength, UltraLightweight Proppant Lends New Dimensions to Hydraulic Fracturing Application," SPE 84308 presented at the SPE Annual Technical Conference and Exhibition, Denver, Colorado, 5-8 October 2003.

Roodhart, L.P., Kuiper, T.O.H., and Davies,O.R.: "Proppant Pack Impairment during Hydraulic Fracturing," SPE 15629 presented at the 1986 Annual Technical Conference, Las Vegas, NV, Sept. 1986.

Rushing, J.A. and Sullivan, R.B.; "Evaluation of a Hybrid Water-Frac Stimulation Technology in the Bossier Tight Gas Sand Play," SPE 84394 presented at the SPE Annual Technical Conference and Exhibition, Denver, Colorado, 5-8 October 2003.

Walker, Ray N., Jr., Hunter, Jeffrey L., Brake, Al C., Fagin, Paul A., and Steinsberger, Nick: "Proppants, We Still Don't Need No Proppants - A Perspective of Several Operators," SPE 49106 presented at the SPE Annual Technical Conference and Exhibition, New Orleans, La., Sept. 27-30, 1998.

Warpinski, N. P., Wright, T. B., Uhl, J. E., Engler, B. P., Drozda, P. M., Peterson, R. E., and Branagan, P. T.: "Microseismic Monitoring of the B-Sand Hydraulic Fracture Experiment at the DOE/GRI Multi-Site Project," SPE 36450 presented the SPE Annual Technical Conference and Exhibition, Denver, Co., Oct. 6-9, 1996.

Rae, P., and Lullo, G.D.: "Fracturing Fluids and Breaker Systems-A Review of the State-ofthe-Art," SPE 37359 presented at the SPE Easten Regional Meeting, Columbus, Ohio, October, 1996.

Roodhart, L.P., Kuiper, T.O.H., and Davies, O.R.: "Proppant Pack Impairment During Hydraulic Fracturing," SPE 15629 presented at the 1986 Annual Technical Conference, Las Vegas, NV, Sept. 1986.

Thomas, R.L. and Brown, J.E.; "The Impact of Fracturing Fluids on Conductivity and Performance in Low-Temperature Wells," SPE 18862 presented at SPE Production Operations Symposium, Oklahoma city, Oklahoma, March 13-14,1989.

Volk, J., Gall, B.L., and Carrol, H.B.: "Method for Evaluation of Formation Damage Due to Fracturing Fluids," SPE 11638 presented at the 1983 SPE/DOE Symposium of Low Permeability, Denver, Colorado, March 1416, 1983.

Voneiff, G.W., Robinson, B.M. and Holditch, S.A.; "The Effects of Unbroken Fracture Fluid on Gaswell Performance," SPE 26664 presented at the 1993 SPE Annual Technical Conference and Exhibition, Houston, 3-5 October.

Zou, C.: "Development and testing of an Advanced Acid Fracture Conductivity Apparatus," M.S. thesis, Texas A\&M University, 2006. 


\section{Appendix A:}

\section{REFERENCE LIST: Technology/ Operation type}

Completion

(2)

Kubitz, J. R., 1963, Producer-Engineer-Purchaser... A Case History. SPE paper 689

Rose, R. E., 1988, New Techniques Lead to Better Completions in Red Fork and Other LowPermeability Formations. SPE paper 17305

\section{Completion, Expert system, ANN}

Eberhard, M. J. E. et al., 2000, Integrated Field Study for Production Optimization: J ohan Field Sublette County, Wyoming. SPE paper 59790

\section{Completion, multi-stage stimulation, composite bridge plug}

Colwell, D. A. F., O'Brien, C.G.J., Gates, T.D., 2006, Evolution of Completion Practices in the Wild River Tight Gas Sand. SPE paper 89719

Garfield, G., 2001, Formation Damage Control Utilizing Composite-Bridge-Plug Technology for Monobore, Multizone Stimulation Operations. SPE paper 70004

Plante, M. E., 2000, Advantages to Remedial Operations of Coiled-Tubing -Enables Under-Balanced Removal of Latest Generation Composite Bridge Plug. SPE paper 60718

\section{Drilling fluid (1)}

Carterand, T. S., Faui, G.L., 1992, Successful Application of the ACBM System in a Deep West Texas Well. SPE paper 24590

\section{Drilling, cementing}

Cowthran, J. L., 1982, Technology Used To Improve Drilling Performance and Primary Cementing Success in Katy Field. SPE paper SPE 10956

Seidel, F. A., Greene, T.G., 1985, Use of Expanding Cement Improves Bonding and Aids in Eliminating Annular Gas Migration in Hobbs Grayburg-San Andres Wells. SPE paper 14434

\section{Drilling, Cementing, casing-conveyed perforation (1)}

Succesful Optimization and Application of Primary Cement Design Enables Annular Placement of Casing Gun for Multiple Zone Completion. SPE paper 64256

\section{Drilling, horizontal}

(2)

Burkett, M. A., Application of Horizontal Drilling in Low-Permeability Reservoirs. SPE paper

Cox, G. W., 2000, Horizontal Drilling Proves Cost-effective in Boosting Gas Production: World Oil. SPE paper 1

\section{Drilling, I nfill (1)}

Cipolla, C. L., 1996, Infill Drilling \& Reserves Growth Determination in Lenticular Tight Gas Sand. SPE paper 36735

\section{Expert system(14)}

Aminian, S. A., Yos II, A.B., 1987, Data Base for Eastern Gas-Bearing Formations: Development and Application

SPE paper 17065 
Chatterjee, D., et al., 2001, Integrated production Database in Unocal Indonesia. SPE paper 68758

Dent. L., A., K., 2000, The Japan National Data repository: A Multi-User Database Challenge. SPE paper 59444

Douglas, J. e. a., 2005, Accurate and Credible Reserve Requires More Than Best engineering Practices. SPE paper 94681

Steinke, S. C., et al. , 1988, Applications of a Computerized Bit record Database SPE paper 17189

Strickland, B. D., et al, 2003, Analysis of Stimulation Effectiveness in the Ammo field Granite Wash Based on Reservoir Characterization \& Completion Database. SPE paper 80893

Xiong, H. e. a., A Fuzzy Evaluator For the Optimal Stimulation Treatment Type: S.V.I.P. SPE paper 006

Xiong, H. e. a., Using a Fuzzy Expert System to Choose Target Wells and Target Formations for Stimulation. SPE paper

Xiong, H. e. a., 1993, An Expert System to Select the Injection Method and Evaluate Tubular Conditions for a Stimulation Treatment. SPE paper

Xiong, H. e. a., 1993, Using Fuzzy Expert System to Choose Target Wells and Target Formations for Stimulation. SPE paper

Xiong, H. e. a., 1994, Intelligent Interfaces for Fracturing Stimulations: Part I - System Overview and Design. SPE paper 28236

Xiong, H. e. a., 1994, An Investigation the Application of Fuzzy Logic to Well Application Treatment Design. SPE paper 27672

Xiong, H. e. a., 1995, A Comprehensive Approach to Formation Diagnosis and Corresponding Stimulation Type and Fluid Selection. SPE paper 29531

Xiong, H. e. a., 1996, A New Approach to Develop Petroleum Engineering Software. SPE paper 36000

\section{Expert system, ANN (2)}

Grieser, B., Stark, J., 1998, I dentifying High-Impact parameters in Stimulation Treatments Using a Trend Empirical Analysis Model. SPE paper 39966

Mohaghegh, S., et al, 2000, Development of an Intelligent System Approach for Restimulation Candidate Selection. SPE paper 59767

\section{Expert system, best practices}

Leshchyshyn, T., Ried, B., 2004, Case Studies in Production Optimization Using Chosen Information Sources and Information Technology. SPE paper 90848

\section{Expert system, best practices, ANN, fuzzy combinatorial analysis, HIP (1)}

Mohaghegh, S. D. e. a., 2001, Identifying Best Practices in Hydraulic Fracturing Using Virtual Intelligence Techniques. SPE paper 72385

Expert system, best practices, recommendations (1)

Mohaghegh, S. D. e. a., 2005, Analysis of Best Hydraulic Fracturing Practices in the Golden Trend Fields of Oklahoma. SPE paper 95942

Expert system, Data quality control, ANN (1)

Popa, A. S. e. a., 2003, Identification of Contaminated Data in Hydraulic Fracturing Databases: Application to the Codell Formation in the DJ Basin. SPE paper 83446

\section{Expert system, Data-mining (1)}

Mohaghedh, S. D., 2003, Essential Components of an Integrated Data Mining Tool for the Oil \& Gas Industry, With an Example Application in the DJ Basin. SPE paper 84441 
Irrgang, R., et al., 2001, Assessment of Risk and Uncertainty for Field Developments: Integrating Reservoir and Drilling expertise. SPE paper 71419

\section{Expert system, Framework - Computer Science}

Brule, M., et. al. , 1995, A RAD Approach to Client/Server System Development SPE paper 28270

\section{Expert System, Fuzzy logic (2)}

Xiong, H. e. a., 1993, Using an Expert System to Select the Optimal Fracturing Fluid and Treatment Volume SPE paper 26188

Xiong, H. e. a., 1999, Using Stimulation Expert System to Design Hydraulic Fracturing Treatments Field Examples SPE paper 52223

\section{Expert system, optimization (1)}

Irrang R., e. a., 2001, Assessment of Risk and Uncertainty for Field Developments: Integrating Reservoir and Driling Expertise. SPE paper 71419

\section{Expert system, questionnaire, expert interview, fuzzy logic, knowledge acquisition, missing data substitution

Xiong, H. e. a., 1994, Intelligent Interfaces for Fracturing Simulators: Part II - System Implementation and Application. SPE paper 28521

\section{Formation evaluation, Logging}

Fairhurst, D. L. e. a., 2006, Oligocene Vicksburg Thin Bed Production Optimization Derived From OilBased Mud Imaging-A Case Study. SPE paper 99720

Foret, R. P., Diggons, W.f., Grace, L.M., 1983, A New Approach to Air-Hole Interpretation in the Canyon Sands of Central Texas. SPE paper 11619

\section{Formation evaluation, stress dependent permeability}

Davies, J. P., Davies, D.K., 1998, Improved Evaluation and Reservoir Management of Low Permeability, Gulf Coast Reservoirs: Significance of Stress Dependent Permeability. SPE paper 39873

Fracpack

Mathis, S. P., Saucier, R.J ., 1997, Water-Fracturing vs. Frac-Packing: Well Performance Comparison and Completion Type Selection Criteria. SPE paper 38593

\section{Fracpack, fines, proppant pack damage}

Blauch, M. e. a., 1999, New Insights into Proppant-Pack Damage Due to Infiltration of Formation Fines SPE. SPE paper 56833

General

Bennion, D. B., Thomas, F.B., Bietz, R.F., 1996, Low Permeability Gas Reservoirs: Problems, Opportunities and Solutions for Drilling, Completion, Stimulation and Production. SPE paper 35577

Carter, R. H., Holditch, S.A., Wolhart, S.L., 1996, Results of a 1995 Hydraulic Fracturing Survey and a Comparison of 1995 and 1990 Industry Practices. SPE paper 36483 
Davies, J. P. e. a., 1998, Improved Evaluation and Reservoir Management of Low Permeability, Gulf Coast Reservoirs: Significance of Stress Dependent Permeability. SPE paper 39873

\section{Perforation (2)}

Lestz, R. S., et al, 2002, Perforating for Stimulation: An Engineering Solution. SPE paper 76812

Patino, A. H., et al, 2004, Case Histories - Combining Crossed Dipole Sonic Anisotropy and Oriented Perforating to Optimize Hydraulic Fracturing in the Burgos Basin - Reynosa, Mexico. SPE paper 92014

\section{Perforation, casing-conveyed}

(4)

Casing-Conveyed Perforating System Presents a Unique Set of Drilling and Cementing Challenges: A Case History Study Kenai Gas Field, Alaska. SPE paper 79877

Eller, J. G., et al., 2002, A Case History_ Use of a Casing-Conveyed Perforating System to Improve Life of Well Economics in Tight Gas Sands SPE paper 76742

Garner, J. J., et al, 2004, A Case History Of Optimizing Casing-Conveyed Perforating And Completion Systems In Tight Gas Reservoirs, Kenai Gas Field, Alaska. SPE paper 90722

Krawietz, T. E., 2004, An Application of an External Casing Perforation Completion Process in the Wilshire Devonian Field of West Texas - A Case History. SPE paper 89772

Perforation, casing-conveyed, lab testing, completion

Management of Completion Systems Utilizing State-of-the-Art Technologies CCPS Beluga. SPE paper 77707

\section{Perforation, underbalance}

Birrd, K., Blok, R.H.J., 1996, Perforating In Tight Sandstones_Effect Of Pore Fluid And Underbalance SPE paper 36860

Ramirez, J., et al, 2001, Proppelant-assisted Perforation in High-Pressure and Temperature Wells at Campo Bosque in Northern Monagas State. SPE paper 71644

\section{Production}

Libson, T. N., Henry, J.R., 1980, Case Histories: Identification of and Remedial Action for Liquid Loading in Gas Wells - Intermediate Shelf Gas Play. SPE paper 7467

\section{Proppant convection, encapsulation, general, theoretical (1)}

Cleary, M. P., 1992, Proppant Convection and Encapsulation in Hydraulic Fracturing: Practical Implications of Computer and Laboratory Simulations. SPE paper 24825

\section{Proppant flow back (1)}

Weaver, J. D. e. a., 1999, Application of Surface Modification Agent in Wells with High Flow Rates: SPE. SPE paper 54645

\section{Proppant flow back, DIP}

Myers, R. R., et al., 2000, Sand Flowback Control in the Rockport Gas Storage Field in Northern West Virginia. SPE paper 65640

Rae, P., Lullo, G.D., d'Huteau, E., 2001, New Technique for Proppant Flowback and Improved Fracture Conductivities. SPE paper 69580 
Increased Resistance to Proppant Flowback by Adding Deformable Particles to Proppant Packs Tested in the Laboratory. SPE paper 56593

Need Stress Relief A New Approach to Reducing Stress Cycling Induced Proppant Pack Failure. SPE paper 49247

\section{Proppant flow back, LRS}

Krismartopo, B. D., et al., 2005, A Fracture Treatment Design Optimization Process to Increase Production and Control Proppant Flowback for Low-Temperature, Low Pressure Reservoirs. SPE paper 93168

\section{Proppant flow back, LRS, RCS}

(2)

Nguen, P. D., et. al., 1998, New Guidelines for Applying Curable Resin-Coated Proppants. SPE paper 39582

Nguen, P. D., Weaver, J.D., 2003, Controlling Proppant Flowback in High-Temperature, HighProduction Wells SPE paper 82215

\section{Proppant flow back, SMA}

Guoynes J ., e. a., 2005, Long-Term Gas Storage Deliverability Improvement from Fracturing and Refracturing Treatments Using a Proppant Surface Modification Agent. SPE paper 97981

Guoynes J., K., G.A., Shaw, J.S., McCallister, J., 2005, Long-Term Gas Storage Deliverability Improvement from Fracturing and Refracturing Treatments Using a Proppant Surface Modification Agent. SPE paper 97981

Kozera, G. A., Willis, S.F., Shaw, J.S., 2001, Multi Year Gas Storage Deliverability Results Using a Proppant Surface Modification Agent SPE paper 72366

Lehman, L. V., et al., 2003, Conductivity Maintenance: Long-Term Results from the Use of Conductivity Enhancement Material. SPE paper 82241

Lehman, L. V., et al., and L. V. Lehman, Shelley, B., Crumrine, T., Gusdorf, M., Tiffin, J., 2003, Conductivity Maintenance: Long-Term Results from the Use of Conductivity Enhancement Material. SPE paper 82241

Nguyen, P. D., Dewprashad, B.T., Weaver, J.D., 1998, A New Approach for Enhancing Fracture Conductivity. SPE paper 50002

Weaver, J. D. e. a., 1999, Application of Surface Modification Agent in Wells With High Flow Rates. SPE paper 53293

\section{Proppant, Light weight}

Rickards, A. R. e. a., 2003, High Strength, Ultra-Lightweight Proppant Lends New Dimensions to Hydraulic Fracturing Applications. SPE paper 84308

Wood, W. D., et al., 2003, Ultra-Lightweight Proppant Development Yields Exciting New Opportunities in Hydraulic Fracturing Design. SPE paper 84309

\section{Proppant, Light weight, Partial monolayer (2)}

Brannon, H. D., et. al, 2004, Maximizing Fracture Conductivity with Proppant Partial Monolayers: Theoretical Curiosity or Highly Productive Reality. SPE paper 90698

Myers, R. R., et al., 2004, Field Application of New Lightweight Proppant in Appalachian Tight Gas Sandstones. SPE paper 91469

\section{Stimulation, Completion}

Paiand, V. J. a. G., S.J., 1982, Review of the Completion Practices in the Morrow Formation in Eddy, Chaves and Lea Counties of Southeast New Mexico. SPE paper 11335 
Webster, K., 1977, Current Completion Practices in Tight Gas Reservoirs. SPE paper 6379

Stimulation, Completion of horizontal wells, Diverting Agent, Limited entry

McDaniel, B. W., Willett, R.M., and Underwood, P.J ., 1999, Limited-Entry Frac Applications on Long Intervals of Highly Deviated or Horizontal Wells. SPE paper 56780

\section{Stimulation, Completion of horizontal wells}

(5)

Abou-Sayed, I. S. e. a., 1996, Multiple Hydraulic Fracture Stimulation in a Deep, Horizontal Tight-Gas Well. SPE paper 30532

Cipolla, C. L., Hansen, K.K., Ginty, W.R. et al, 2000, Case Study of Hydraulic Fracture Completions in Horizontal Wells, Wouth Arne Field Danish North Sea. SPE paper 64383

Duda, J. R., Kumar, H.K., 1988, Production Forecast for Alternative Completion Methods in LowPermeability Gas Reservoirs: Stimulation of High-Angle and Horizontal Wells. SPE paper 18291

Edgeman, J. R. m. W., D.W., 2003, Comparison of Two Low-Permeability Horizontal Devonian Projects in the Permian Basin with Competing Completion Techniques. SPE paper 84391

Willett, R. M., 2002, Effective Well Planning and Stimulation Improves Economics of Horizontal Wells in a Low-

Permeability West Texas Carbonate. SPE paper 77932

\section{Stimulation, Completion of horizontal wells, modeling}

Goktas, B., Ertekin, T., 2000, Performances of Openole Completed and Cased Horizontal/Undulating Wells in Thin-Bedded, Tight Sand Gas Reservoirs. SPE paper 65619

\section{Stimulation, Diverting Agent, limited entry (1)}

Harrison, N. W., 1972, Diverting Agent-History and Application. SPE paper 3653

\section{Stimulation, Fracture mapping}

Cipolla, C. L. e. a., 2005, Effect of Well Placement on Production and Frac Design in a Mature Tight Gas Field. SPE paper 95337

\section{Stimulation, Fracturing}

Caron, J. D., 1998, Successful Application of Advanced Stimulation Technologies_ A Multi-Field Case History. SPE paper 39951

Cipolla, C. L., 1996, Hydraulic Fracturing Technology in the Ozona Canyon and Penn Sands. SPE paper 35196

Cleary, M. P., 1994, Major New Developments in Hydraulic Fracturing, with Documented Reductions in Job Costs and Increases in Normalized Production. SPE paper 28565

Cramer, D. D., 2003, Evaluating Well Performance and Completion Effectiveness in Hydraulically Fractured Low-Permeability Gas Wells. SPE paper 84214

Handren, P. e. a., 2001, The Impact of Non-Darcy Flow on Production from Hydraulically Fractured Gas Wells. SPE paper 67299

Holditch, S. A., Ely, J., 1973, Successful Stimulation of Deep Wells Using High Proppant Concentrations. SPE paper 4118

Holditch, S. A., Tchirhart, N.R., 2005, Optimal Stimulation Treatments in Tight Gas Sands. SPE paper 96104

Linroth, M. A., 2005, Effects of Two-Phase Flow in a Step-Down Test. SPE paper 94002

Pai, V. J., Keith, M.M. and Hust, P., 1994, New Technique of Fracture Stimulating the Morrow and the Atoka Formations of Southeastern New Mexico. SPE paper 27690

Rosene, R. B., Shumaker, E.F., 1971, Viscous Fluids Provide Improved Results from Hydraulic Fracturing Treatments. SPE paper 3347 
Wright, C. A. e. a., 1996, Fracture Treatment Design and Evaluation in the Pakenham Field: A RealData Approach. SPE paper 36471

Dawson, J. C., et al. , 1998, Successful Application of a Novel Fracturing Fluid in the Wasatch Formation in Eastern Utah: SPE. SPE paper 49042

\section{Stimulation, fracturing, artificial barrier, height growth}

Mukherjee, 1995, Successful Control of Fracture Height Growth by Placement of Artificial Barrier. SPE paper 25917

\section{Stimulation, fracturing, flow back, guideline}

Ely, J. W., 1990, New Techniques and Quality Control Find Success in Enhancing Productivity and Minimizing Proppant Flowback. SPE paper 20708

\section{Stimulation, Fracturing, Fluid}

Fairhurst, D. L. e. a., 2007, Fracturing Previously Bypassed Highly Laminated Tight Gas Sands, A Production Optimization Case Study in South Texas. SPE paper 105681

Malone, M. R., 2001, Fracturing with Crosslinked Methanol in Water-Sensitive Formations. SPE paper 70009

Pearce, K. W., 2002, Fracture Treatment Design and Evaluation in the Pakenham Field: A Real-Data Approach

SPE paper 76721

\section{Stimulation, Fracturing, Fluid, Breaker}

Brannon, H. D., et. al, 2003, Enzyme Breaker Technologies: A Decade of Improved Well Stimulation SPE paper 84213

\section{Stimulation, Fracturing, fracture evaluation}

Crafton, J. W., Anderson, D, 2006, Use of Extremely High Time-Resolution Production Data To Characterize Hydraulic Fracture Properties. SPE paper 103591

Holditch, S. A., et al., 1998, Evaluation of Fracture Treatments Using a Layered-Reservoir Description_Field Examples. SPE paper 26187

\section{Stimulation, Fracturing, limited entry}

Magalski, M. J., Carlson, N.R., 1994, Evaluation of Gas Well Fracture Stimulation Using New Production Profiling Method. SPE paper 27722

\section{Stimulation, Fracturing, Modeling}

Green, C. A., 2007, Development of a Methodology for Hydraulic Fracturing Models in Tight, Massively Stacked, Lenticular Reservoirs. SPE paper 106269

Walser, D. W., 2005, Utilizing Flowing Pressure-transient and Mass-Balance Analysis of SENM Morrow Producers to Calibrate Hydraulic-Fracture Modeling - A Case History. SPE paper 94305

\section{Stimulation, Fracturing, perforation, fracture tortuosity}

Cleary, M. P., 1993, Field Implementation of Proppant Slugs to Avoid Premature Screen-Out of Hydraulic Fractures with Adequate Proppant Concentration. SPE paper 25892

\section{Stimulation, Fracturing, Pin-point frac, horizontal wells}

Meeks, M. H., Susewind, K.D., Templeman, T.L., 2006, Maximizing Gas Recovery from Tight Gas 
Reservoirs In Trawick Field. SPE paper 101221

Stimulation, fracturing, real-data on-site analysis, minifrac, tortuosity, guideline, General (1)

Johnson, D. E. e. a., 1993, Real-Data On-site analysis of Hydraulic Fracturing Generates Optimum Procedures for J ob Design and Execution. SPE paper 25920

\section{Stimulation, fracturing, technology (2)}

Kessler, C., Venditto, J im, McMechan, David, 1994, A Synergistic Approach to Optimizing Hydraulic Fracturing. SPE paper 28802

Voneiff, G. W., Holditch, S.A. , 1994, Economic Assessment of Applying Advances in Fracturing Technology. SPE paper 24888

\section{Stimulation, fracturing, theoretical (1)}

Cleary, M. P., Wright, C.A., Wright, T.B., 1991, Experimental and Modeling Evidence for Major Changes in Hydraulic Fracturing Design and Field Procedures. SPE paper 21494

Stimulation, fracturing, tortuosity, near wellbore friction, proppant slugs

Cleary, M. P., et al, 1993, Field Implementation of Proppant Slugs to Avoid Premature Screen-out of Hydraulic Fractures With Adequate Proppant Concentration. SPE paper 25892

\section{Stimulation, fracturing, tortuosity, near wellbore friction (1)}

Cleary, M. P., J ohnson, D.E., Kogsbøll, H-H., Owens, K.A., Perry, K.F., de Pater, C.J., Stachel, A., Schmidt, H., 1993, Field Implementation of Proppant Slugs To Avoid Premature Screen-Out of Hydraulic Fractures With Adequate Proppant Concentration. SPE paper 25892

\section{Stimulation, Fracturing, waterfrac (1)}

Walker, R. N. J., Hunter, J.L., Brake, A.C., Fagin, P.A., Steinsberger, N., 1998, Proppants, We Still Don't Need No Proppants - A Perspective of Several Operators SPE paper 49106

\section{Stimulation, general (1)}

Vincent, M. C., 2002, Proving It - A Review of 80 Published Field Studies Demonstrating the Importance of Increased Fracture Conductivity. SPE paper 77675

Stimulation, modeling of fracture flow back, recommendations!! guideline

Barree, R. D., 1995, Engineering Criteria for Fracture Flowback Procedures SPE paper 29600

Stimulation, of chalk reservoirs, horizontal wells (1)

Cipolla, C. L., Hansen, K.K., Ginty, W.R., 2004, Fracture Treatment Design and Execution in Low Porosity Chalk Reservoirs. SPE paper 86485

\section{Stimulation, Restimulation}

Moore, L. P., Ramakrishnan, H., 2006, Restimulation_Candidate Selection Methodologies and Treatment Optimization. SPE paper 102681 


\section{Appendix B:}

TGR “Advisor”:Perforation phasing selection

Membership functions:

1) Young's modulus, MMpsi ${ }^{-1}$

$$
\begin{aligned}
& \mathrm{F}_{180}(\mathrm{E})= \begin{cases}0.1 * \mathrm{E} & \left(\mathrm{E}<5,000,000 \mathrm{psi}^{-1}\right) \\
\frac{1}{1+1.6^{5-E}} & \left(\mathrm{E} \geq 5,000,000 \mathrm{psi}^{-1}\right)\end{cases} \\
& \mathrm{F}_{60}(\mathrm{E})= \begin{cases}1-e^{\frac{E-5.8}{1.5}} & \left(\mathrm{E}<5,000,000 \mathrm{psi}^{-1}\right) \\
\frac{0.7}{0.7+4^{E-5}} & \left(\mathrm{E} \geq 5,000,000 \mathrm{psi}^{-1}\right)\end{cases}
\end{aligned}
$$

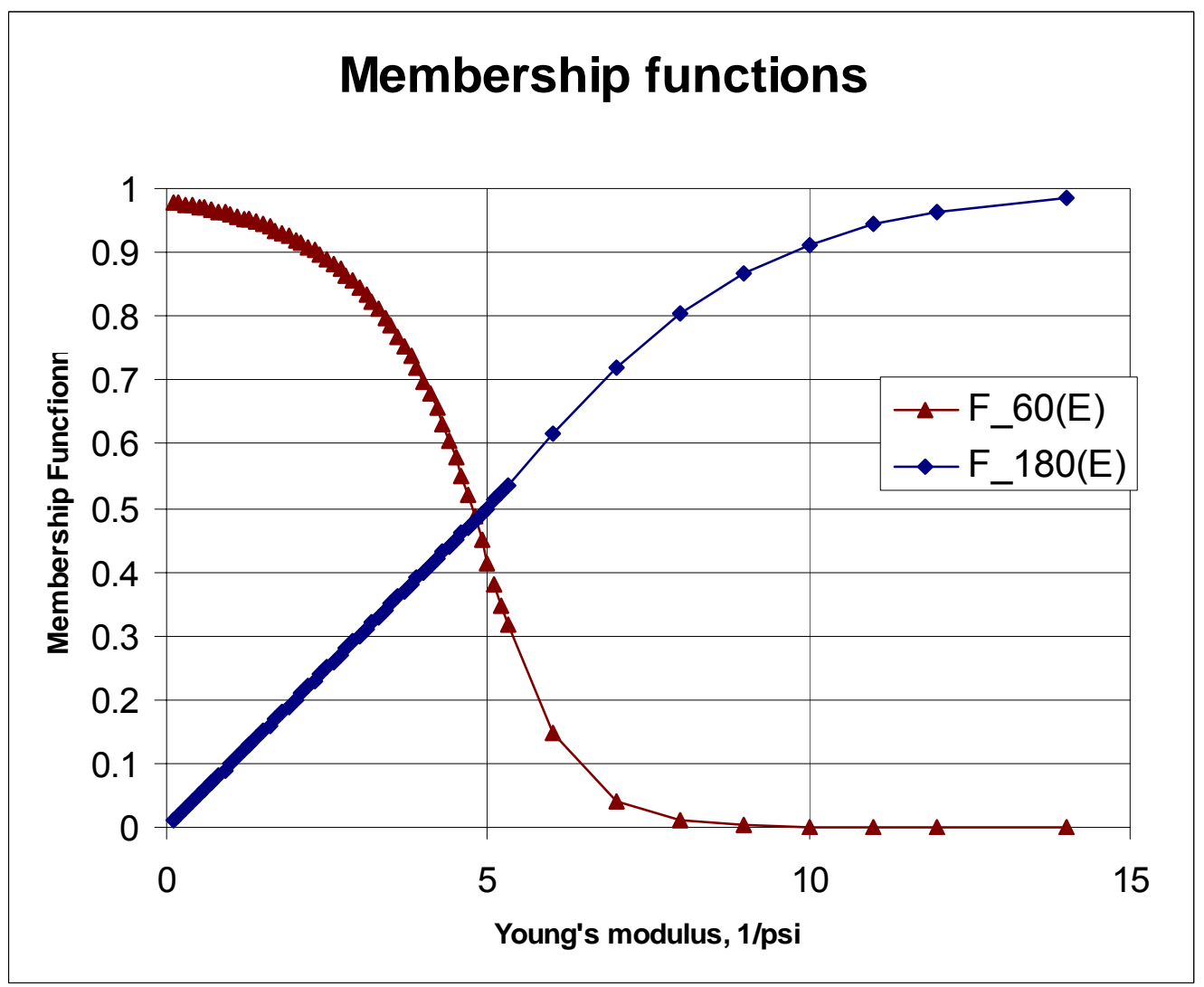

Figure A.1 Membership functions for Young's modulus

2) Anisotropy

$$
\mathrm{F}_{180}(\mathrm{~A})= \begin{cases}0 & (\text { Low }) \\ 0.5 & (\text { Moderate) } \\ 1 & (\text { High })\end{cases}
$$


$\mathrm{F}_{60}(\mathrm{~A})=\left\{\begin{array}{l}0.8 \\ 0.4 \\ 0\end{array}\right.$

3) Natural fractures

$$
\begin{aligned}
& \mathrm{F}_{180}(\mathrm{NF})= \begin{cases}0 & \left\{\begin{array}{l}
\text { (very few natural fractures) } \\
0.5
\end{array}\right. \\
1 & \begin{array}{l}
\text { (moderately naturally fractured) } \\
\text { (highly naturally fractured) }
\end{array}\end{cases} \\
& \mathrm{F}_{60}(\mathrm{NF})= \begin{cases}0.8 & \text { (very few natural fractures) } \\
0.5 & \text { (moderately naturally fractured) } \\
0 & \text { (highly naturally fractured) }\end{cases}
\end{aligned}
$$

4) Sand production

$$
\mathrm{F}_{180}(\mathrm{SP})=\left\{\begin{array}{l}
1 \\
0
\end{array}\right.
$$$$
\mathrm{F}_{60}(\mathrm{NF})=\left\{\begin{array}{l}
0.5 \\
0
\end{array}\right.
$$

5) Horizontal stress contrast

$$
\begin{aligned}
& \mathrm{F}_{180}(\mathrm{HC})= \begin{cases}1 & \left\{\begin{array}{l}
\text { (low) } \\
0.4
\end{array}\right. \\
0 & \begin{array}{l}
\text { (moderate) } \\
\text { (high) }
\end{array}\end{cases} \\
& \mathrm{F}_{60}(\mathrm{HC})= \begin{cases}0 & \text { (low) } \\
0.5 & \text { (moderate) } \\
0.8 & \text { (high) }\end{cases}
\end{aligned}
$$

Perforation phasing indexes:

$$
\begin{aligned}
& I_{180}=F_{180}(E) * W_{E}+F(A)_{180} * W_{A}+F_{180}(N F) * W_{N F} \\
& I_{60}=F_{60}(E) * W_{E}+F_{60}(A) * W_{A}+F_{60}(N F) * W_{N F}
\end{aligned}
$$

where

$$
\begin{aligned}
& W_{X}-\text { weighting factors } \\
& W_{E}=0.25 \\
& W_{A}=0.15 \\
& W_{N F}=0.25 \\
& W_{S P}=0.1 \\
& W_{H C}=0.25 \\
& \sum W_{i}=1
\end{aligned}
$$


Perforation phasing decision:

If $I_{180} \leq I_{60}$ Then $60^{\circ}$ phasing

If $I_{180}>I_{60}$ Then $180^{\circ}$ phasing:

Additional recommendations:

If $F_{180}(E)<0.5$ Then Optional phasing orientation with $\sigma_{\max }$

If $F_{180}(E) \geq 0.5$ Then Necessary phasing orientation with $\sigma_{\max }$, high energy large perforations, shots close together 